NUREG/CR--3965

\title{
MASTER
}

\section{An Investigation of the Strength of H440 Graphite When Subjected to Combined Primary and Secondary Stress}

\author{
Charles A. Anderson \\ Gerald W. Fly \\ Lynn B. Lundberg \\ Joe A. Romero
}
Manuscript submitted: January 1986
Date published: April 1986
Prepared for
Mechanical/Structural Engineering Branch
Division of Engineering Technology
Office of Nuclear Regulatory Research
US Nuclear Regulatory Commission
Washington, DC 20555

NRC FIN No. A7240

\section{DISCLAIMER}

\begin{abstract}
This report was prepared as an account of work sponsored by an agency of the United States Government. Neither the United States Government nor any agency thereof, nor any of their employees, makes any warranty, express or implied, or assumes any legal liability or responsibility for the accuracy, completeness, or usefulness of any information, apparatus, product, or process disclosed, or represents that its use would not infringe privately owned rights. Reference herein to any specific commercial product, process, or service by trade name, trademark, manufacturer, or otherwise does not necessarily constitute or imply its endorsement, recommendation, or favoring by the United States Government or any agency thereof. The views and opinions of authors expressed herein do not necessarily state or reflect those of the United States Government or any agency thereof.
\end{abstract}




\section{DISCLAIMER}

This report was prepared as an account of work sponsored by an agency of the United States Government. Neither the United States Government nor any agency Thereof, nor any of their employees, makes any warranty, express or implied, or assumes any legal liability or responsibility for the accuracy, completeness, or usefulness of any information, apparatus, product, or process disclosed, or represents that its use would not infringe privately owned rights. Reference herein to any specific commercial product, process, or service by trade name, trademark, manufacturer, or otherwise does not necessarily constitute or imply its endorsement, recommendation, or favoring by the United States Government or any agency thereof. The views and opinions of authors expressed herein do not necessarily state or reflect those of the United States Government or any agency thereof. 


\section{DISCLAIMER}

Portions of this document may be illegible in electronic image products. Images are produced from the best available original document. 
ABSTRACT ............................. . . 1

I. INTRODUCTION . . . . . . . . . . . . . . . . . . . 1

II. CONCLUSIONS AND RECOMMENDATIONS ................... 6

III. H440 GRAPHITE DATA BASE . . . . . . . . . . . . . . . . . . . 7

A. Introduction ..................... . . 7

B. Tension Tests .................... . . . 10

C. Compression Tests . . . . . . . . . . . . . . . . 14

D. Torsion Tests . . . . . . . . . . . . . . . . . 18

E. Elastic Constants from Sonic Testing . . . . . . . . . . . . 21

IV. NUMERICAL AND ANALYTICAL RESULTS . . . . . . . . . . . . . . . 22

A. Thermoelastic Behavior of Thick-Walled Rings........... . 23

B. Finite Element Calculations . . . . . . . . . . . . . . . 26

C. Modeling the Fracture Behavior of H440 Graphite Rings . . . . . 29

V. EXPERIMENTAL HARDWARE AND TEST PROCEDURES ............... 33

A. Overall concept . . . . . . . . . . . . . . . . . . 33

B. Heater Design . . . . . . . . . . . . . . . . . . . . 34

C. Mechanical Loading Design ................. . 44

D. Instrumentation . . . . . . . . . . . . . . . . . . . 46

E. Test Procedure . . . . . . . . . . . . . . . . . . . . . . 50

F. Free Thermal Expansion of H440 Graphite and the Correction Curve.................. . 51

VI. EXPERIMENTAL RESULTS AND COMPARISONS WITH THEORY . . . . . . . . . . . 54

A. Results from Unheated Tests (Mechanical Load Only) . . . . . . . 55

B. Results from Heated Tests with Mechanical Load......... . 61

REFERENCES ............................... 69 
FIGURES

3.1. Cutting plan for $H 440$ graphite block. . . . . . . . . . . . . 8

3.2. Graphite tensile specimen ................... . . 10

3.3. Typical uniaxial tensile stress-strain curve for $H 440$ graphite

illustrating the three tabulated modulus values and unload-

reload behavior ...................... 11

3.4. Frequency plot for the ultimate tensile strength $\sigma_{u}$ for

H440 graphite specimens ................... 13

3.5. Frequency plot for the ultimate tensile strain $\varepsilon_{u}$ for

H440 graphite specimens .................... 13

3.6. Frequency plot for the secant modulus $E_{7 / 3}$ for $H_{440}$ graphite

specimens . . . . . . . . . . . . . . . . . . . 14

3.7. Typical uniaxial compressive stress-strain curve for $\mathbf{H 4 4 0}$

graphite showing load-reload behavior ............... 15

3.8. Frequency plot for ultimate compressive strength $\sigma_{C}$ for $\mathrm{H440}$

graphite specimens...................... . 17

3.9. Frequency plot for ultimate compressive strain $\varepsilon_{\mathrm{C}}$ for $\mathrm{H440}$

graphite specimens . . . . . . . . . . . . . . . . . 17

3.10. Frequency plot of initial compressive modulus $E_{C}$. . . . . . . . . 17

3.11. Schematic of system for measuring the angular rotation of the

tubular graphite test specimen ................. 18

3.12. Typical shear stress-strain curve for $H 440$ graphite showing

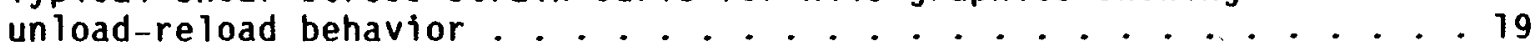

3.13. Frequency plot of torsion elastic modulus $G$ and strength parameters $T_{u}$ and $Y_{u}$ for $H 440$ graphite in the $W / G$ direction ..... 21

3.14. Frequency plot of torsion elastic modulus $G$ and strength parameters $T_{u}$ and $Y_{u}$ for $H 440$ graphite in the A/G direction ..... 21

4.1. Thick-walled ring subjected to mechanical and thermal loads .....25

4.2. Circumferential stress $\sigma_{\theta} / p$ in a thick-walled circular disc loaded by diametrically opposed pressure loading, $\beta=13.5^{\circ}$,

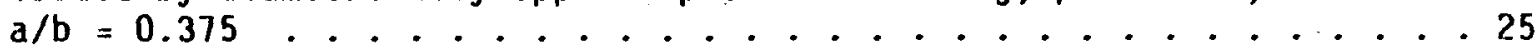

4.3. Circumferential stress $\sigma_{\theta} / p$ in a thick-walled circular disc loaded by diametrically opposed pressure loading, $\beta=6.1^{\circ}$, $a / b=0.352$. . . . . . . . . . . . . . . . 25 
4.4. Distribution of circumferential and radial stress in a thick-walled ring subjected to a uniform internal heat flux, $a / b=0.375$

4.5. Fracture surface for a thick-walled graphite ring subjected to uniform internal heat flux and diametrically opposed pressure loadings, $a / b=0.375$

4.6. Finite element mesh for thick-walled graphite ring . . . . . . . 27

4.7. Cumulative probability distribution functions for across-grain $(A / G)$ and with-grain $(W / G)$ tensile strength data for $\mathrm{H440}$ graphite. The Weibull parameters are: $\sigma_{u}=3027, m=19.3$ for $A / G$ data and $\sigma_{u}=3710, m=14.8$ for $W / G$ data ........ . 31

4.8. Probability of failure versus load showing experimental points and corrected failure curve. Isothermal case for small graphite ring

4.9. Probability of failure versus load showing experimental points for $225^{\circ} \mathrm{C}$ temperature drop through the small graphite ring 32

5.1. Large graphite thermomechanical ring specimen . . . . . . . . 33

5.2. Radiation-coupled heater schematic ................ 35

5.3. Liquid-metal-coupled heater schematic . . . . . . . . . . . 37

5.4. Estimated temperature profile through the thermal load system, the graphite specimen, and the chill ring . . . . . . . . . . 39

5.5. Sealing mechanism for large graphite rings.............. 40

5.6. Chill ring schematic .................... 42

5.7. Photograph of the chill ring....................43

5.8. Photograph of the load frame and hydraulics . . . . . . . . . . 45

5.9. Thermocouple and strain gage layout on the small graphite ring... 48

5.10. Thermocouple and strain gage layout on the large graphite ring. . . 48

5.11. Apparent strain versus temperature curve for the with-grain axis of H440 graphite... . . . . . . . . . . . . . . . . . 52

5.12. Apparent strain versus temperature curve for the across-grain axis of $H 440$ graphite

5.13. Thermal expansion of $H 440$ graphite (strain versus temperature) in the with- and across-grain directions 
6.1. Typical fracture patterns for graphite rings loaded in the across-grain direction at room temperature . . . . . . . . . . . 56

6.2. Circumferential strain under the applied load versus load for Test 13 showing experimental values and values calculated by the ABAQUS code using the orthotropic elastic-plastic model and the mesh of Fig. 4.6........................ 57

6.3. Circumferential strain on the load axis near $r=a$ versus load for Test 13 showing experimental values and values calculated by the ABAQUS code using the orthotropic elastic-plastic model and

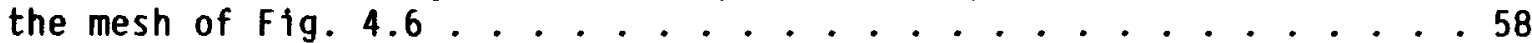

6.4. Circumferential strain at $90^{\circ}$ from the load axis near $r=a$ versus load for Test 13 showing experimental values and values calculated by the ABAQUS code using the orthotropic elasticplastic model and the mesh of Fig. $4.6 . . . . . . . . . . .59$

6.5. Circumferential strain at $90^{\circ}$ from the load axis near $r=b$ versus load for Test 13 showing experimental values and values calculated by the ABAQUS code using the orthotropic elasticplastic model and the mesh of Fig. $4.6 . . . . . . . . . . . .660$

6.6. Temperatures measured at various radial positions and angles on the graphite ring as well as the $\log r$ fit to the data . . . . . 62

6.7. Circumferential strain on the load axis near $r=a$ versus load for Test 14 showing experimental values and values calculated by the ABAQUS code using the orthotropic elastic-plastic model and the mesh of Fig. 4.6..................... 64

6.8. Circumferential strain at $90^{\circ}$ from the load axis near $r=a$ versus load for Test 14 showing experimental values and values calculated by the ABAQUS code using the orthotropic elasticplastic model and the mesh of Fig. $4.6 . . . . . . . . . . . .665$

6.9. Circumferential strain at $90^{\circ}$ from the load axis near $r=b$ versus load for Test 14 showing experimental values and values calculated by the ABAQUS code using the orthotropic elasticplastic model and the mesh of Fig. $4.6 . . . . . . . . . . . .666$

6.10. Average fracture load $P_{f}$ versus temperature drop $\Delta T$ and leastsquares fit to the experimental data...............66 


\section{TABLES}

3.1. Mechanical Tests Performed on H440 Graphite............ 9

3.2. Uniaxial Tensile Behavior of H440 Graphite at Room Temperature . . 12

3.3. Uniaxial Compressive Behavior of $H 440$ Graphite at Room Temperature ................... . . 16

3.4. Torsional Shear Behavior of $\mathbf{H 4 4 0}$ Graphite at Room Temperature . . . 20

3.5. H440 Elastic Constants from Sonic Measurements . . . . . . . . . 22

5.1. Maximum and Minimum Thermoelastic Stresses . . . . . . . . . . 34

6.1. Summary Data for Graphite Ring Tests . . . . . . . . . . . . . 54

6.2. Statistical Data on Room Temperature Tests . . . . . . . . . . 61

6.3. Statistical Data on Smal1 Graphite Ring Tests . . . . . . . . . 67 
AN INVESTIGATION OF THE STRENGTH OF H440 GRAPHITE

WHEN SUBJECTED TO COMBINED PRIMARY AND SECONDARY STRESS

by

Charles A. Anderson, Gerald W. Fly, Lynn B. Lundberg, and Joe A. Romero

\section{ABSTRACT}

An experimental and analytical investigation of the strength of a fine-grained graphite, $\mathrm{H} 440$, under combined mechanical and thermal stress is described. Small sample laboratory tests were carried out to establish a mechanical property data base from which statistical parameters could be determined and then used in finite element codes for predicting failure probabilities of large graphite strucural components under load. The theory was applied to graphite rings under an imposed thermal stress from a heat flux applied to the inner surface of the rings and under mechanical stress caused by diametrically opposed concentrated loads applied to the outer surface of the rings. Rings of $\mathrm{H440}$ graphite were fabricated in two sizes and tested to the combined thermal and mechanical loadings. From the results of theory and the experiments, a design rule for combining mechanical and thermal stress in graphite structural components is proposed.

\section{INTRODUCTION}

Because of its unique combination of neutronic, chemical, thermal and mechanical properties, graphite has been used for the design of support structures for the core of the Fort St. Vrain reactor and other proposed high-temperature gas-cooled reactors (HTGR). Graphite performance requirements include the ability to withstand a variety of thermostructural loadings and to do this with a high degree of reliability, to resist corrosion and erosion by the reactor coolant, and to maintain dimensional stability over a fairly wide range of temperatures, including accident and normal operating temperatures. The ability of graphite to meet these very requirements has made it the prime material candidate for reentry vehicle nose-tip applications. 
The mechanical behavior of reactor-grade graphites for HTGR applications is characterized by anisotropy, brittleness, and variability--particularly variability of fracture behavior. In order to meet the structural reliability requirements, it is therefore necessary to develop a failure theory that incorporates failure statistics. Implementation of that statistically based fallure prediction theory in finite element thermostructural analysis codes is also needed in order to assess the structural reliability of HTGR structural components. This computational effort and its experimental verification have been one of the major goals of the program described in this report.

In 1981 a thermoelastic stress analysis of a graphite core support block, a complex three-dimensional structure in the Fort St. Vrain HTGR, was complet$e^{2}$ by personnel of the Los Alamos National Laboratory. The support block was subjected to thermal stresses caused by a loss of forced circulation (LOFC) accident of the reactor system. Two- and three-dimensional finite element analyses of the core support block, modeled as an isotropic material, revealed

1. primary (direct) stresses in the core support block are much less than the secondary (thermal) stresses arising from the thermal gradients caused by the LOFC accident;

2. thermal stresses induced in the core support block were enhanced by stress concentration factors and approached the minimum ultimate tensile strength of the graphite. The factor of safety was 1.27 for the case considered; and

3. the effects of primary and secondary stress in the failure of graphite were unknown at that time, and there was no generally accepted method of combining these two types of stress--particularly in cases where there were high thermal gradients and localized peaks. It was recommended in Reference 2 that an experimental study be initiated that would provide a consistent method for combining primary and secondary stress in large graphite structural components and for determining the proper factor of safety for the component. This recommendation was a major impetus for the work described in this report.

As mentioned previously, the problem of designing reliable structures from graphite for reactor and aerospace applications was realized early in the past decade, and there are numerous 1970 s reports on failure criteria, material property measurements, ${ }^{3}$ and statistical studies of graphite 
strength. 4 It is not our purpose to review that literature, but rather to describe how the basic graphite property data can be used in the design or analysis of the strength of engineered structures. Initial attempts in this direction were provided by the proposed Section III, Division 2, American Society of Mechanical Engineers (ASME) code dealing with design requirements for graphite core supports ${ }^{5}$ and by an Nuclear Regulatory Commission (NRC) sponsored study by the Franklin Research Institute on the evaluation of the structural integrity of HTGR core and support elements. 6

The overall objective of this investigation is to carry out analyses and experiments that explain how primary and secondary stress combine to produce fracture fallure in large graphite structural components representative of those used in high-temperature gas-cooled reactors. The approach to achieve the desired goal is the generation of statistically significant mechanical property data from small graphite samples, analysis of graphite rings subjected to both primary and secondary stress using both closed form solutions (for linear isotropic elastic material behavior) and finite element techniques (for anisotropic inelastic behavior), and testing of large graphite rings with an imposed, resolvable primary and secondary stress field. Another approach to this problem is described in Ref. 7; however, in the experiments described there, only a thermal load was applied to the graphite test specimen, and it was applied as a high-temperature transient. The experiments described in this report are carried out on larger graphite test specimens at relatively low temperature, at steady state, and with the presence of both a primary and secondary stress field.

A statistically significant mechanical property data base was developed for H440 graphite. Dynamic elastic moduli were determined at Los Alamos, while stress-strain and strength measurements were performed in spectal facilities at the Southern Research Institute (SoRI). 8 The stress-strain and strength data were obtained from uniaxial tension and compression tests and torsional shear tests performed at room temperature under both monotonlcally increasing load and load-unload-reload conditions. A description of these tests is given in Section III of this report.

All specimens used in this study were taken from a single molded and pressed block of a fine-grained graphite designated $\mathrm{H} 440$ and produced by Great Lakes Carbon Company. The rectangular graphite block possessed two with-grain $(W / G)$ directions normal to the block length and one across-grain $(A / G)$ 
direction parallel to the block length. H440 graphite is closely comparable to ATJ graphite in all aspects, and it was chosen primarily because it was available in block sizes sufficiently large to allow both the large rings and all of the data base specimens to be taken from a single block in reasonable numbers for developing good statistics. The data from the small sample tests are summarized in Section III.

In Section IV we discuss the analytical and numerical models for graphite behavior that we used in this investigation. Basically, in our simplified analyses we use an isotropic linear elastic model to represent the fracture behavior of $H 440$ graphite. For this simplified situation, analytical thermoelastic solutions for a thick-walled ring under specified internal and external traction and heat flux can be developed. The solution for a constant internal heat flux and a specified external temperature is reproduced from Ref. 9, and the solution for a thick-walled ring under diametrically opposed localized pressure loadings is numerically evaluated from Ref. 10. The solutions are then combined, and the maximum tensile stress regions in the ring are used to determine the fracture load. For different temperature gradients in the ring and for different localized pressure loadings, we have constructed brittle failure regimes.

Graphite cannot be adequately modeled as an isotropic, elastic material with well-characterized fracture properties. As mentioned previously, the mechanical behavior of graphite involves anisotropy, some inelasticity due to cracking on the micro-scale, and considerable statistical variation in its fracture behavior. In the more complex modeling described in Section IV, we use the finite element method to account for the anisotropy and inelasticity in graphite behavior. In addition, we used the Weibull statistical model to represent the statistical variation in strength properties of the $H 440 \mathrm{graph}$ ite given in Section III.

Section $v$ describes the experimental hardware and the procedures used to validate failure predictions for large graphite components subjected to both primary and secondary stress. The configuration selected for testing was a thick-walled ring. Solid rings loaded by diametrically opposed localized pressure loadings have long been used for laboratory testing and the determination of the tensile strength of rocks. The test is frequently referred to as the Brazilian test and provides an easy method of inducing complicated stress fields in rock specimens and for studying anisotropy in rocks. The 
test is described in Ref. 11. By using hollow rings we could accommodate a heater that supplied a steady-state temperature gradient (and induced thermal stress) in the graphite and yet could maintain the basic attributes of the Brazlilian test. In order to examine the usual effects of scale found in brittle materials, two sizes of graphite rings--one approximately twice the size of the other-were included in the test program.

Section $V$ discusses the design parameters for the graphite ring expertments. Because of the high thermal conductivity of graphite, heat fluxes applied to the inner surface of the graphite ring are very large and the design of a heater for this purpose was extremely difficult. Two different heater designs that were fabricated and tested are discussed in section $V$. The second heater design based on a liquid-metal coupling to the graphite proved successful and was used for all tests conducted on this program. In Section $V$ we also describe the mechanical loading apparatus, the strain gage and thermocouple instrumentation, the test procedures, and the experimental measurement of the thermal expansion coefficient. Once the heater problems were solved, the remaining experimental hardware was fabricated and operational procedures were carried out with relatively few problems encountered.

In Section VI of this report, we present the results of the small and large graphite ring experiments and how the results compare with the analytical and numerical predictions of Section IV. First, the thermal expansion coefficient of 1440 graphite was determined, and that procedure is described in this section. The room temperature load tests of the smaller graphite rings were carried out, and strain as a function of load as well as the ultimate strain and load were determined. Several small graphite rings were so tested in order to develop a sense of the variation in the behavior of the rings because of differences in strength properties of the $H 440$ graphite. How the ultimate load statistics compare with the predictions of the weibull model described in section IV is described.

Load tests of the small graphite rings were then carried out with successively larger steady-state thermoelastic stress fields imposed by heating the inner surface of the ring. Again strain versus load and ultimate strain and load were determined as well as fallure statistics, and comparisons were made with the predictions of Section IV.

The final sequence of tests on this program involved the testing of the large 4440 graphite rings to the same levels of direct stress and at room 
temperature and with imposed thermoelastic stress fields. The results of the tests on the large rings are compared with theory and with the results on the smaller graphite rings.

\section{CONCLUSIONS AND RECOMMENDATIUNS}

From the resuits of the numerous laboratory and engineering scale experiments that were carried out in this program, together with the supporting analysis, we have arrived at the following conclusions and recommendations concerning the thermomechanical behavior of $H 440$ graphite structural components subjected to combined thermal and direct stresses.

1. Even for modest thermal stresses (compared with the direct stresses) the fracture characteristics of a fine-grained graphite are affected. Our experiments show that, even though $H 440$ graphite exhibits some plasticity through microcracking, it should be treated for strength analys is purposes as a $100 \%$ brittle material. Furthermore, for strength analysis, the thermal and direct stresses should be added and compared with the ultimate tensile stress of the material in the most affected material direction.

2. The statistical nature of the $H 440$ graphite strength properties must be taken into account in the analysis of large graphite structural components subjected to direct or combined stresses in those situations where a large factor of safety does not exist. With a suitable statistical data base on the strength of small graphite specimens and finite element calculational techniques, one can generate the probability of fallure curve for graphite structural components. The accuracy of the generated curve depends on deriving from the small sample data the correct volume dependence of the strength of the graphite.

3. No substantial size effect was observed in testing the small and large graphite rings to direct and thermal stress.

4. Similar experiments should be carried out on a large-grained graphite characteristic of large-grained graphites (e.g., PGX) used for HTGR structural components. Since we experienced difficulty in measuring thermally induced strains in the $\mathrm{H440}$ experiments, the experiments on a large-grained graphite ring should not be extensively instrumented with strain gages. Extensive analysis and the technique used in section VI.B 
can be used to verify the proper stress combination rules for largegrained graphite structural components.

5. Although the graphite rings tested in this program were characterized with non-uniform stress fields in the ring, the variation of stress with position was not as strong as it would be near a stress concentration. Since stress risers are present in HTGR graphite structural components, we recommend subjecting a graphite ring with a notch to combined thermal and direct stress to verify that thermal and direct stress contributed equally to fracture at the notch. The question here is whether the small plasticity effects observed in the behavior of the smoother graphite rings will be greatly enhanced at a stress riser.

6. Finally, our difficulties with heater fabrication seem to preclude testing graphite rings to large steady-state thermal stresses (compared to the direct stresses) and investigating the fracture behavior of mainly thermally stressed graphite structural components.

\section{H440 GRAPHITE DATA BASE}

\section{A. Introduction}

A statistically significant mechanical property data base was developed for $H 440$ graphite. Uynamic elastic modult were determined at Los Alamos while stress-strain and strength measurements were performed in special facilities at the Southern Research Institute. These data were obtained from uniaxial tension and compression tests and torsional shear tests.

All specimens used in this study were taken from a single molded and pressed block of a fine-grained graphite designated $\mathrm{H} 440$ and produced by Great Lakes Carbon Company. Originally, the rectangular graphtte block measured $58 \mathrm{in.}$ long by $17 \mathrm{in.}$ wide by $8 \mathrm{in}$. thick, and it possessed two W/G directions normal to the block length and one $A / G$ direction parallel to the block length. The graphite is isotropic in behavior in planes normal to the block length. H440 graphite is closely comparable to ATJ graphite in all aspects, and it was chosen primarily because it was available in block sizes sufficiently large to allow for both thermomechanical ring and data base specimens to be taken from a single block in reasonable numbers for developing good statistics.

Samples were removed from various locations in the large graphite block to define block variability and obtain data from sections of the block close 
to the thermomechanical ring specimens. The three regions from which the tension, compression, and torsion test specimens were removed from the graphite block are indicated in Fig. 3.1. Specimens were cut so that about half were aligned in the $A / G$ direction and the other half aligned in the $W / G$ direction.

The mechanical properties data base was collected from tests performed at room temperature. This was considered to be quite appropriate because of the fact that graphite mechanical properties do not change significantly at temperatures below about $1000 \mathrm{~K}$. The mechanical tests included the determination of stress-strain behavior to failure of this graphite material in tension, compression, and torsional shear. Because of a concern for cyclic loading

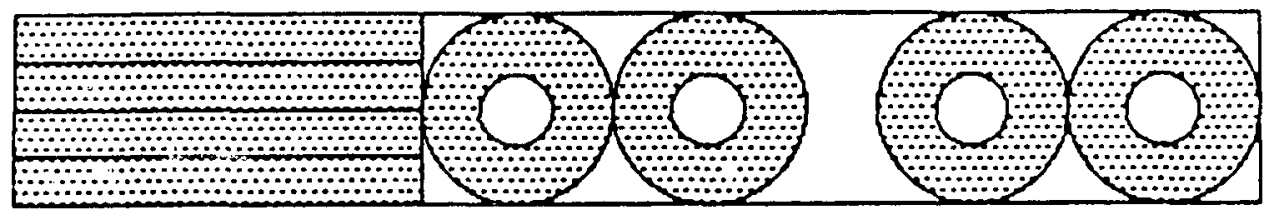
$W / G(c)$

THERMOMECHANICAL STRENGTH OATA SAMPLES

H:
BASE SAMPLES

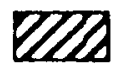

ELASTIC CONSTANTS

DATA BASE SAMPLES
$A / G$

(b)
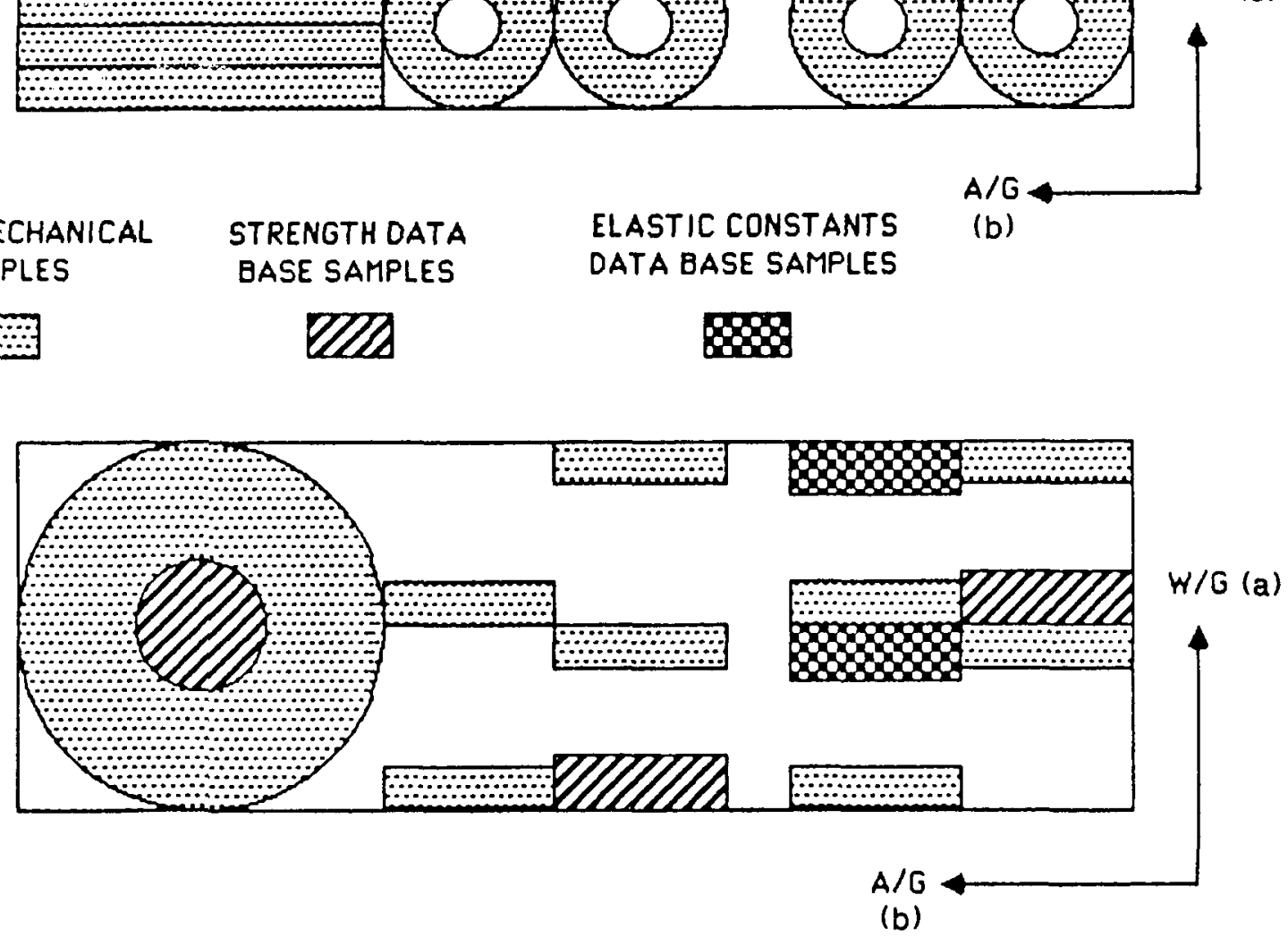

4 in.

Fig. 3.1. Cutting plan for $H 440$ graphite block. 
effects, about one-half of the specimens were taken through one loadingunloading cycle before being taken to fallure. The mechanical tests that were performed are listed in Table 3.1. The details of the mechanical tests, which were conducted at SoR1, can be found in Ref. 8 .

The five independent elastic constants were also measured at Los Alamos using ultrasonic methods, and static values of the two Young's and shear moduli plus the two Poisson's ratios were obtained from the stress-strain data obtained at SoRI.

TABLE 3.1

MECHANICAL TESTS PERFORMED ON H440 GRAPHITE

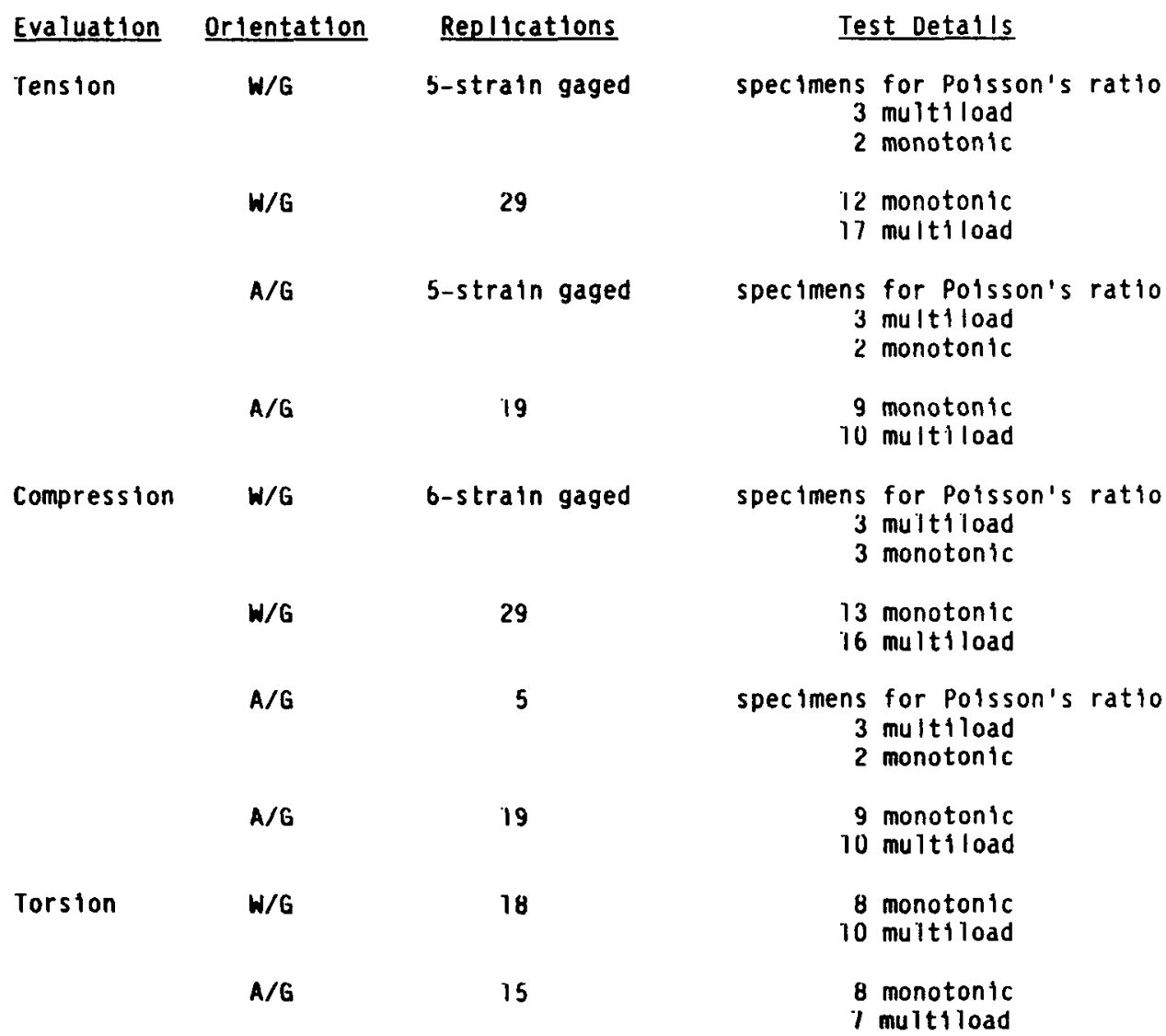




\section{B. Tension Tests}

Tensile stress-strain data were obtained from $24 \mathrm{~A} / \mathrm{G}$ and $34 \mathrm{~W} / \mathrm{G}$ specimens. From these data were obtained the ultimate strength and load-deformation properties.

The data were obtained using a mechanical drive tensile test machine equipped with special gas bearings that automatically provided precise alignment of the specimens during loading. 8 The load was measured with a 15,000-1bcapacity, SR-4 Baldwin load cell, and the longitudinal strain was measured with an optical extensometer. A few specimens were fitted with strain gages to measure both longitudinal and transverse strain during loading for determination of Poisson's ratio.

The specimens tested were machined from the blanks into the configuration shown in Fig. 3.2. The specimens had an overall length of 3 inches and a

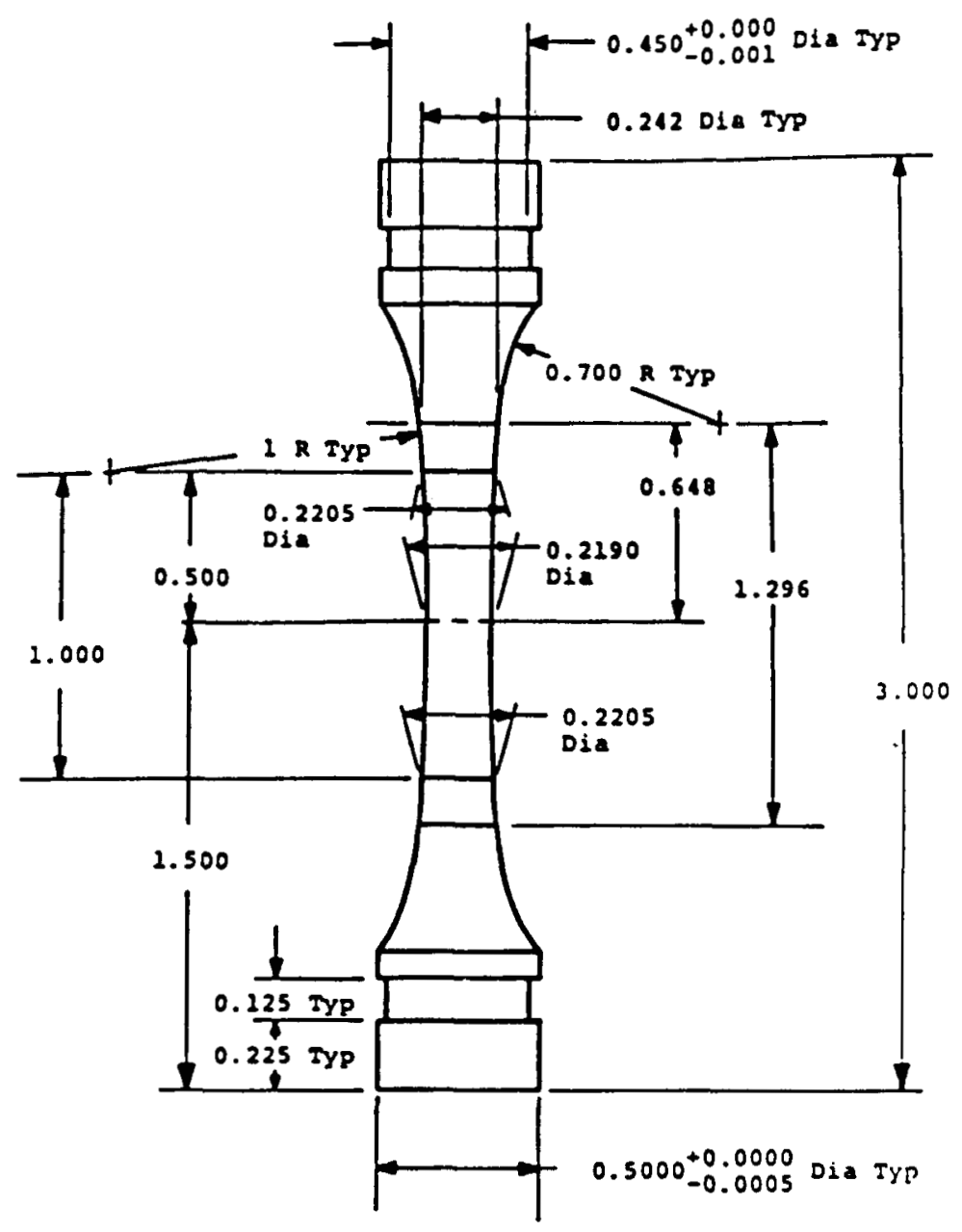

Fig. 3.2. Graphite tensile specimen. 
major dlameter of $0.500 \mathrm{in.,}$ and they had a gage section $1.00 \mathrm{in}$. long and $0.202 \mathrm{in}$. in diameter. In keeping with accepted practice, the gage section was tapered slightly to promote fracture away from the gage section to grip section transition region.

The simple tensile tests were performed by monotonically loading the specimens to fallure. The cyclic tests were performed by first loading the specimens monotonically to a significant fraction (about one-third) of the ultimate strength followed by unloading monotonically to near zero stress, and finally the specimens were loaded to failure monotonically. A typical cyclic stress-strain curve is presented schematically in Fig. 3.3 . These curves

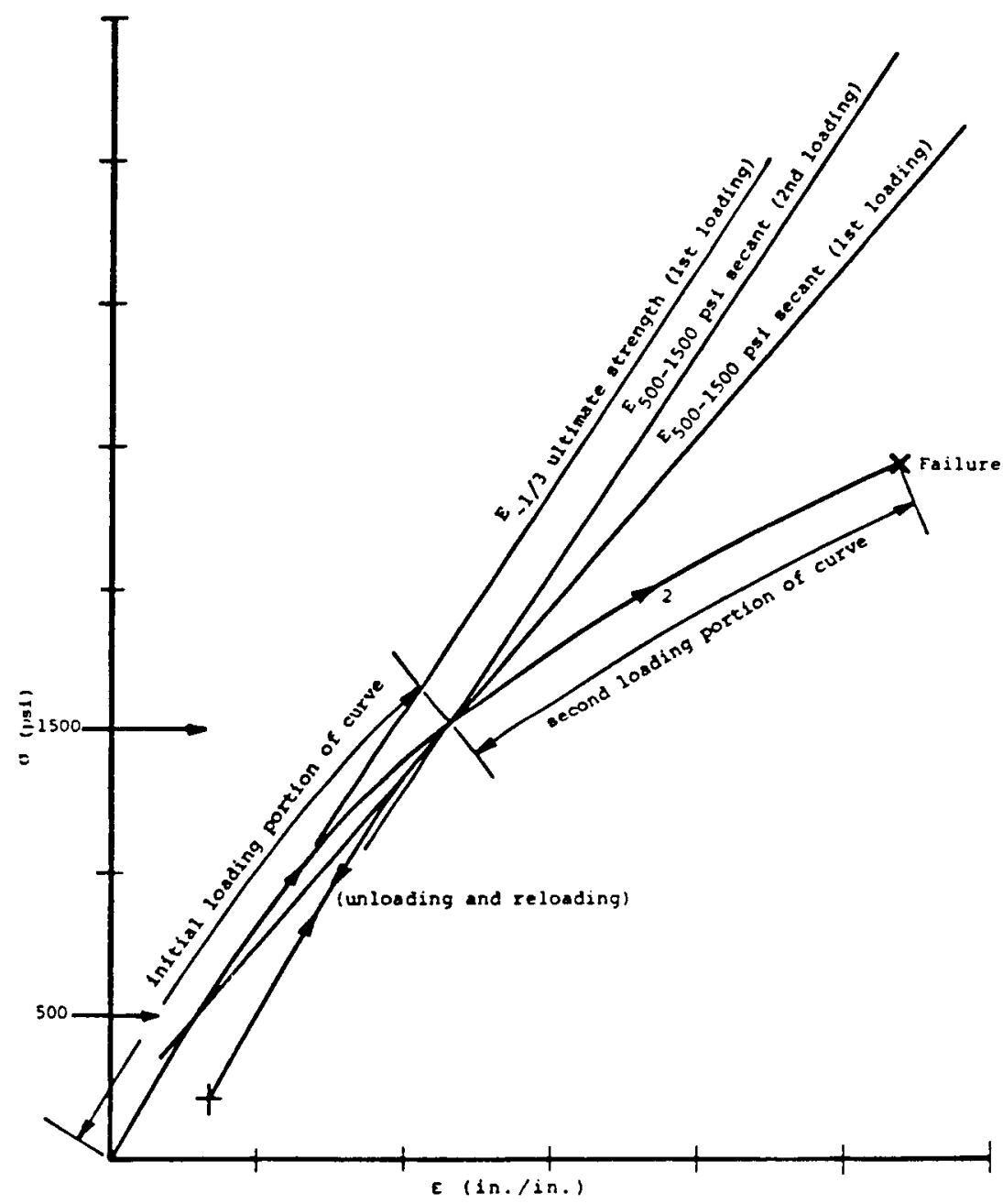

Fig. 3.3. Typical untaxial tensile stress-strain curve for $\mathrm{H} 440$ graphite illustrating the three tabulated modulus values and unload-reload behavior. 
indicate a permanent deformation due to the initial loading, but upon reloading, the curve was essentially retraced and picked up where initial loading terminated. In this sense the material behaves as an elastic-plastic solid. The procedures used for calculating the various moduli listed in Table 3.2 are also indicated graphically in Fig. 3.3. Average values for these moduli plus the ultimate tensfle strengths, $\sigma_{u}$, and strains-to-failure, $\varepsilon_{u}$, are listed in Table 3.2. Averages were determined separately for both $W / G$ and $A / G$ loading directions under both monotonic and cyclic loading conditions. Comparison of the property data in this table reveals that $E_{1 / 3}$ (the secant modulus at $1 / 3 \sigma_{u}$ ), $\sigma_{u}$ and $\varepsilon_{u}$ are not significantly affected by the loading schedule, so the overall averages were calculated and listed in Table 3.2 .

TABLE 3.2

UNIAXIAL TENSILE BEHAVIOR OF H440 GRAPHITE AT RODM TEMPERATURE

( $s \rightarrow$ standard deviation of mean, max $\rightarrow$ maximum value, min $\rightarrow$ minimum value, med $\rightarrow$ median value)

Loading

Direction

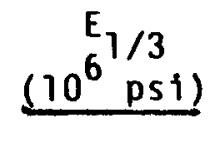

1.33

0.07

W/G Mono

$s \rightarrow$

W/G Cyclic

$s \rightarrow$

1.32

0.59

W/G Avg

$s \rightarrow$

$\max \rightarrow$

min $\rightarrow$

med $\rightarrow$

$A / G$ Mono

$S \rightarrow$

$A / G$ Cycitic

$s \rightarrow$

$A / G$ Avg

$s \rightarrow$

$\max \rightarrow$

$\min \rightarrow$

med $\rightarrow$
1.22

0.06

1.44

1.22

1.34

1.08

0.06

1.12

0.08

1.10

0.07

1.27

0.96

1.10

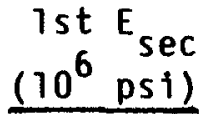

1.22

0.06

1.42

0.08

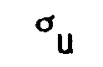

(psi)

3615

217

3600

235

3606

225

4020

3190

3560

2950

162

3050

213

3000

195

3430

2660

2980

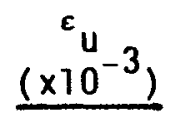

3.7

0.2

3.7

0.4

3.7

0.3

4.3

3.2

3.7

3.7

0.4

3.8

0.4

3.7

0.4

4.5

3.1

3.7 
The distributions of the $\sigma_{u}$ and $\varepsilon_{u}$ values for all samples regardless of loading schedule are presented graphically in Figs. 3.4 and 3.5, and histograms for $E_{1 / 3}$ values are presented in Fig. 3.6. The standard deviations of the means of these properties are listed in Table 3.2 along with their maximum, minimum, and median values.

Bilinear fits were obtained from composite stress-strain curves from the monotonically loaded specimens for both orientations. The slopes and intercept of the two linear portions of the bilinear curves were obtained through minimization of the area between these curves and the average stress-strain curves. The initial slope of the $W / G$ curve was determined to be $1.27 \times 10^{6} \mathrm{ps} i$, and the second slope was determined to be $7.85 \times 10^{5}$ psi. The "yield stress" and "yield strain" were determined to be $2190 \mathrm{psi}$ and 0.0017 , respectively. The initial slope of the $A / G$ curve was determined to be $1.02 \times 10^{6} \mathrm{psi}$, and
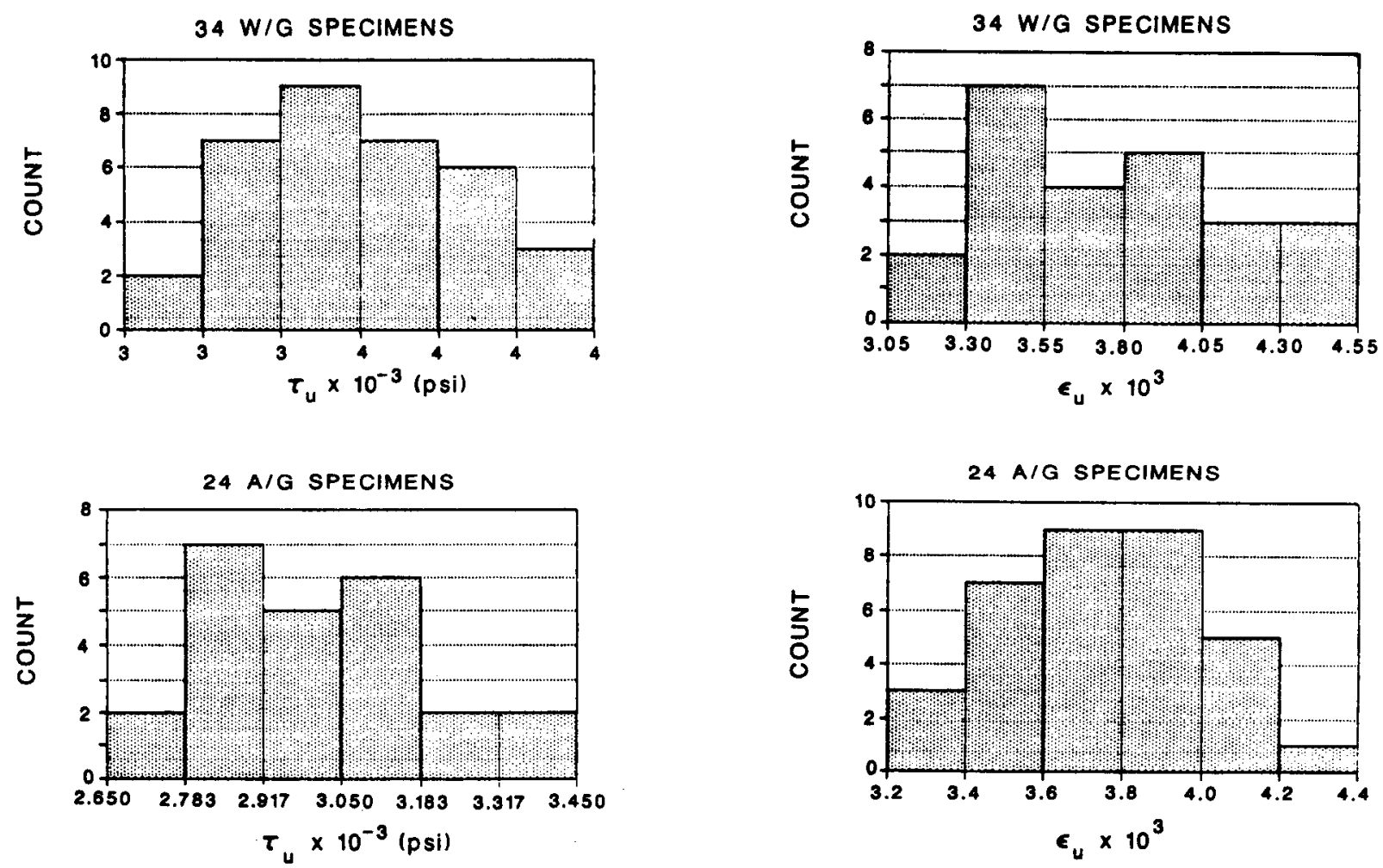

Fig. 3.4. Frequency plot for the ultimate tensile strength $\sigma_{u}$ for $H 440$ graphite specimens.

Fig. 3.5. Frequency plot for the ultimate tensile strain $\varepsilon_{u}$ for $H 440$ graphite specimens. 

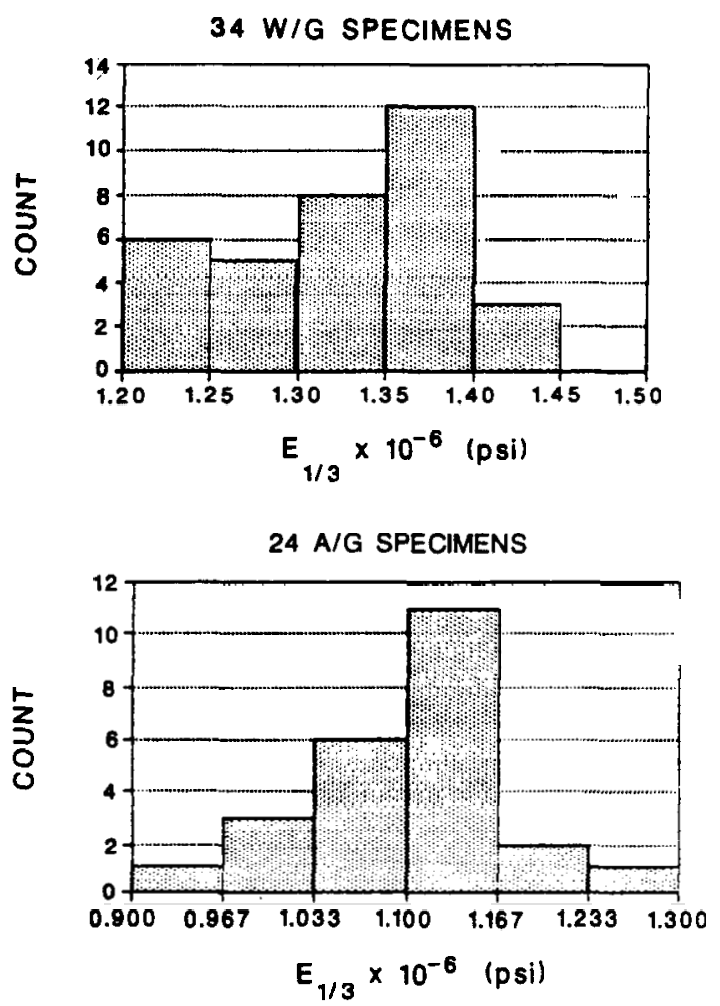

Fig. 3.6. Frequency plot for the secant modulus $E_{1 / 3}$ for $H 440$ grahite specimens.

the second slope was determined to be $5.96 \times 10^{5}$ psi. The "yield stress" and "yield strain" were determined to be 1970 psi and 0.0019 , respectively.

\section{Compression Tests}

Compression tests were performed on $24 \mathrm{~A} / \mathrm{G}$ and $35 \mathrm{~W} / \mathrm{G}$ dog-bone type specimens. Cyclic tests in which the specimens were initially loaded to about 50\% of their ultimate load, unloaded, and immediately reloaded to failure were performed on 13 of the $A / G$ specimens and 19 of the $W / G$ specimens.

The compressive properties-fallure strain and strength, secant elastic moduli at various stresses, and full stress-strain curves--were obtained with a 50-ton screw-jack loading train fitted with gas bearings to insure precise alignment of the specimens during loading. ${ }^{8}$. The load was measured with a 20,000-pound-force, SR-4 Baldwin load cell mounted in the load train, and the 
strain was measured over an 0.875-inch-long gage length using an electrooptical extensometer. The specimens were loaded to failure at a constant loading rate of 10,000 psi/min.

A typical cyclic stress-strain curve is presented in Fig. 3.7 , and the averaged data from the curves derived from all the specimens are summarized in Table 3.3. Eint is the initial modulus determined by measuring the slope of each stress-strain curve from 0 to $500 \mathrm{psi}$, and the $E_{\text {sec }}$ values were obtained for the stress range 1250 to $3750 \mathrm{psi}$. The 1 st $E_{\mathrm{sec}}$ values were obtained from the initial loading curves, while the 2 nd $E_{\text {sec }}$ values were obtained from the reload curves. As there was little difference between the terminal behavior of either the cyclic or monotonically loaded specimens, all of the values of ultimate strength, ultimate strain, and initial modulus were averaged together and tabulated in Table 3.3 .

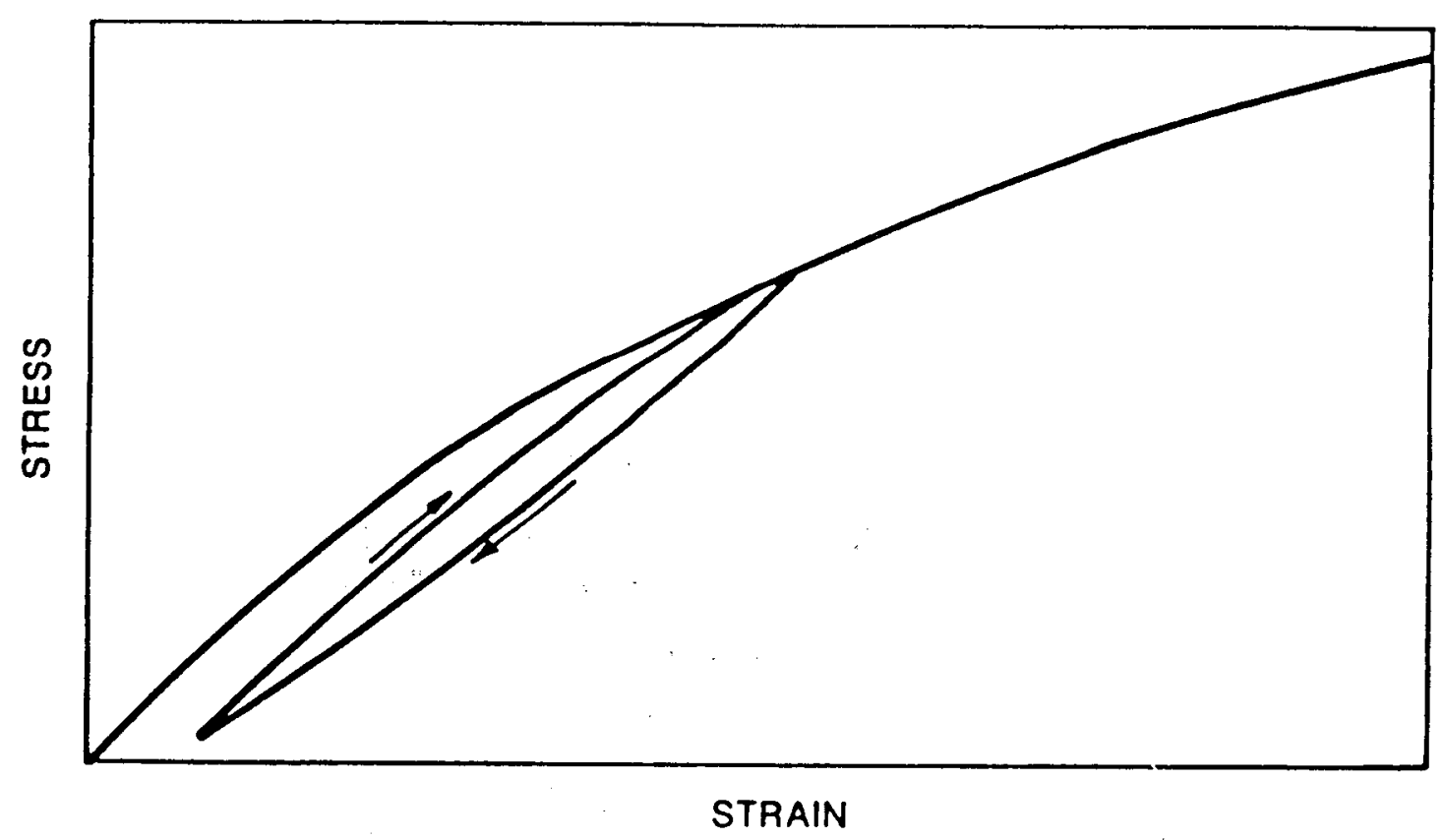

Fig. 3.7. Typical uniaxial compressive stress-strain curve for 1440 graphite showing load-reload behavior. 
TABLE 3.3

UNIAXIAL COMPRESSIVE BEHAVIOR OF H440 GRAPHITE AI ROOM TEMPERATURE

( $s \rightarrow$ standard deviation of mean, max $\rightarrow$ maximum value, min $\rightarrow$ minimum value, med $\rightarrow$ median value)

Loading

Direction

W/G Mono

$s \rightarrow$

W/G Cyclic

$s \rightarrow$

W/G Avg

$s \rightarrow$

$\max \rightarrow$

$\min \rightarrow$

med $\rightarrow$

$A / G$ Mono

$s \rightarrow$

$A / G$ Cyclic

$s \rightarrow$

$\begin{array}{cl}A / G \text { Avg } & 1.07 \\ s \rightarrow & 0.09 \\ \max \rightarrow & 1.30 \\ \min \rightarrow & 0.91 \\ \operatorname{med} \rightarrow & 1.10\end{array}$

1.33

0.09

1.60

1.20

1.30

1.09

0.08

1.06

0.11 2nd $E_{\text {sec }}$
$\left(10^{6}\right.$ psi)

$\sigma_{\mathrm{u}}$

(ksi)

$\left(\begin{array}{c}\mathrm{e}^{\mathrm{u}} \\ \left(\mathrm{1} 0^{-3}\right)\end{array}\right.$

9.770

27.0

1.36

0.70

1.31

0.08

0.93

0.05

1.09

0.07

0.338

0.2

26.0

0.3

0.356

26.4

9.776

2.4

10.600

31.0

9.075

21.0

9.775

26.0

0.73

0.07

0.87

0.09

9.990

36.0

0.240

0.7

34.0

0.5

9.988

0.400

35.1

9.989

0.330

6.3

10.750

48.0

9.300

26.0

9.975

Distributions of the values for the ultimate strength, ultimate strain, and intial modulus are represented graphically in the histograms found in Figs. $3.8,3.9$, and 3.10 , respectively. Some variability in properties was also observed as a function of location from which the sample was taken out of the original graphite block. Even though there was an indication of variability due to sample location, property values varied only about $\pm 5 \%$ around their grand means, which is not considered significant.

Each specimen failed catastrophically, breaking into several pieces. This is a typical compressive failure mode for quasi-brittle materials such as graphite. 


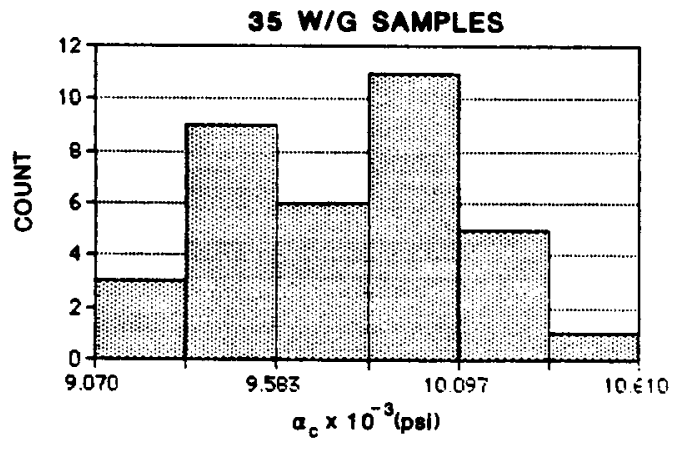

24 A/G SAMPLES

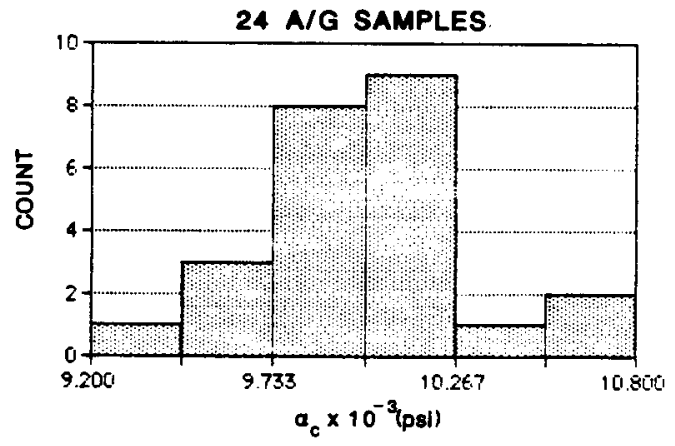

Fig. 3.8. Frequency plot for ultimate compressive strength $\sigma_{C}$ for $\mathrm{H440}$ graphite specimens.
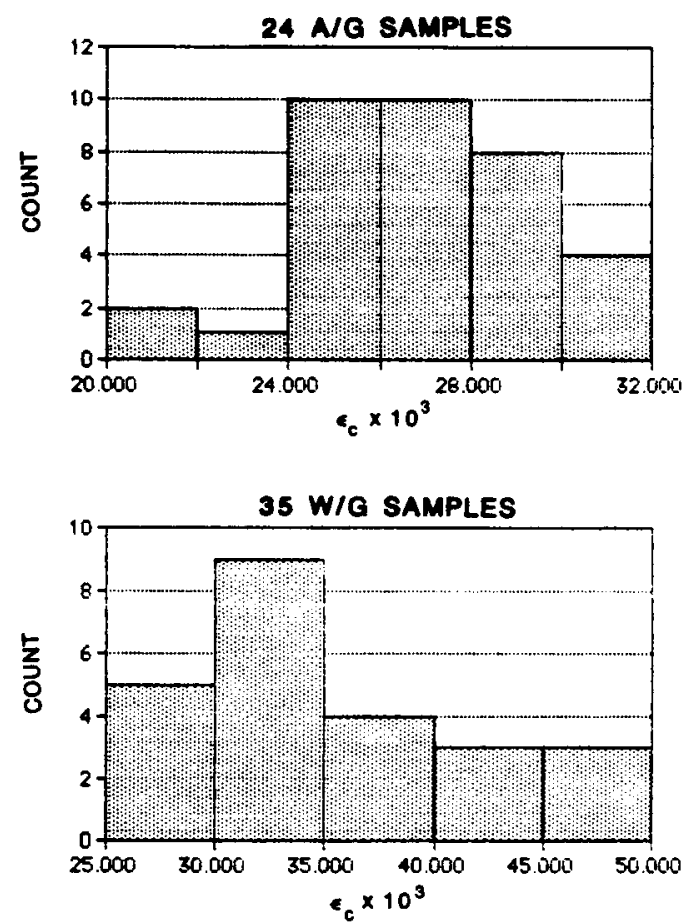

Fig. 3.9. Frequency plot for ultimate compressive strain $\varepsilon_{c}$ for $H 440$ graphite specimens.
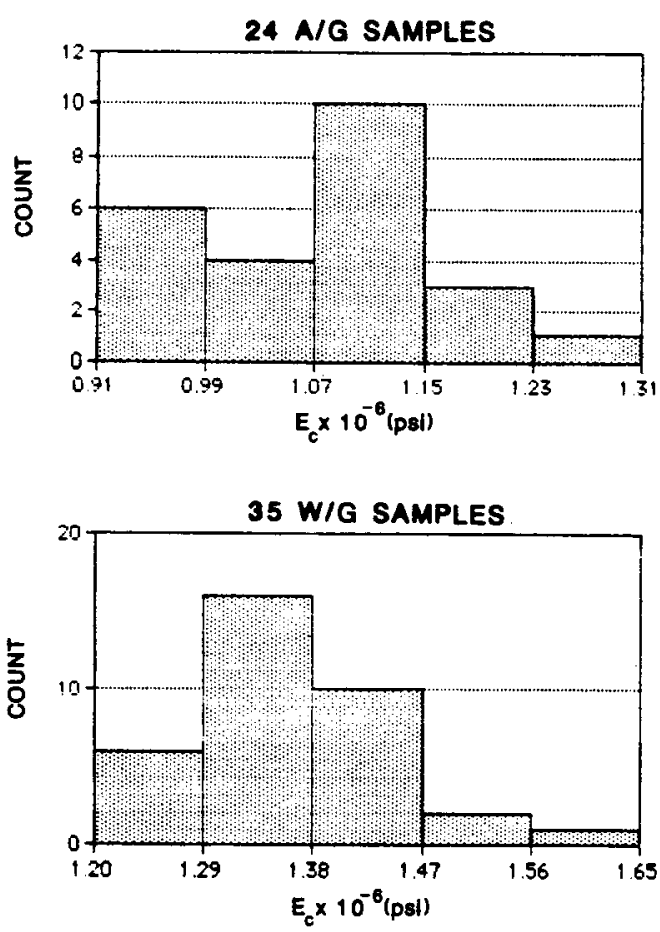

Fig. 3.10. Frequency plot of initial compressive modulus $E_{C}$. 
Strain gages were attached to measure both the lateral and longitudinal strain of four $A / G$ specimens and one W/G specimen in order to measure Poisson's ratio. The $A / G$ specimens yielded an average value of 0.10 , while Poisson's ratio for the W/G specimen was measured to be 0.12 , about the same values as measured in the tensile tests.

\section{Torsion Tests}

Tests were performed on tubular specimens to determine the room temperature torsional shear behavior of $H 440$ graphite using a gas-bearing torsion test apparatus. 8 Specimen strain was measured with a device like that shown schematically in Fig. 3.11. Two graphite rings were attached concentrically at opposite ends of the 1-inch gage length, and graphite yarn was wound around each ring in a $V$-groove cut into its circumference. The free end of each piece of yarn was attached to the core of a linear variable differential transformer (LVDT) to measure relative rotational displacement of the ends of the specimen gage section.

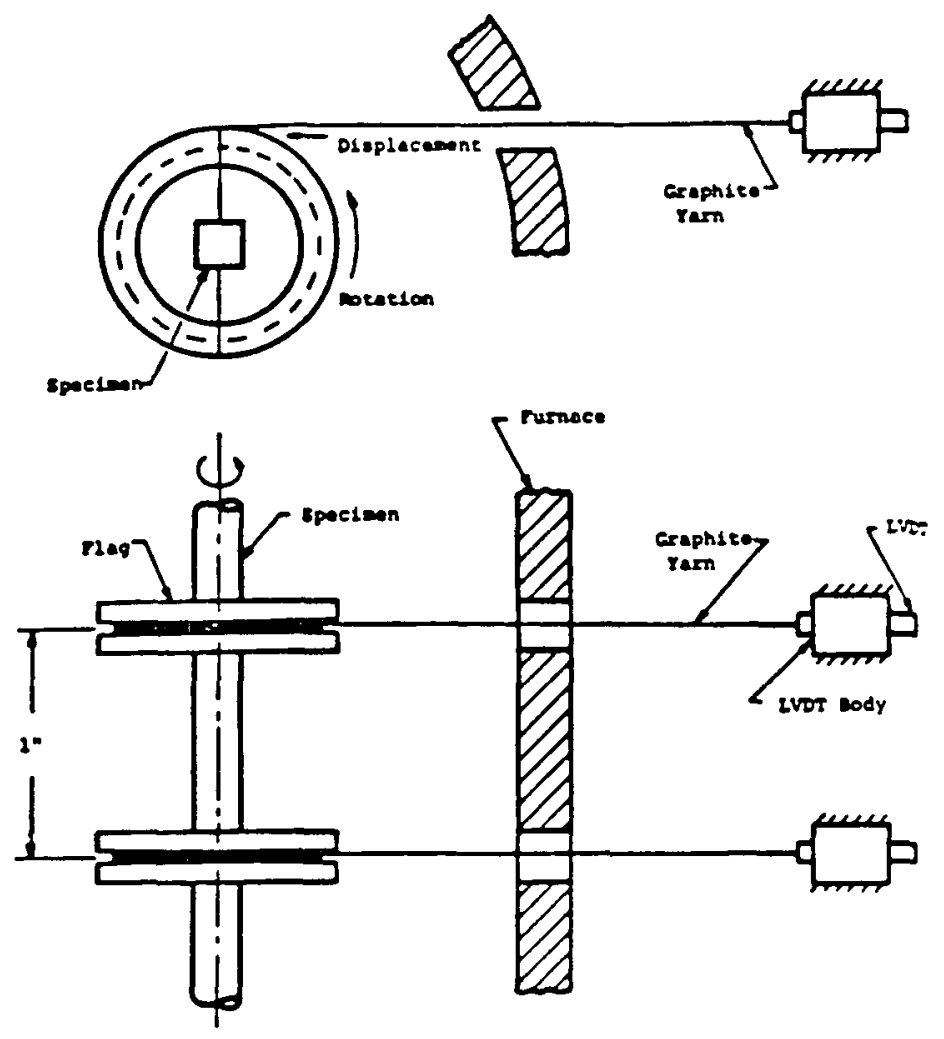

Fig. 3.11. Schematic of system for measuring the angular rotation of the tubular graphite test specimen. 
Stress-strain data were obtained to failure from $18 \mathrm{~W} / \mathrm{G} \mathrm{spec}$ imens and 15 $A / G$ specimens. Specimen orientations represent the grain orientation parallel to the axis of the tubular specimen. Ten of the $W / G$ specimens and seven of the $A / G$ specimens were first loaded to $1500 \mathrm{psi}$, unloaded, and immediately reloaded to failure. The remaining specimens of both types were loaded monotonically to failure at a rate of $10 \mathrm{ksi} / \mathrm{min}$. A typical cyclic stress-strain curve is presented in Fig. 3.12. This curve is typical for both sample orientations, and the envelope curve is typical of the monotonically loaded specimens.

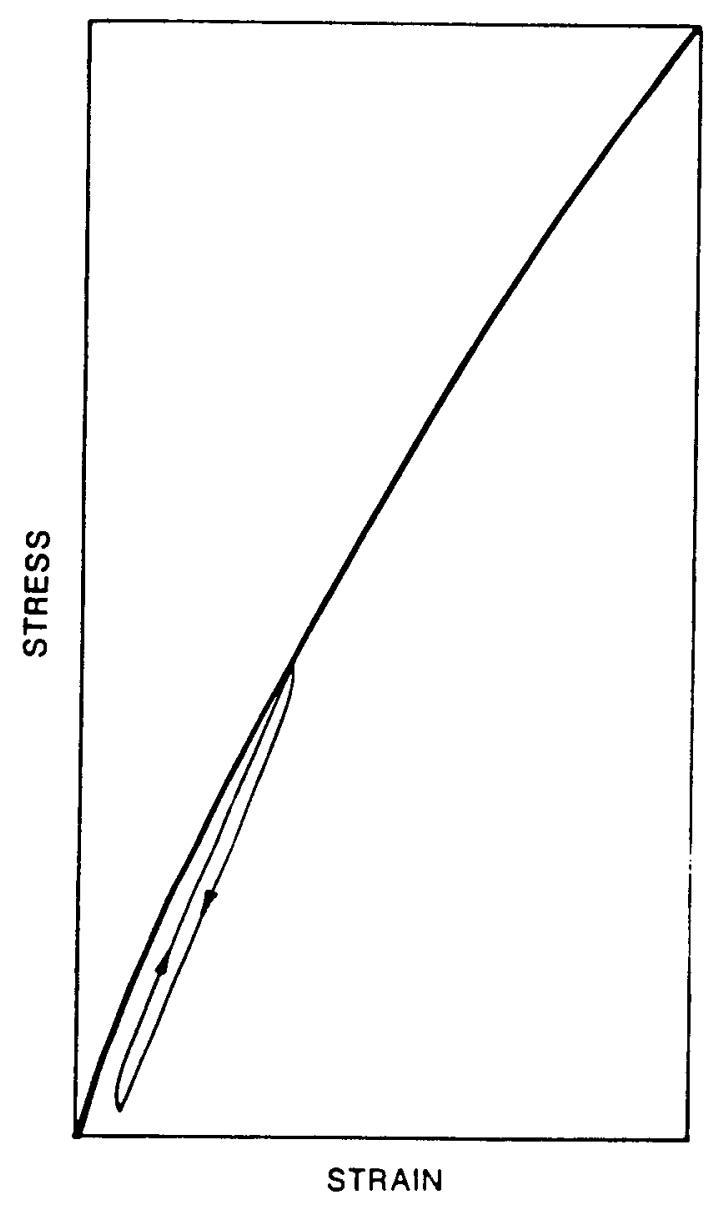

F1g. 3.12. Typical shear stress-strain curve for $H 440$ graphite showing unload-reload behavior. 
Data derived from these curves are summarized below in Table 3.4. The $G_{\text {int }}$ values are actually 0-500 psi secant shear moduli, while both of the $G_{\text {sec }}$ values are 500-1500 psi secant shear moduil. These indicate that failure stresses, $\tau_{u}$, and the fallure strains, $Y_{u}$, do not vary significantiy due to the loading procedure.

The distributions of ultimate strength, ultimate strain, and $G_{\text {int }}$ values are presented graphically in histogram form for the $W / G$ samples in Fig. 3.13 and for the $A / G$ samples in Fig. 3.14.

\section{TABLE 3.4}

TORSIONAL SHEAR BEHAVIOR OF H440 GRAPHITE AT ROOM TEMPERATURE

( $s \rightarrow$ standard deviation of mean, max $\rightarrow$ maximum value, min $\rightarrow$ minimum value, med $\rightarrow$ median value)

Loading

Direction

W/G Mono

$S \rightarrow$

W/G Cyclic

$s \rightarrow$

W/6 Avg

$S \rightarrow$

$\max \rightarrow$

8.6

min $\rightarrow$

med $\rightarrow$

A/G Mono

$s \rightarrow$

A/6 Cyclic.

$s \rightarrow$

A/G Avg

$s \rightarrow$

$\max \rightarrow$

$\min \rightarrow$

med $\rightarrow$

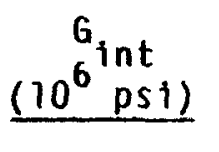

0.71

0.14

0.71

0.07

0.71

0.10

0.87

0.53

1.30

0.68

0.11

0.62

0.05

0.65

0.09

0.82

0.51

0.62

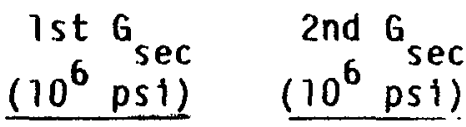

$\left(10^{6} \mathrm{psi}\right) \quad\left(10^{6} \mathrm{psi}\right)$

$\tau$

(ksi)

3.272

0.156

0.61

0.54

0.04

0.01

3.386

0.252

3.335

0.217

2.945

9.775

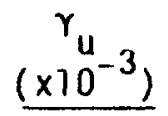

7.4

0.6

7.6

0.8

7.5

0.7

3.645

6.1

26.0

3.206

0.189

3.217

0.097

7.6

0.51
0.02

0.58

0.02

3.211

0.148

3.415

2.975

3.250

0.2

7.6

0.3

8.1

6.8

7.6 

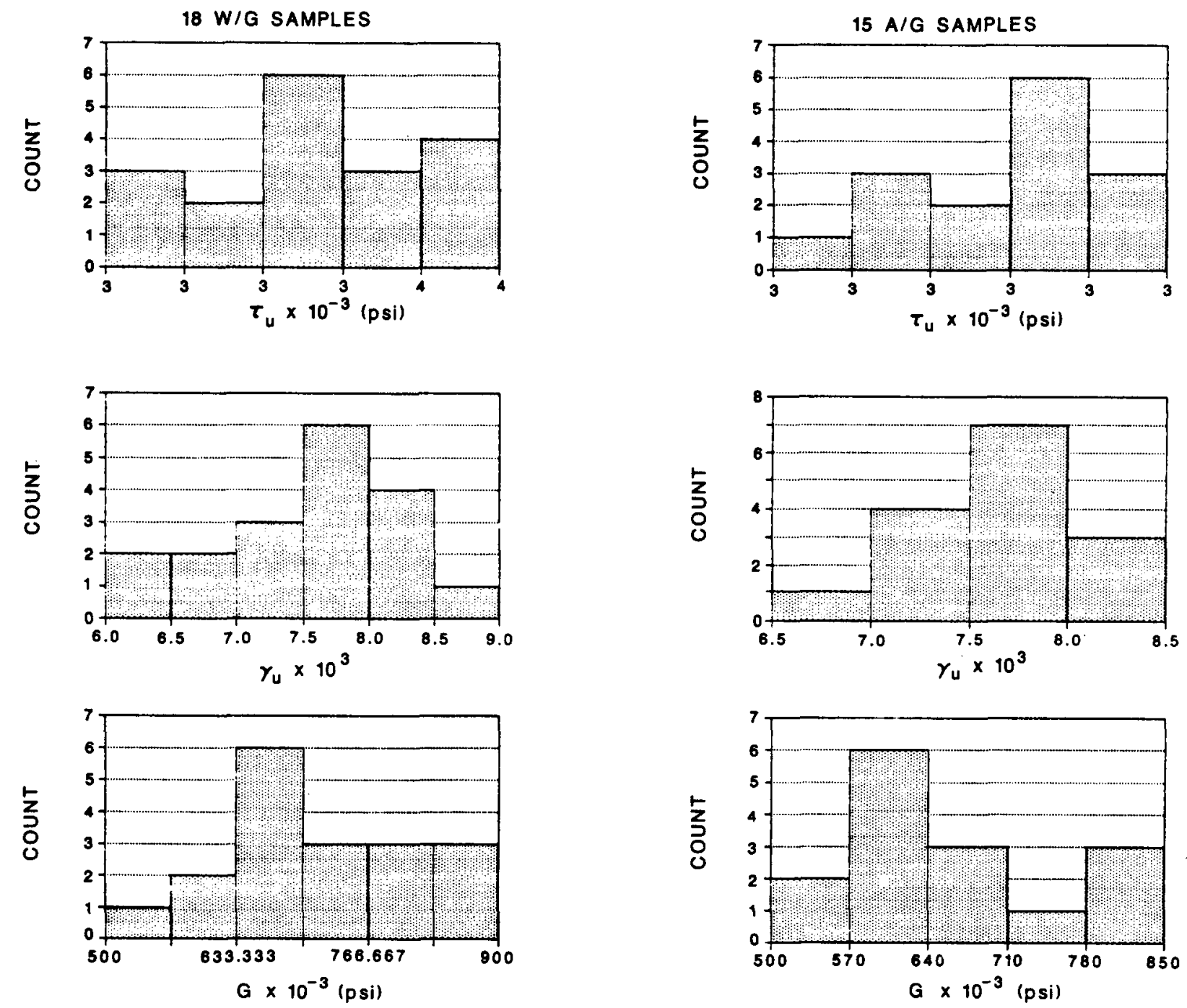

Fig. 3.13. Frequency plot of torsion elastic modulus $G$ and strength parameters $\tau_{u}$ and $Y_{u}$ for $H 440$ graphite in the $W / G$ direction.

Fig. 3.14. Frequency plot of torsion elastic modulus $G$ and strength parameters $\tau_{u}$ and $Y_{u}$ for $H 440$ graphite in the $A / G$ direction.

\section{E. Elastic Constants from Sonic Testing}

Elastic constants were also determined for $\mathrm{H} 440$ graphite from ultrasonic measurements made at Los Alamos. Because they are valid at only very low strain levels, these constants were not used in the calculations described later in this report. Consequently, we list the values here for reference purposes only. 
TABLE 3.5

H440 ELASTIC CONSTANTS FROM SONIC MEASUREMENTS

\begin{tabular}{|c|c|c|c|c|c|}
\hline $\begin{array}{c}\text { Sample } \\
\text { Block No. }\end{array}$ & $\mathrm{C}_{11}{ }^{*}$ & $\mathrm{C}_{33}$ & $\mathrm{C}_{13}$ & $\mathrm{C}_{12}$ & $c_{44}$ \\
\hline $2 A$ & $1.73 \pm 0.30$ & $1.50 \pm 0.03$ & $0.30 \pm 0.06$ & $0.38 \pm 0.20$ & $0.66 \pm 0.03$ \\
\hline $3 A$ & $1.85 \pm 0.12$ & $1.62 \pm 0.04$ & $0.25 \pm 0.18$ & $0.36 \pm 0.07$ & $0.66 \pm 0.04$ \\
\hline
\end{tabular}

*Values given in $10^{6}$ psi. Constants refer to Eq. (3) of Section IV.B.

IV. NUMERICAL AND ANALYTICAL RESULTS

The lack of a complete constitutive law for graphite, which includes the effects of anisotropy and a fallure surface valid for all combinations of stress, as well as the statistical nature of its material properties, makes the analysis of the behavior of large graphite structural components a formidable task. Consequently, to support the experimental work of this program, we have used several approaches to the stress analysis of graphite and the prediction of fallure under combined mechanical and thermal loadings. First, we have used some analytical solutions for the linearly elastic behavior of thickwalled discs and tubes subjected to diametrically opposed pressure loadings and axially symmetric steady-state thermal loadings to predict the failure of the graphite rings tested in this program. Here we focus only on the region of maximum principal tensile stress in the ring, and we postulate that failure occurs whenever that stress, regardless of its origin, reaches the value of the ultimate tensile strength in the direction associated with the principal tensile stress direction. Results, in terms of a fracture surface (for ultimate tensile stress or strain) for the graphite rings subjected to the combined loadings, are presented in Section IV.A below. In Section IV.B, we treat the same problem numerically with the finite element method where we allow for anisotropic material behavior and use a bilinear stress-strain law to model the observed non-linearity in the $H 440$ graphite stress-strain curve described in section ILI.B. The numerical calculations also allow for the finite ring 
thickness. Finally, in Section III.C, we couple the Weibull statistical model for graphite fracture behavior with the finite element stress analysis method to generate probability of failure curves for the graphite rings subjected to combined mechanical and thermal stress.

\section{A. Thermoelastic Behavior of Thick-Walled Rings}

Figure 4.1 illustrates a thick-walled ring of inner radius a and outer radius $b$ subjected to an inner uniform heat flux $q$ and to diametrically opposed pressure loads $p$, each applied along an arc of the outer surface of length $2 \beta \mathrm{b}$. The material of the ring is presumed to be isotropic in all respects and perfectiy elastic with a coefficient of linear thermal expan$\operatorname{sion} \alpha$.

A solution for the elastic stresses in the ring caused by the normal pressure loading on the outer surface is given as a Fourier series in sine (2ne) and cosine $(2 n \theta), n=1,2 \ldots \infty$, in Reference 10. That series has been numerically evaluated* for the circumferential stress $\sigma_{\theta} / p$ in the ring for the ratios $a / b$ $(0.375$ and 0.352$)$ and half-angles $\beta\left(13.5^{\circ}\right.$ and $\left.6.1^{\circ}\right)$ corresponding to the values of the small and large 1440 graphite rings tested in the experimental program. The variation of $\sigma_{\theta} / p$ through the thickness at $\theta=0^{\circ}$ and $\theta=90^{\circ}$ is shown in Fig. 4.2 for the small graphite ring; in Fig. 4.3 is shown the corresponding variation of ${ }^{\theta} / p$ for the large graphite ring. As can be clearly seen, the maximum tensile stress in the graphite is at the inner surface of the ring and directly on the load axis. These curves for distribution of the circumferential stress were duplicated within $1 \%$ with numerical calculations for the finite element mesh described in section IV.B using the ABAQUS code and its linear, isotropic elastic model.

In the experiments described in Section $V$, a steady heat flux is applied at the inner surface of the ring, which will induce a thermoelastic stress field in the ring. We can estimate the stress field induced in the ring by a given temperature drop across the ring (or flux applied to the inner surface) by evaluating the thermoelastic solution for a thick ring with a heat source

*About 100 terms were used to evaluate the series. 
along its inner circumference, again treating the graphite as isotropic in the plane of the ring and using average graphite mechanical properties. The thermoelastic solution for axisymmetric steady heat flow is given in Iimoshenko ${ }^{9}$ and, in polar coordinates $(r, \theta)$ with principal stresses $\sigma_{r}, \sigma_{\theta}$, and $\sigma_{z}$ is

$$
\begin{aligned}
& \sigma_{r}=\frac{\alpha E \Delta T}{2(1-v) \log b / a}\left[-\log b / r-\frac{a^{2}}{\left(b^{2}-a^{2}\right)}\left(1-\frac{b^{2}}{r^{2}}\right) \log \left(\frac{b}{a}\right)\right] \\
& \sigma_{\theta}=\frac{\alpha E \Delta T}{2(+1-v) \log b / a}\left[1-\log b / r-\frac{a^{2}}{\left(b^{2}-a^{2}\right)}\left(1+\frac{b^{2}}{r^{2}}\right) \log \left(\frac{b}{a}\right)\right](1) \\
& \sigma_{z}=\frac{\alpha E \Delta T}{2(1-v) \log b / a}\left[1-2 \log b / r-\frac{2 a^{2}}{\left(b^{2}-a^{2}\right)} \log \left(\frac{b}{a}\right)\right],
\end{aligned}
$$

where $\Delta T$ is the temperature drop across the ring, and $E, v$, and a are Young's modulus, Poisson's ratio, and the temperature coefficient of linear expansion, respectively. Figure 4.4 shows the vartation of $\sigma_{r}$ and $\sigma_{\theta}$ through the $r$ ing thickness for $a / b=0.375$, corresponding to the small graphite ring, and for $E$ $=1.2 \times 10^{6} \mathrm{psi}, v=0.12$, and $\alpha=4.0 \times 10^{-6} / \mathrm{K}$. The maximum compressive stress is the circumferential stress on the inner surface, while the maximum tensile stress is that stress component on the outer surface.

$$
\begin{aligned}
& \sigma_{\theta}(r=a)=-1.3077 \frac{\alpha E \Delta T}{2(1-v)}, \quad \text { and } \\
& \sigma_{\theta}(r=b)=+0.6922 \frac{\alpha E \Delta T}{2(1-v)} .
\end{aligned}
$$

The effect of the compressive hoop or circumferential stress on the inner surface of the ring induced by the outward steady heat flow will be to initially increase the capability of the ring to sustain diametrically opposed pressure leadings, since it is at the inner surface under the applied loading where the direct tensile stress is a maximum. As the thermally induced stress is increased by increasing the heat flux, at some point the fallure will shift to the outer surface of the ring, at $90^{\circ}$ from the load axis, where both the 


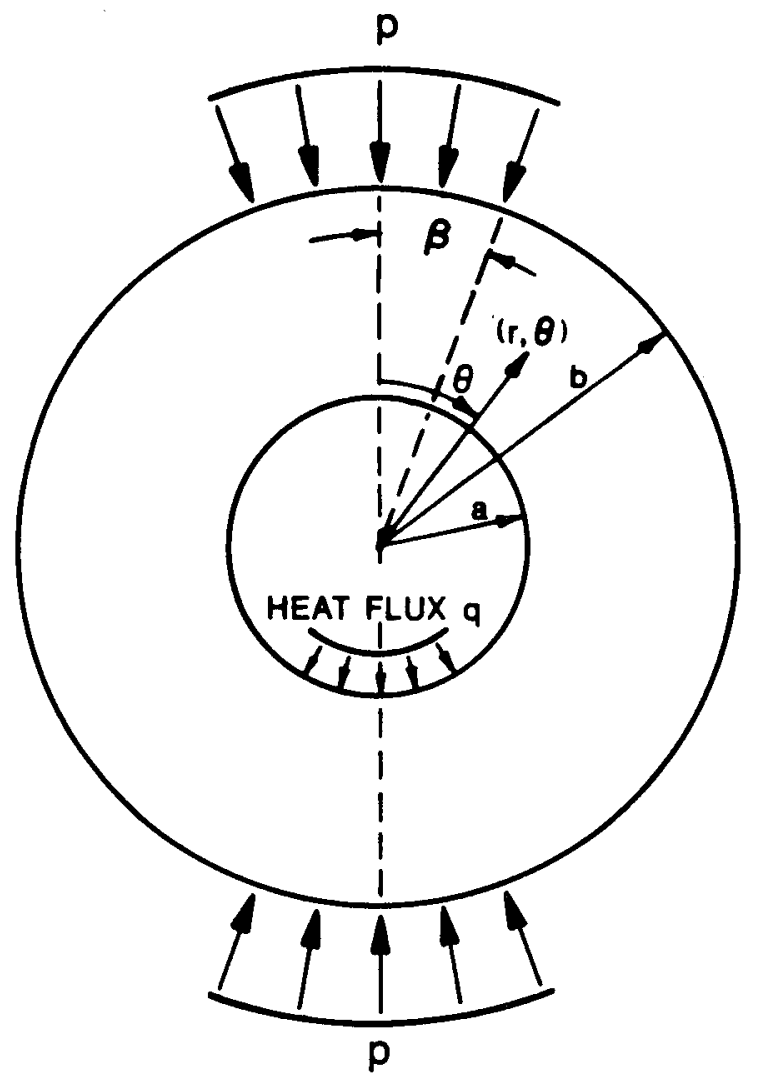

Fig. 4.1. Thick-walled ring subjected to mechanical and thermal loads.

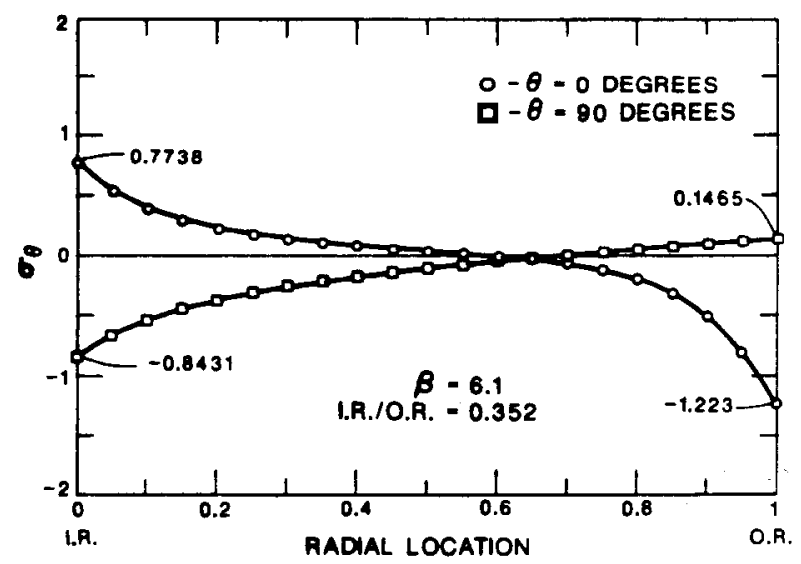

Fig. 4.3. Circumferential stress $\sigma_{\Theta} / p$ in a thick-walled circular disc loaded by diametrically opposed pressure loading, $\beta=6.1^{\circ}, a / b=0.352$.

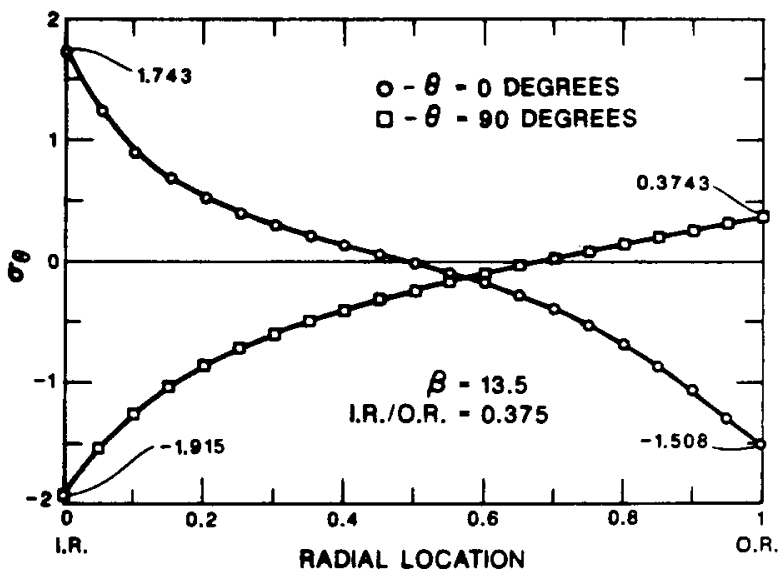

Fig. 4.2. Circumferential stress $\sigma_{\theta} / p$ in a thick-walled circular disc loaded by diametrically opposed pressure loading, $\beta=13.5^{\circ}, a / b=0.375$.

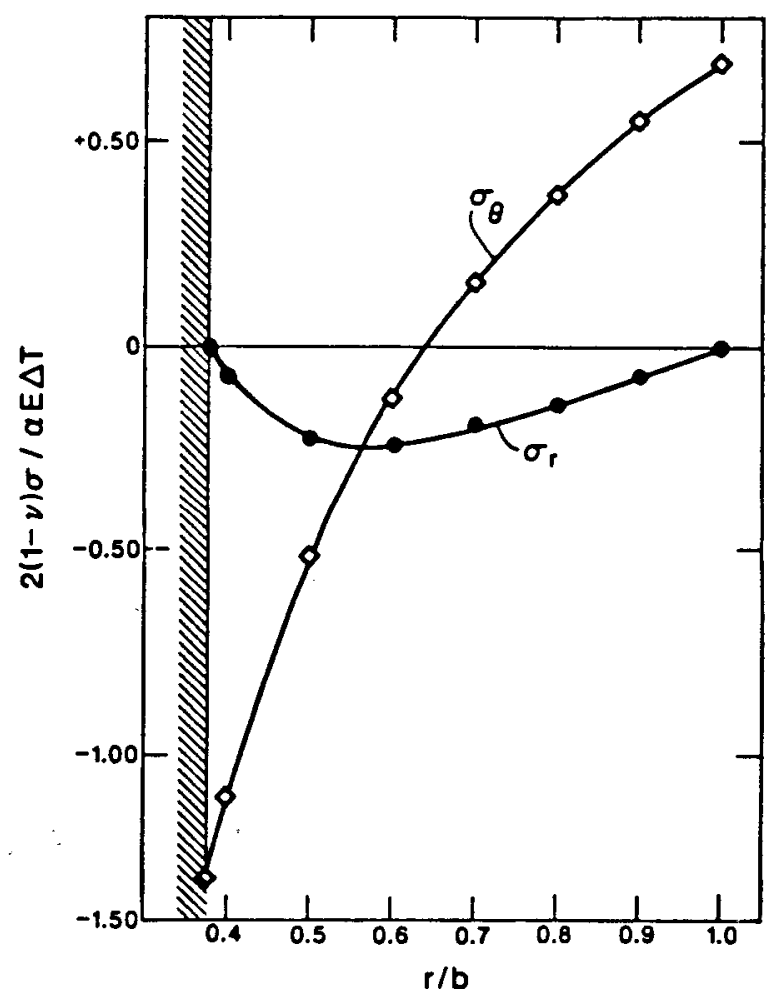

Fig. 4.4. Distribution of circumferential and radial stress in a thick-walled ring subjected to a uniform internal heat flux, $a / b=0.375$. 
primary and secondary stress are tenstle. Using the ring geometry, loading angle, and mechanical properties of graphite mentioned previousiy, and assuming that fallure occurs whenever the sum of the direct and thermal stress achieves a maximum equal to the ultimate tensile strength of the graphite, we can generate a fallure curve for the graphite ring. The fallure curve is illustrated in Fig. 4.5 for an ultimate tensile strength of the graphite of 3600 psi.

\section{B. Finite Element calculations}

The previously described analytical solutions for the stress and strain distribution in a graphite ring under combined direct and thermal stress neglected important aspects of graphite behavior--its inelasticity caused by cracking on the microscale (as exhibited by Fig. 3.3 in Section III) and by its anisotropy. In addition, the analytical solutions assume certain distributions of axial stress on the planar surfaces of the ring to maintain a plane strain condition; i.e., the solutions require a distribution of $\sigma_{z}$ on

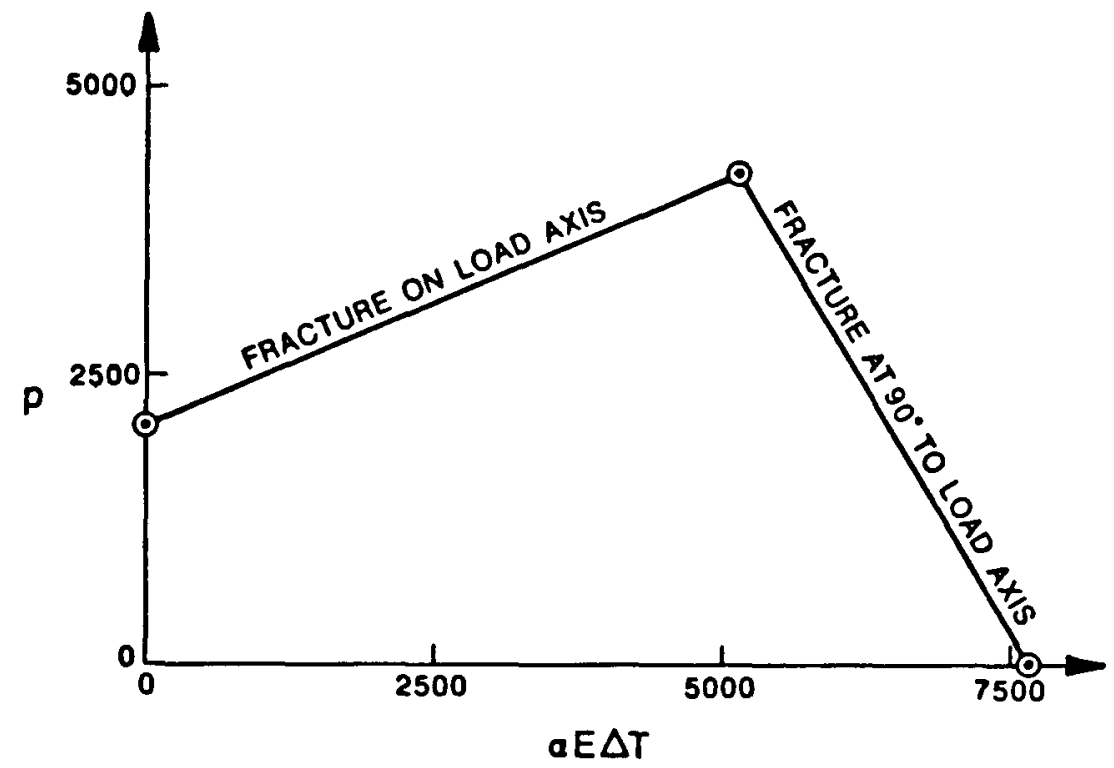

Fig. 4.5. Fracture surface for a thick-walled graphite ring subjected to uniform internal heat flux and diametrically opposed pressure loadings, $a / b=0.315$. 
the face although the net axial force from that distribution is zero. These limitations can be overcome by using modern stress analysis calculational techniques such as the finite element method.

Figure 4.6 illustrates a typical finite element mesh that has been used to model thermal and direct stress effects in finite thickness graphite rings and that takes into account the inelasticity and anisotropy of graphite stressstrain behavior. Four 8-node bricks are used through the thickness, ten along a radius and twenty circumferentially. Because of symmetry, only one quadrant of the ring needs to be modeled; symmetric boundary conditions of no transverse shear stress and no normal displacement are set on the edges $\theta=0^{\circ}$ and $\theta=90^{\circ}$. The calculations are carried out using the ABAQUS code, "which has the capability to handle general anisotropic elastic material behavior.

The graphite rings were cut (see Fig. 3.1) so that the $x_{1}-x_{2}$ planes of Fig. 4.6 are planes of isotropy and the $x_{3}$ direction (the against-grain direction) possesses different properties. The material of the rings is thus transversely isotropic with $x_{1}-x_{2}$ planes being the planes of isotropy. The elastic constitutive law for a transversely isotropic body involves five material

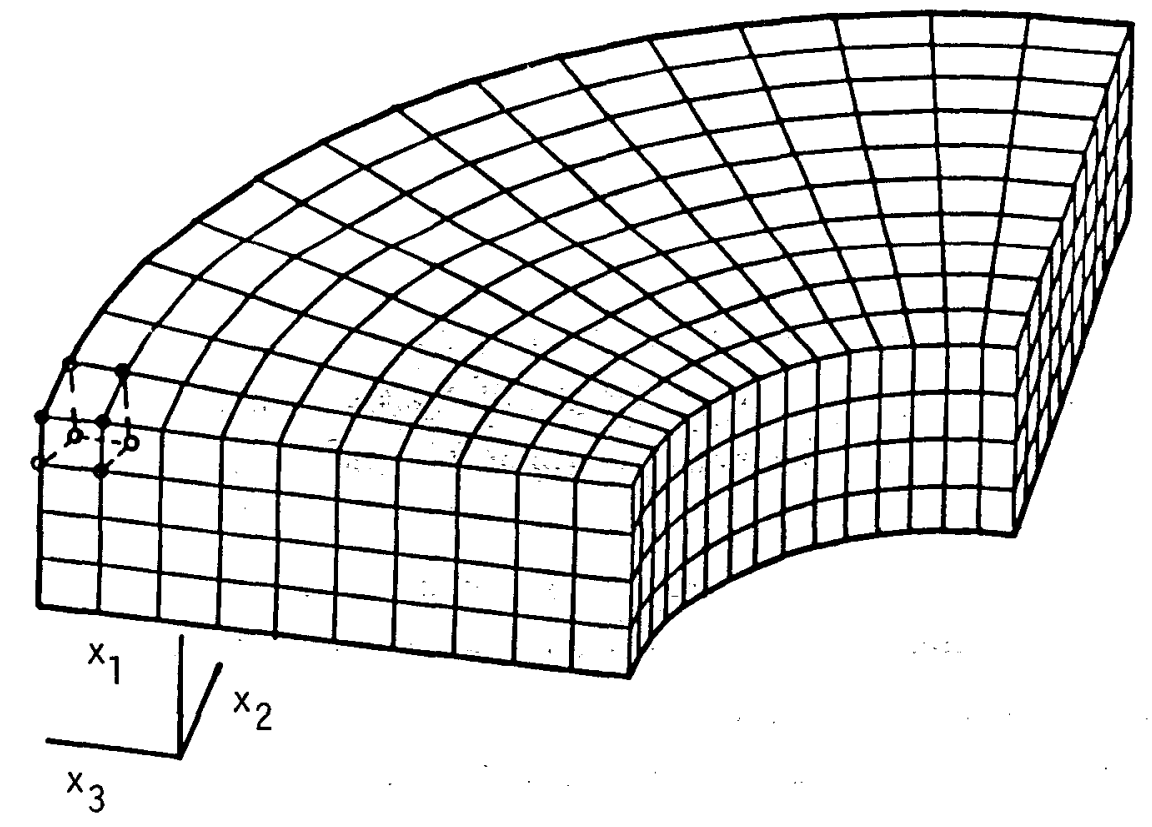

Fig, 4.6. Finite element mesh for thick-walled graphite ring. 
constants that relate the stresses $\left(\sigma_{11}, \sigma_{22}, \sigma_{33}, \sigma_{13}, \sigma_{23}, \sigma_{12}\right)$ and the strains $\left(\varepsilon_{11}, \varepsilon_{22}, \varepsilon_{33}, \varepsilon_{13}, \varepsilon_{23}, \varepsilon_{12}\right)$, and the matrix of elastic coefficients is 13

$$
\left[\begin{array}{llllll}
c_{11} & c_{12} & c_{13} & & & \\
c_{12} & c_{11} & c_{13} & & & \\
c_{13} & c_{13} & c_{33} & & & \\
& & & c_{44} & & \\
& & & & c_{44} & \\
& & & & & 112\left(c_{11}-c_{12}\right)
\end{array}\right]
$$

We used the stress-strain data for tension (Section [11.B) and torsion (Sertion III.O) to determine the elastic constants for $\mathrm{H} 440$ graphite from the secant modulus at 500 psi. These data are

$\begin{array}{ll}\text { W/G Modulus } & 1.27 \times 10^{6} \mathrm{psi} \\ \text { A/G Modulus } & 1.02 \times 10^{6} \mathrm{ps} 1 \\ \text { In-plane Poisson's Ratio } & 0.12 \\ \text { W/G Shear Modulus } & 0.71 \times 10^{6} \mathrm{ps} 1 \\ \text { Out-of-plane Poisson's Ratio } & 0.12 .\end{array}$

After some lengthy algebra, the constants $C_{11}, C_{12}, C_{13}, C_{33}$, and $C_{44}$ in the representation (3) were obtained and used in the ABAQUS code as the orthotropic elastic parameters.

In order to deal with inelasticity in the graphite material behavior, we used a bilinear fit to the average tensile stress-strain curve for both the with-grain and against-grain directions as described in Section IIL.B. The hardening parameters were then used as input to the elastic-plastic model for ABAQUS.

To verify the ability of the numerical model described here to predict the stresses in loaded graphite rings, we calculated perfectly elastic behavior of the small graphite ring treated as an isotropic material. We used the mesh shown in Fig. 4.6. The stresses at selected points in the mesh agreed to within a line-width of the analytical solution as shown in Fig. 4.2. 
These material models and associated finite element meshes were used with the ABAQUS code to analyze the results of the thermomechanical experiments described in sections $V$ and $V I$ of this report.

\section{Modeling the Fracture Behavior of H440 Graphite Rings}

The fracture behavior of the graphite rings is modeled using a modified version of the finite element code ADINA. ${ }^{14}$ since fracture of the graphite rings is a statistical phenomenon and the behavior of the rings is nonlinear at loads approaching ultimate load due to microcracking of graphite, we carried out a calculation of fallure probability at each of successively incremented load steps. The probabtlity of fallure calculation is based on a Weibull statistical model that has been incorporated in the ADINA code, which is described below.

The statistical model initially chosen for coupling with the stress analysis codes is a slight modification of the weibull model described in Refs. 15 and 16. In the isotropic version of this model, the probabllity of fallure, $P_{f}$, of a structure modeled by $n$ elements is given by

$$
P_{f}=1-P_{s}\left(v_{1}\right) \cdot P_{s}\left(v_{2}\right) \ldots P_{s}\left(v_{n}\right)
$$

where $P_{S}\left(V_{i}\right)$ is the probability of survival of the ith element of volume, $v_{f}$, and $i$ spans the range of all elements. The probability of survival of the ith element is computed as

$$
P_{s}\left(v_{i}\right)=\exp \left\{-\left(\frac{1}{m} !\right)^{m} \cdot \frac{1}{U}\left(s_{1}\left(v_{1}\right)+s_{2}\left(v_{1}\right)+s_{3}\left(v_{i}\right)\right)\right\} \text {, }
$$

where $(1 / m !)^{m}$ is the material consistency factor (a function only of the Weibull modulus $m$ ), $U$ is a unit volume conversion factor, and $s_{j}\left(v_{i}\right)$ is the stress volume integral in the $j$ th direction for the ith element. The stress volume integral is given by

$$
S_{j}\left(v_{j}\right)=\int v\left\{\frac{\sigma_{j}-\sigma_{u}^{(j)}}{\sigma_{f v}^{(j)} H\left(\sigma_{j}\right)}\right\}^{m} d v
$$


where $\sigma_{j}$ are the principal stresses, $j=1,3 ; H\left(\sigma_{j}\right)$ is defined as

$$
\begin{aligned}
& H\left(\sigma_{j}\right)=1, \sigma_{j}>0 \\
& H\left(\sigma_{j}\right)=-\lambda, \sigma_{j}>0
\end{aligned}
$$

and where $\lambda$ is the ratio of compressive to tensile strength of the material.

The quantity $o_{f v}(j)$ is the unit volume strength of the material corresponding to the direction of the principal stress. For an anisotropic material with known strengths in the direction of the material axis, the untt volume strengths are assumed to lie upon a triaxial ellipsoid in stress space with values

$$
\bar{\sigma}_{f v}\left(m_{1}\right) \text {, and } \bar{\sigma}_{f v}\left(m_{2}\right) \text {, }\left(m_{3}\right)
$$

in the $m_{1}, m_{2}$, and $m_{3}$ directions defining the semi-major axes. A point $\bar{\sigma}_{f v}$ on the ellipsoid having direction cosines $\ell_{1}, \ell_{2}, \ell_{3}$ will be given by

$$
\bar{\sigma}_{f v}=1 \sqrt{\left(\frac{l_{1}}{\bar{\sigma}_{f v}\left(m_{1}\right)}\right)^{2}+\left(\frac{l_{2}}{\bar{\sigma}_{f v}\left(m_{2}\right)}\right)^{2}+\left(\frac{l_{3}}{\bar{\sigma}_{f v}\left(m_{3}\right)}\right)^{2}} .
$$

The tensile and compressive ultimate strengths obtained on small samples as described in Sections $I I I$.B and III.C were used as a data base from which the Weibull parameters $m$ and $U$ were calculated as well as best-fit cumulative probability distribution functions. Only monotonically loaded specimen strength data were used. The calculations were carried out with the statistical program package called STATS. Figure 4.7111 ustrates the fit to the monotonically loaded $W / G$ and $A / G$ tensile strength data and the Weibull parameters.

A unit volume conversion factor $U$ was then calculated from the laboratory sample tensile data of Section III.B. A finite element calculation of the probability of fallure of the small graphite ring was then carried out using 

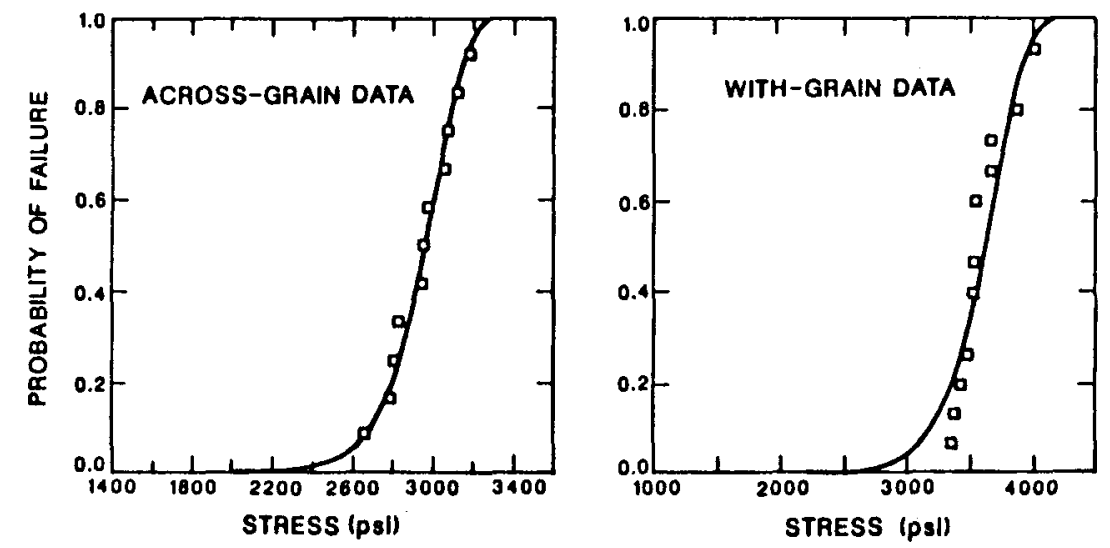

Fig. 4.7. Cumulative probability distribution functions for acrossgrain $(A / G)$ and with-grain $(W / G)$ tensile strength data for H440 graphite. The Weibull parameters are: $\sigma_{u}=3027$, $m=19.3$ for $A / G$ data and $\sigma_{U}=3710, m=14.8$ for $W / G$ data.

the Weibull statistical method described above and an isotropic thermoeleasticplastic model in the ADINA code. The rings were oriented so that the strong axis was normal to load, as in the calculations of the previous sections. Our previous calculations had shown that, although the strain fields in 1440 graphite rings are somewhat affected by anistropic elastic properties, such is not the case for the stress fields. For the room temperature situation, the results are shown in Fig. 4.8 as Curve I. Also shown are experimentally measured loads that caused fracture of the ring specimens. Their mean is at the $35 \%$ fallure probability point, and, although there are only four tests to base our results on, we adjusted the unit volume conversion factor to give a mean failure probability of $50 \%$ at the mean of the four experimentally determined failure loads, 9020 lbs. This is Curve II in Fig. 4.8.

In Fig. 4.9 is illustrated the results of the probability of failure calculation for cross-axis loading when a $225^{\circ} \mathrm{C}$ drop in temperature simultaneously occurs across the graphite ring caused by a steady heat flux at the inner surface of the ring. Here the calculation presumes that thermal and direct stress effects are additive and that there is no stress redistribution caused by more cracking of the graphite. The calculation uses the revised volume conversion factor that produced Curve II in Fig. 4.8. 


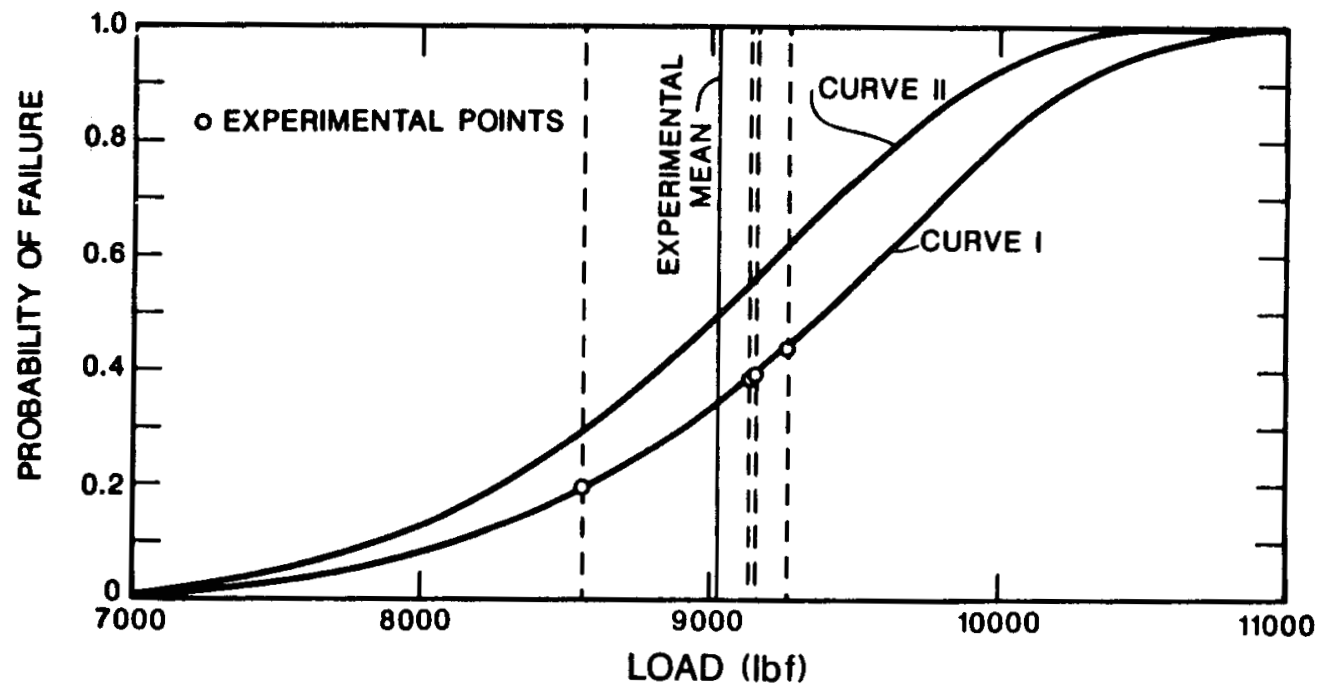

F1g. 4,8. Probability of fallure versus load showing experimental points and corrected fallure curve. Isothermal case for small graphite ring.

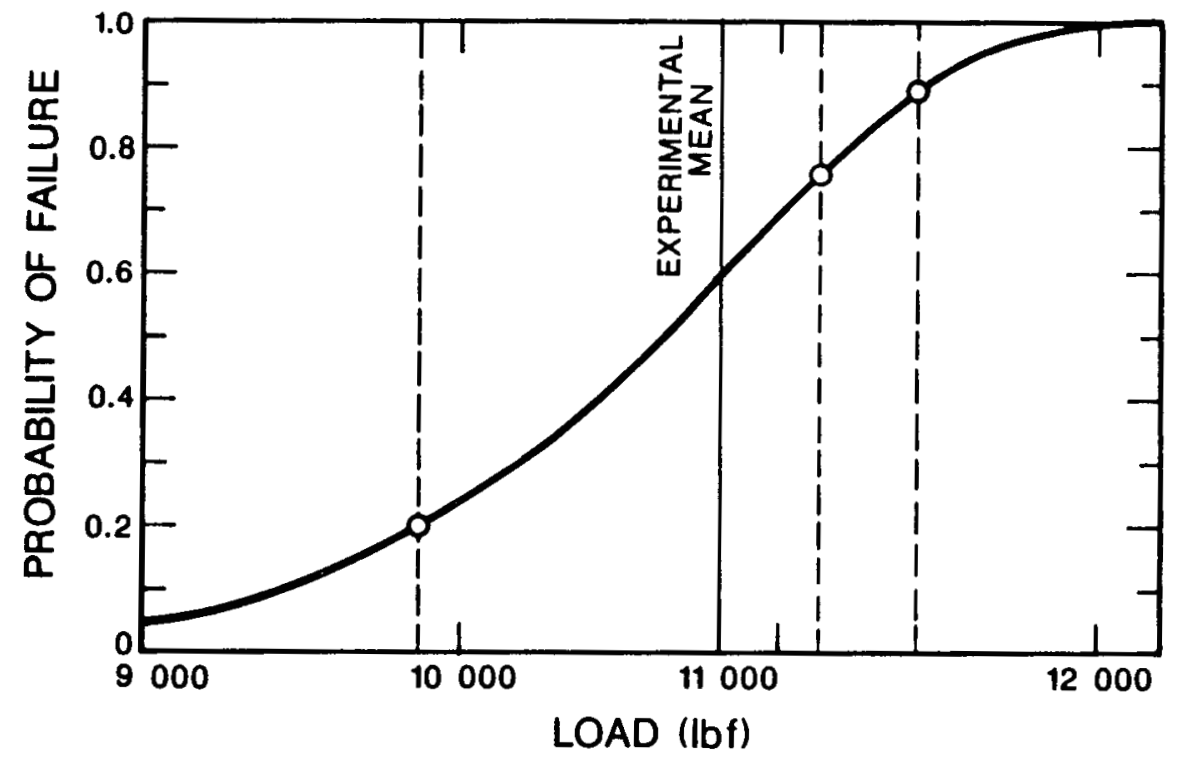

Hig. 4.9. Probability of fallure versus load showing experimental points for $225^{\circ} \mathrm{C}$ temperature drop through the small graphite ring. 


\section{EXPERIMENTAL HAROWARE AND TEST PROCEDURES}

\section{A. Overall Concept}

In an operating reactor system, the thermal loads and mechanical loads acting on graphite structural components are coupled. In order to separate the effects on graphite of the two types of loading and to determine their interaction, it was necessary to design an experiment in which both the thermal load and the mechanical load can be varied independently. This required that the thermal loads be imposed by stationary boundary conditions or be internally generated. In the experiment described here, the thermal loads are internally generated by imposing a radial temperature gradient upon a cylindrical ring specimen. A mechanical load is imposed by a two-point radial loading on the outside diameter of the ring. Aluminum pads are used to load the ring. The nigh thermal conductivity of the aluminum minimizes the distortion of the thermal gradient during loading. A schematic diagram of this system is shown in Fig. 5.1 .

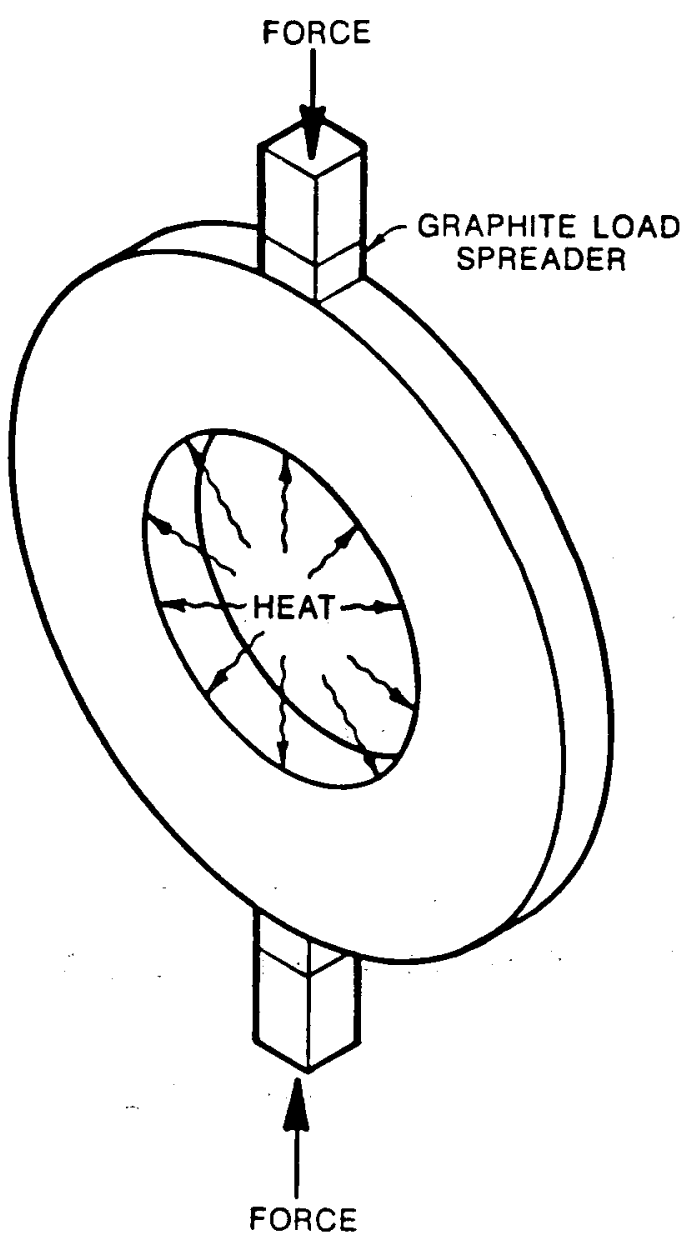

Fig. 5.1. Large graphite thermomechanical ring specimen. 
Two sizes of rings were chosen for these tests in order to apply a more extended range of thermal stress and to be able to discern any scaling effects. The smaller rings are 8.00 in. in diameter with an inner diameter of $3.00 \mathrm{in}$. They are $2.00 \mathrm{in}$. thick. The larger rings have an outer diameter of $17.00 \mathrm{in}$. and an inner diameter of $6.00 \mathrm{in}$. and a thickness of $1.80 \mathrm{in}$. Both small and large rings were fabricated from a single block of fine-grained $H 440$ graphite. orientation of the rings in the block is shown in fig. 3.1 .

\section{B. Heater Design}

Graphite has a high thermal conductivity and a low thermal expansion coefficient that, along with its high temperature strength, make it an ideal material for use as structural components in high temperature gas-cooled reactors. However, this fact works against us in conducting these experiments because, in order to produce significant thermal strains, very high thermal gradients must be imposed upon the test specimen. The thermal strains and stresses developed in the ring are directly proportional to the temperature drop across the ring. For the small ring to produce a temperature drop of $250^{\circ} \mathrm{C}$ requires a heat flow of $12 \mathrm{~kW}$ and a corresponding thermal flux of 100 watts per square centimeter. A heat flow of $16 \mathrm{~kW}$ and a corresponding heat flux of 75 watts per square centimeter are required to develop a temperature drop of $400^{\circ} \mathrm{C}$ in the large rings.

We used Equations (1) and (2) to estimate the stresses induced on a graphite ring by a given temperature difference across the ring provided by a heat flux on the inner surface of the ring. Using an average Young's modulus of $1.2 \times 10^{6} \mathrm{psi}$, an expansion coefficient of $4 \times 10^{-6} / \mathrm{K}$ and a Poisson's ratio of 0.12 , we calculated the maximum and minimum thermoelastic stresses in the small and large rings shown in Table 5.1 .

TABLE 5.1

MAXIMUM AND MINIMUM THERMOELASTIC STRESSES

Smal1 Ring

Temperature drop ${ }^{\circ} \mathrm{C}$ Compressive stress Tenstle stress
250

890 psi

470 psi
Large Ring

1520 psi

780 psi 
These maximum and minimum stresses, though approximate in that they are calculated for an isotropic material with constant properties, were the design stress levels used to investigate the influence of thermal stress on the failure of 1440 graphite.

The high heat fluxes required for these tests impose significant restrictions on the heater design. The heater must not generate any significant mechanical loads on the ring, nor can it alter the breaking strength of the graphite. Two heater designs were considered--the first, a radiation-coupled design and the second, a liquid-metal-coupled design. The radiation-coupled approach was attempted first because it imposed the least load on the specimen. Although this heater did not work, it is important to discuss the design and the reasons for its failure so that the same problems may be avoided in future work.

The radiation-coupled heater design is shown in Fig. 5.2. This design uses $0.051-\mathrm{cm}$ platinum wire as a heater element. The surface of the platinum was roughened to enhance its emissivity. The wire was wound on machined

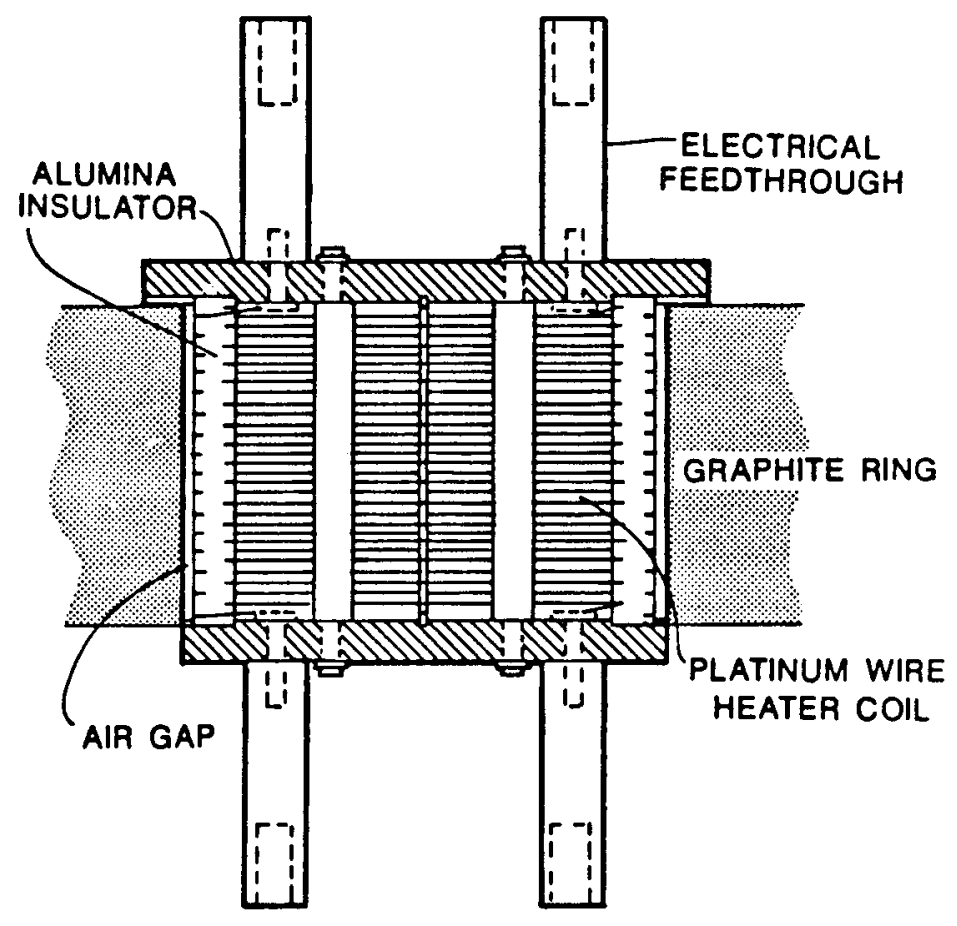

Fig. 5.2. Radtation-coupled heater schematic. 
aluminum oxide slats that were supported in grooves machined into the end plates. Platinum screws served as electrical feedthroughs. The heater wire was laser-welded to these feedthroughs. Nickel clamps were used to connect to the platinum feedthroughs. A small hollow platinum screw was placed in the center of the bottom plate, and a small helium purge flow was introduced into the heater space. This helium flow had a three-fold purpose: first, to improve the conduction heat flow; second, to reduce the convective heat transfer so that the heat flow will be more uniform across the face of the inner surface of the graphite; and third, to minimize oxidation of the graphite surface. The heater was designed to operate at about $1600^{\circ} \mathrm{C}$ at a total heat $f$ lux or power of about $10 \mathrm{~kW}$ and a corresponding temperature drop across the graphite of about 150 degrees. For higher power operation, platinum-rhodium alloy wire was to have been substituted for the platinum wire. The $70 \%$ platinum-30\% rhodium wire could be operated at temperatures of $1800^{\circ} \mathrm{C}$, and thus power levels of $15 \mathrm{~kW}$ could be achieved. This would yield temperature drops of $250^{\circ} \mathrm{C}$ across the small rings.

During the testing of the heaters, the full $10 \mathrm{~kW}$ performance was demonstrated using the pure platinum wire. The heater was installed, and testing was begun on a small ring. After about two hours of testing, the heater wire arced and the fuses blew. The heater was rewound using particular care to see that all of the wires were equally spaced so that arcing would not occur again. But once again after about an hour of testing, the heater arced across two coils and the wire melted. After two more attempts with new methods of winding the coils even more precisely, a storage oscilloscope was placed on the input power line and the voltage and amperage were monitored during the test with a high trigger threshold. During the next failure, a high voltage pulse of nearly 400 volts on a 208 volt line was detected. The pulse lasted for over half a second, and, since the thermal mass of the heater wire was so small, the pulse was sufficient to melt the wire, causing it to sag and short out. Subsequent monitoring showed that these pulses occurred several times a day, and efforts to filter them out were unsuccessful. It became apparent that extremely large isolation transformers would be required to solve this problem and that a large investment in both time and funds would be required. At this point the radiation-coupled heater design was abandoned in favor of a design with a high thermal mass. 
A liquid-coupled heater was designed to replace the radiation-coupled design. The only liquids that would both stand the temperature and provide adequate thermal conductance were liquid metals. Although both mercury and a cadmium bearing alloy called Cerrobend were considered, they were abandoned due to their toxicity. A lead-tin based alloy called cerrotru was chosen as the interface material because of its low melting point, low cost, and lack of toxicity. It was tested in a copper vial with the graphite to a temperature of $450^{\circ} \mathrm{C}$, and no apparent reaction was detected under an optical microscope, although no chemical analysis was done on any of the materials.

The design of the small liquid-metal-coupled heater is shown in Fig. 5.3. This drawing is a section of the heater installed in a graphite ring. A small annulus separates the heater block from the graphite. Proper spacing is provided by spacer wires placed $45^{\circ}$ to each side of the loading axis. Three 0 rings seal the heater block and cap to each other and to the graphite ring,

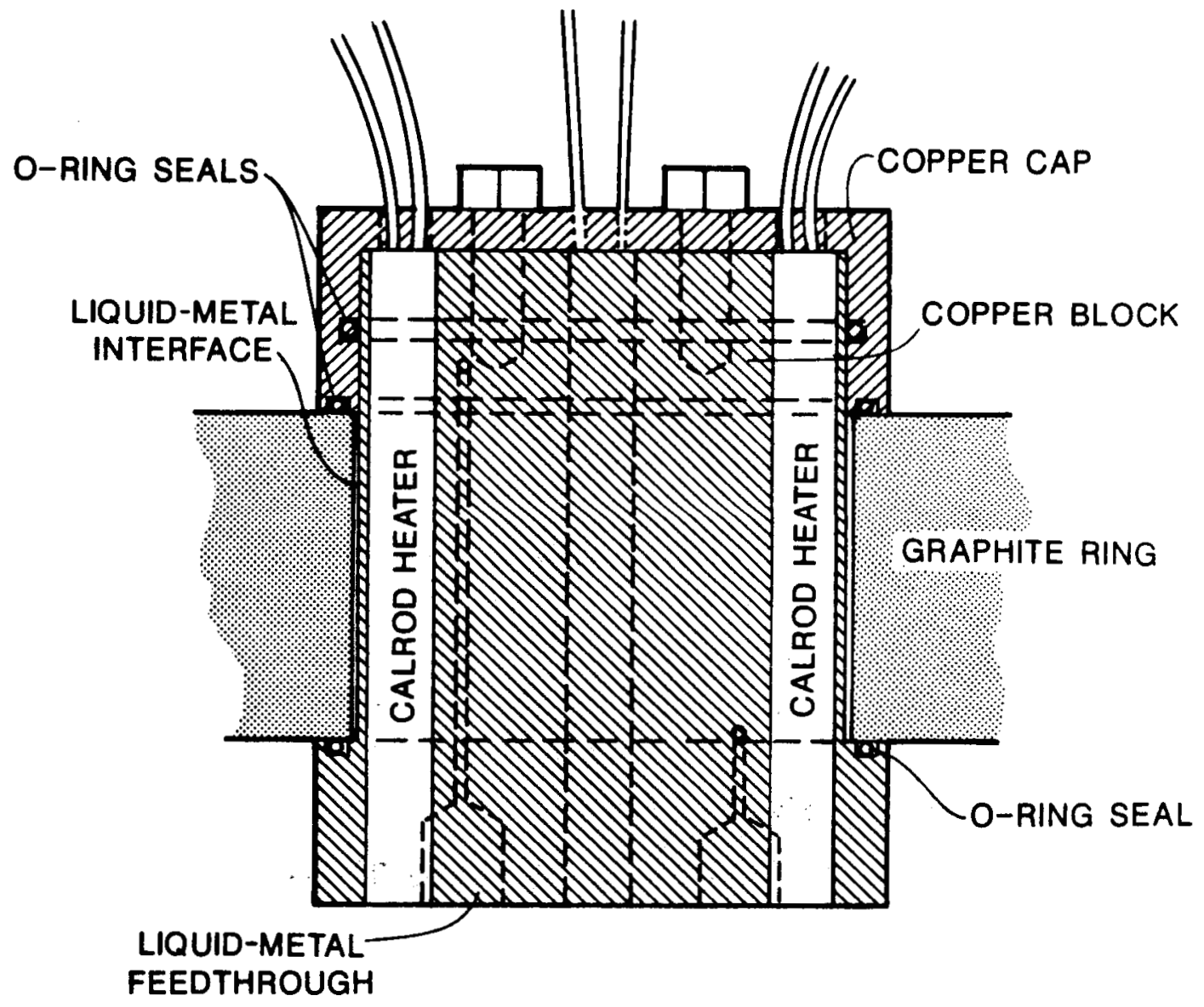

Fig. 5.3. Liquid-metal-coupled heater schematic. 
forming an airtight annulus. The annulus is evacuated using a standard laboratory vacuum pump. There is some small leakage through the graphite, but by pumping through a $6-\mathrm{mm}$ vacuum line, the annulus can still be pumped down to $10^{-3}$ torr. Since the purpose of evacuating the annulus is simply to allow space for the liquid metal, this amount of residual air is not a problem. After evacuating the annulus and fill line, the fill pot is heated to melt the Cerrotru, which then flows into the fill line and chills, forming a liquidmetal seal. After all of the metal in the fill pot is liquid, the heater block is heated to above the melting point of the metal. Helium overpressure is applied to the fill pot and the fill line is heated. When the cerrotru seal in the fill line melts, the liquid metal is forced into the evacuated annulus. The liquid metal also goes into the vacuum line but quickly chills in the unheated vacuum line, forming an airtight seal. Heat is maintained on the fill pot and on the fill line to allow for the volume changes in the annulus caused by differential thermal expansion and due to the compression during mechanical loading.

The heater block consists of a solid copper block in which are drilled twelve $9.4 \mathrm{~mm}$-diameter holes. A WATLOW Firerod cartridge heater is pressed into each of the holes with approximately 0.001 in. press fit. Each cartridge heater is rated at $250 \mathrm{~W}$ at $125 \mathrm{~V}$, but by press fitting them into the heater and overdriving the voltage to $250 \mathrm{~V}$, we have been able to achieve approximately $1000 \mathrm{~W}$ each for a total heater capacity of $12 \mathrm{~kW}$. The maximum temperature capability of the cartridge heaters at this flux level is about $550^{\circ} \mathrm{c}$. Figure 5.4 shows a plot of an estimated temperature proffle through the heater, liquid-metal annulus, graphite, and chill ring.

In this small ring design, both the temperature limitations on the heaters and on the 0-ring seals limit the peak temperature drops through the smaller graphite ring to about $250^{\circ} \mathrm{C}$. Even at these limited temperature drops, the seal rings are operating at about $350^{\circ} \mathrm{C}$, which destroys the seal rings in the duration of the test. The heaters are operating at about $95 \%$ of their ultimate temperature capability, so that higher thermal strain loading on the small rings will require alternate heater schemes.

Two additional heater designs were considered after the problems with the platinum radiation heater were encountered. Rather than increasing the thermal mass of the heater, the ultimate temperature capability of the heater element could be increased. For this purpose, both tungsten and graphite heater 


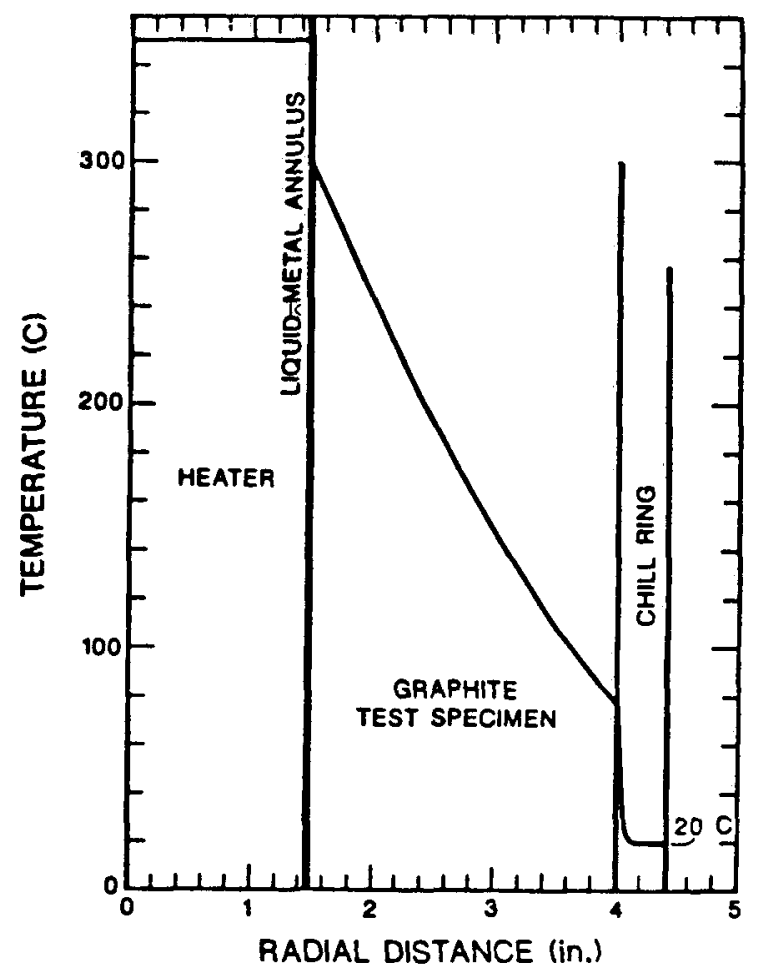

Fig, 5.4. Estimated temperature profile through the thermal load system, the graphite specimen, and the chill ring.

elements were considered. Both suffer from the same major problem: oxidation at high temperatures. In order for this type of a heater to operate successfully, the heater elements must be covered in an inert gas, meaning that the inner diameter of the graphite ring must be sealed against the heater or the heater must be sealed with a transparent shield, such as quartz. The latter technique is probably more acceptable because the problem of sealing against the graphite at high temperatures without imposing significant stresses on the ring is formidable. Though some leakage of a cover gas could be tolerated, this would destroy the heat balance on the inner and outer diameters of the ring and, depending on the flow path taken by the escaping gas, could significantly alter the temperature profile in the ring and thus alter the strain field and the fracture load.

A sealed heater, such as described above, could be used to develop high temperature drops across the rings, but significant problems remain to be solved. These include lead wire attachments, power supply requirements, feedthrough seals, and element fabrication. In addition, the heaters would be 
both expensive and fraglle and could not be rebuilt. To develop the capability of going to higher thermal strains will require a large investment in both time and money.

For the large rings, the heat flux required to generate a given temperature drop (and a given stress) is approximately half of that required for the small rings, and a heater design capable of operating at higher temperatures but lower heat fluxes would thus extend the useful thermal stress range. The major modification to the design of the small liquid-coupled heater shown in Fig. 5.3 was the seal to the graphite. Above a $320^{\circ} \mathrm{C}$ inner surface temperature on the graphite, elastomer seals are simply not feasible, so a new method of sealing was required, and a design was developed which uses the graphite itself as the sealing medium. The seal design is shown in Fig. 5.5. The concept of the heater still uses cartridge heaters in a heater block with liquidmetal coupling to the graphite. The seal is made by spring loading a seal plate directly against the graphite. The spring tension is adjusted to give about 200 psi seal pressure. Since the helium overpressure on the liquid

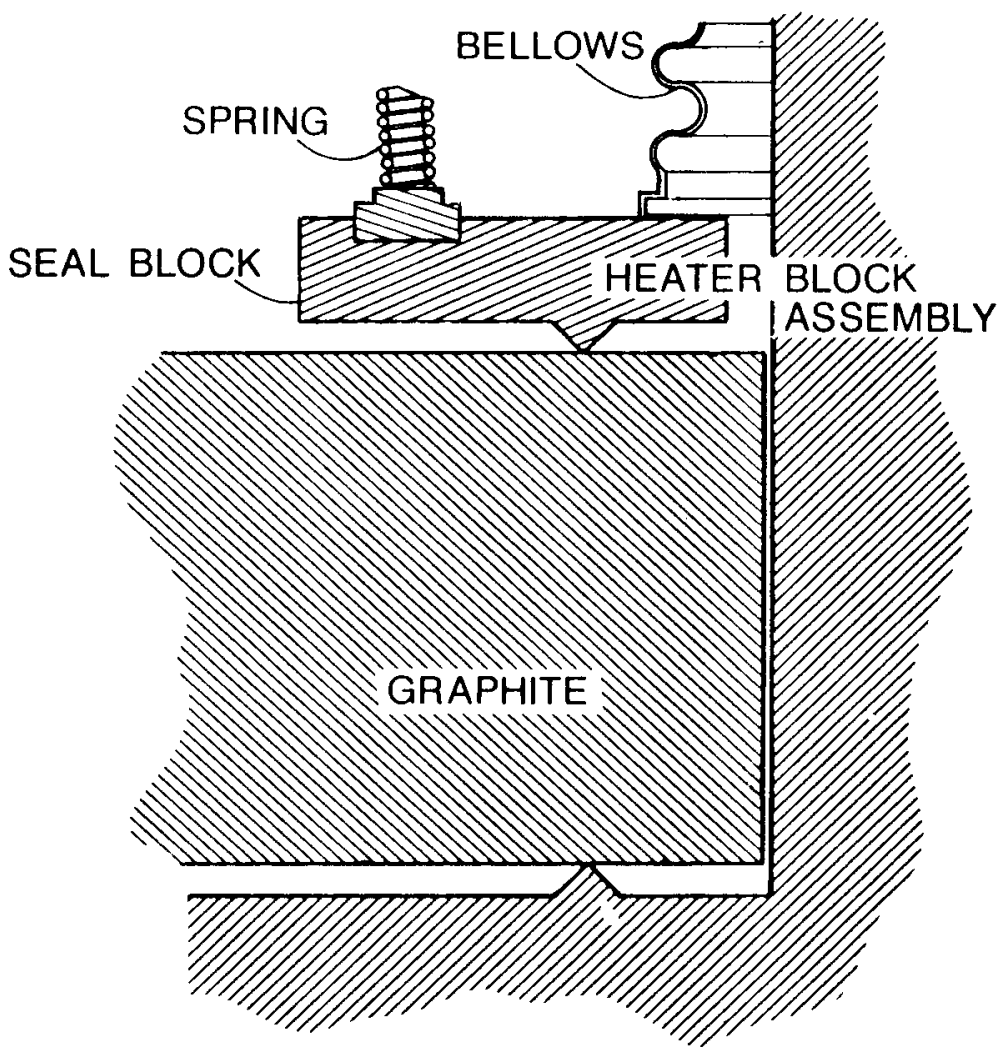

Fig. 5.5. Sealing mechanism for large graphite rings. 
metal is only about 5 psi, a stainless-steel bellows is brought between the heater cap and the seal plate that provides adequate sealing pressure and provides sufficient motion in the assembly. Rather than sealing at the very edge of the graphite, the seal is moved back about 0.5 in. from the inner edge of the ring to minimize the effect of the seal pressure on the stress field at the inner surface. Some other changes were also made in the large heater. Rather than making the heater block out of copper, it was made from yellow brass and then coated with $0.1 \mathrm{~mm}$ of electroless nickel. While the oxidation rates were acceptable with the small heater, the increased temperature of this heater would have caused increased oxidation and additional problems. The nickel plating has adequate oxidation resistance for the required service temperature. Also, the cartridge heaters were changed. In the large heater, fifteen 5/8-in.-diameter cartridge heaters were used. Each one has a power output of 1370 watts, giving a total heater output of 20,550 watts. Operation at $80 \%$ of maximum yields the required $16 \mathrm{~kW}$ for a temperature drop through the ring of $400^{\circ} \mathrm{C}$.

Power for all of the heaters is supplied through three $250 \mathrm{~V}, 30 \mathrm{Amp}$, single-phase Variacs yielding a total input power of 22 kilowatts. Each Variac is wired to a symmetric set of four cartridge heaters in the small heater and to a symmetric set of five cartridge heaters in the large heater. The three Variacs are on a common shaft, which is motor driven. Power is supplied to the variac through a remote contractor unit that acts as a shutdown switch. 0utput current and voltage are monitored at each variac.

The graphite ring and the heater block were both insulated with 2 in. of zircon aluminum oxide fiber insulation. The heat loss through the insulation was calculated to be less than 500 watts for the large rings and 300 watts for the small rings. The input power was calculated from the voltage and current going to the heaters, and the output heat was calculated from measurements of the water flow and the temperature rise in the chill ring. These members were always within $5 \%$ of each other, which indicates the efficiency of the insulation on top and bottom surfaces.

In order to remove 12 to 16 kilowatts of thermal energy from the graphite rings, the outer surface must be chilled. Figure 5.6 shows the chill ring design for the small rings. The chill ring is simply a water channel around the outside of the graphite ring. The chill ring seals against the graphite with standard neoprene 0 rings. Load pads penetrate the chill ring on opposite 


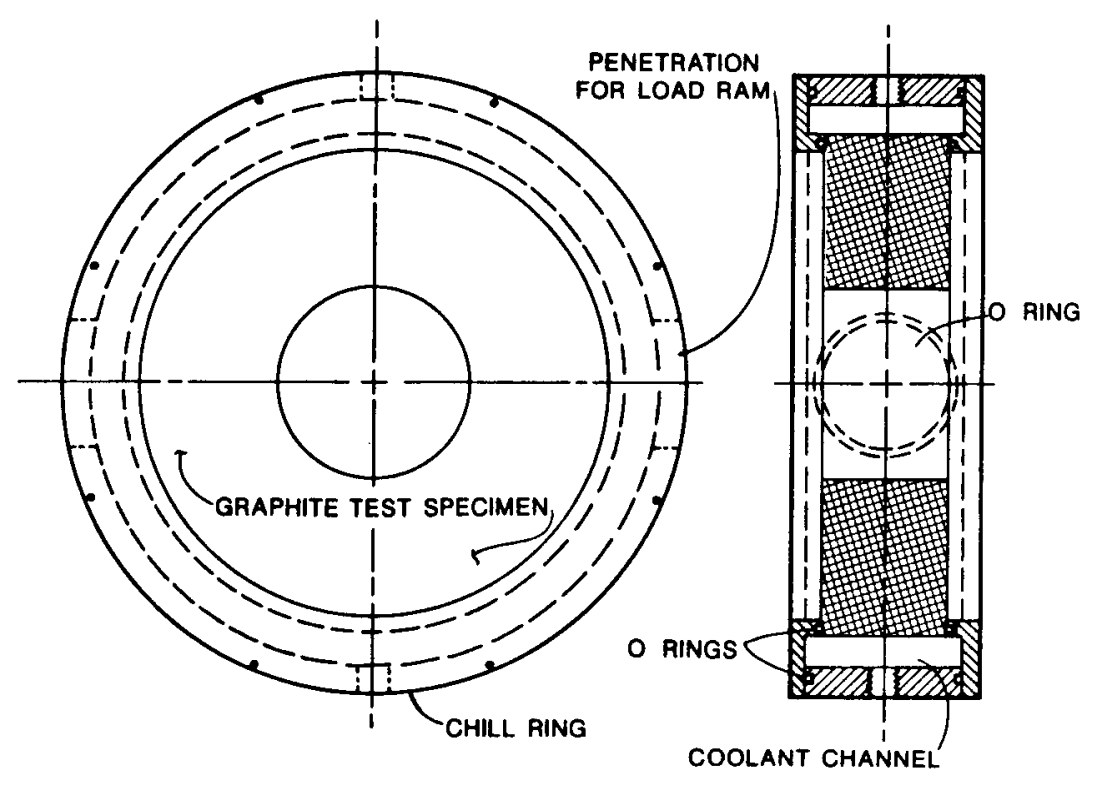

Fig. 5.6. Chill-ring schematic.

sides and are also sealed with 0 rings. Two water inlets are located on opposite sides along the unloaded axis, while four discharge ports are located at the load pad penetrations. In order to maintain a uniform outside temperature on the rings, the temperature increase in the water must be small and the flow field must be uniform. To keep from applying nonuniform loading to the ring, the pressure drop must be kept small. The design shown in Fig. 5.6 keeps the pressure drop in the ring to less than 3 psi with a flow rate of $0.120 \mathrm{~kg} / \mathrm{s}$. At this flow rate, the temperature rise is approximately $2^{\circ} \mathrm{C} / \mathrm{kW}$, giving a maximum temperature rise of $32^{\circ} \mathrm{C}$ in the water. At the highest heat fluxes employed in these experiments, the temperature drop at the graphite-water interface is about $100^{\circ} \mathrm{C}$ or three times the maximum rise in the water. At this heat flux, the drop across the graphite is approximately $400^{\circ} \mathrm{C}$ or 13 times the maximum rise. Less than a $7 \%$ change in radial heat is required to compensate for the temperature rise in the worst case.

A uniform flow field is ensured by using small distribution manifolds to redirect the flow at the water inlets. The discharge ports are located both above and below each load pad. The water must separate to flow around the pad, and the back pressure on the two discharge ports can be varied with valves to give a uniform separation and thus a uniform axial temperature profile. A photograph of the chill ring and plumbing is shown in Fig. 5.7. 


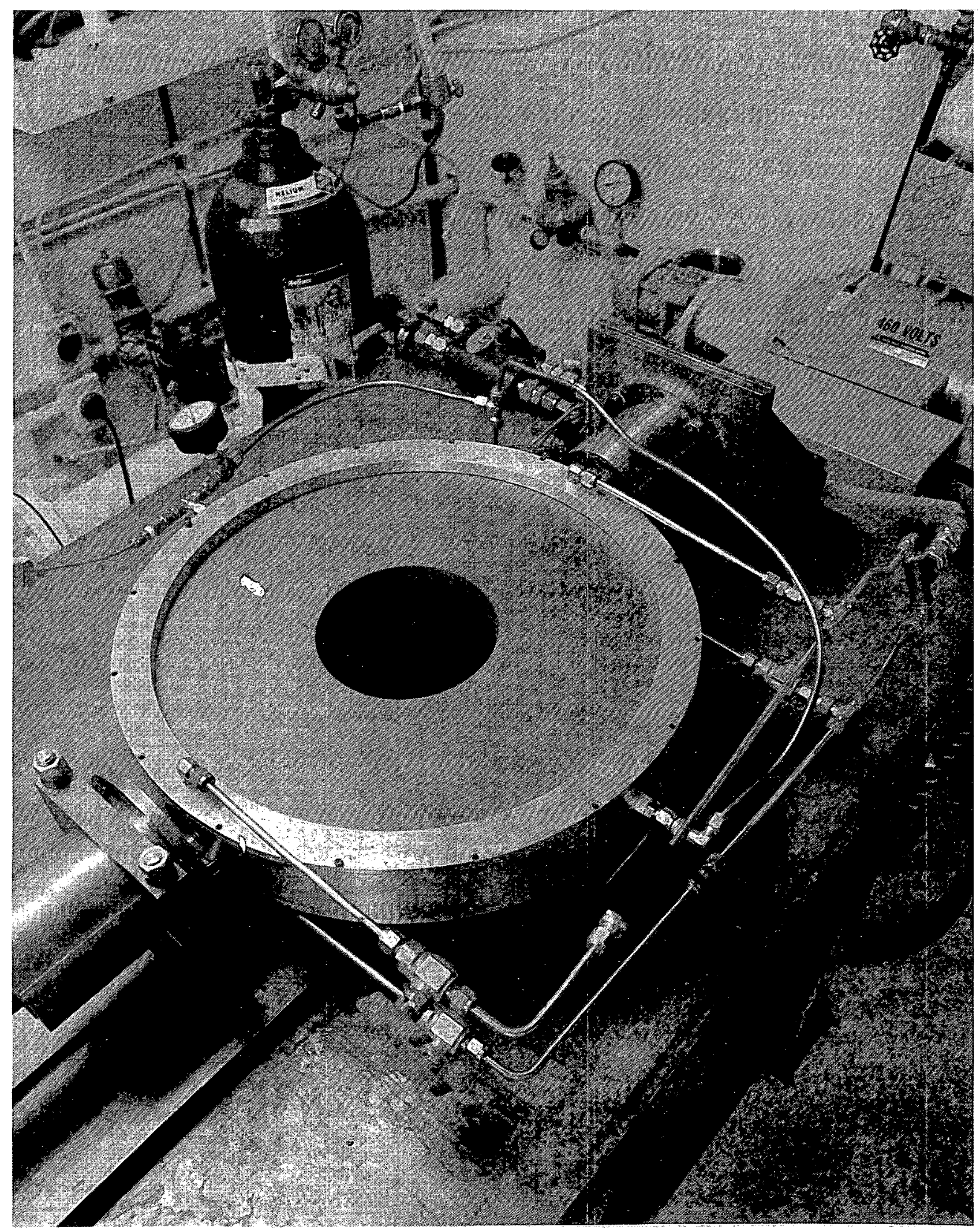

Fig. 5.7. Photograph of the chill ring. 


\section{Mechanical Loading Design}

The rings are radially loaded through two aluminum load pads that penetrate the chill ring. One load pad is held fixed on a backing plate while the other is mounted on a hydraulic ram. Both the hydraulic cylinder and the backing plate are mounted on a heavy steel table, and a top plate attaches to the cylinder and to the top of the backing plate to minimize distortion during the loading process. A separate hydraulic power supply provides hydraulic pressure to the cylinder, and a remote control system controls the load via feedback from a ram mounted load cell. The load frame and hydraulics are shown in Fig. 5.8 .

The load frame consists of a steel table and a carrier frame for the hydraulic cylinder and the backing plate. The table has a 2 -in.-thick steel top that has been milled flat to within 0.001 in. A $0.75-i n$.-thick by 8-in.wide carrier plate is bolted directly to the table. A center keyway was milled down the length of the carrier plate for centering the cylinder support plate and the backing plate. One transverse keyway was cut in the carrier plate at its head and one in the base of the cylinder support plate for longitudinal location of the cylinder support plate. The backing plate also has one longitudinal and one transverse keyway in its base for centering and longitudinal location. Both the cylinder support plate and the backing plate also have a transverse keyway at the top to locate the top plate. The carrier plate and top plate have a single transverse keyway at the cylinder end and have a series of equally spaced keyways at the backing plate end. The backing plate can be adjusted in 2.00-in. increments to allow testing of different size specimens. The keyways in both the carrier plate and top plate are located within $0.0005 \mathrm{in}$. to assure that the squareness tolerance is maintained at all positions. To precisely position the end of the ram, an adjustable carrier bearing is located near the center of the load frame. The carrier bearing holder can be shimmed to locate the ram end and minimize dislocation during loading.

The carrier plate is heavier than the top plate and tied down more securely so that some distortion is present during loading. This distortion was measured at a load of 20,000 lbs. The difference in top and bottom position was less than $\mathbf{0 . 0 0 0 8}$ in. and thus, for the distance across the specimen, would be less than $0.0002 \mathrm{in}$. While this distortion effect is detectable in the strain measurements on the outside diameter of the ring, it is not detectable on the inner diameter. 


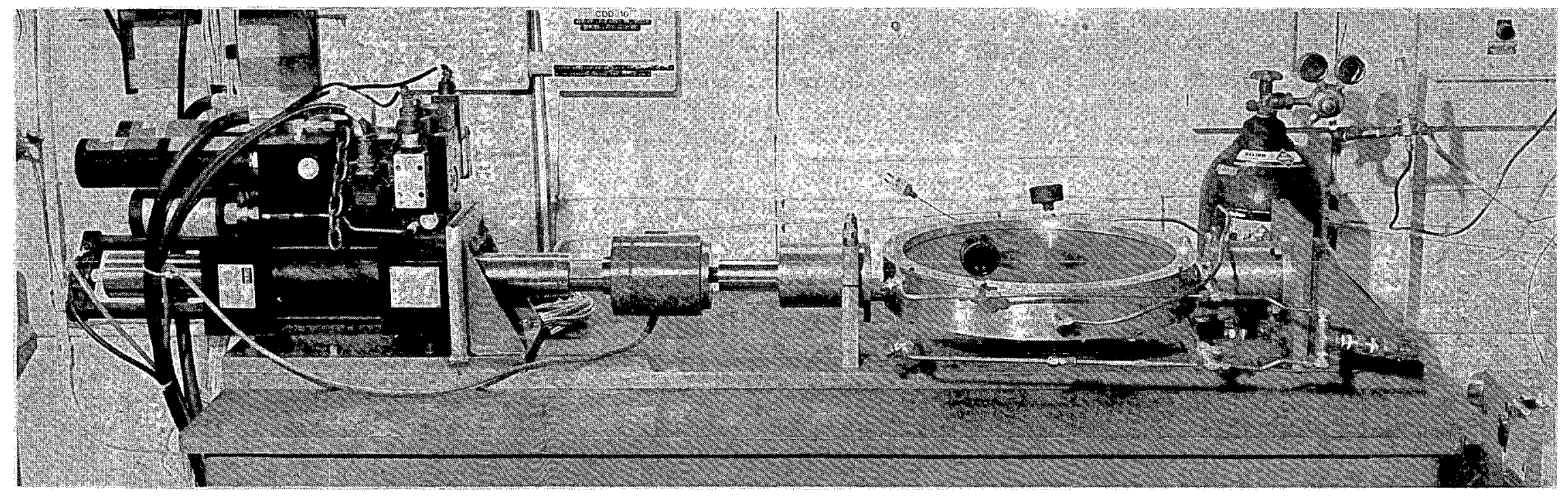


The hydraulic cylinder and hydraulic power supply are both supplied by MTS corporation. The cylinder has a stroke of six inches and a load capacity of 22,000 pounds and is servovalve controlled with full-load capacity in both directions. An MTS load cell is attached to the end of the ram for both load measurement and load control feedback. The ram has an integral linear LVDT for position measurement and for feedback for the stroke and strain control modes.

Control is provided by an MTS controller. The controller utilizes the feedback signals of the load cell and the LVDT and generates the servovalve control signals. Three types of control are avallable: displacement, strain, and load. For these tests only load control is used. The input load signal is generated externaliy using a power supply and precision potentiometer. To soften the input signal, an overdamped low-pass filter is added to the output of the potentiometer, giving the output a time constant of about 5 seconds. This prevents any jerkiness on the pull of the operator from causing a premature failure and prevents transients in the input power from being transmitted into the control signal.

Load control per se can present problems because there are no limitations on stroke after a decrease in load carrying capacity of the structure being tested. This control system, however, has error limit controls so that sudden changes in load generate an error signal which shuts down the entire system. Additional shutdown switches are provided for shutting down auxiliary equipment. Both the water flow and the heater power are controlled by these shutdown switches so that after fracture of the ring, all power to the test is shut down. These error limits are set very tight to prevent damage to the heater subsequent to fracturing the graphite ring.

\section{Instrumentation}

The primary pleces of data obtained from each test are load, strain, and temperature. The load measurement is taken directly from the calibrated load cell on the end of the ram, while the strain and temperature fields are determined from strain gages and thermocouples bonded directly to each side of the graphite ring. Rather than trying to store continuous strain and temperature data as the load is increased, a series of load steps is taken. This keeps the volume of data down to a reasonable level. The ring is allowed to stabilize at a new load increment for 5 to 10 minutes prior to storing the data. Certain key strain gages and thermocouples are monitored continuously, however, 
and new data are acquired but not stored every ten seconds, so that when the fracture occurs, the most recent data are available for storage.

Both the strain and temperature fields have large gradients, and thus positioning of the thermocouples and strain gages on the test specimen is very important. Interpretation of the strain gage information is dependent upon the measured temperature field, so the positioning of the thermocouples and strain gages is doubly important.

All of the thermocouples are type $K$ with fiber glass insulation. The thermocouples are bonded directly to the graphite rings using $3 M$ brand fiber glass tape. Silicone rubber pads are placed over the tape, and aluminum plates are clamped over the pads. A pressure of approximately $0.68 \mathrm{Mpa}$ (100 psi) is applied through the clamps. The assembly is fired at $150^{\circ} \mathrm{C}$ for two hours with care taken to let the temperature rise and fall slowly. The adhesive on the tape hardens, forming a secure bond to the graphite. A second piece of fiber glass tape is bonded in the same manner to the leads of each thermocuple to provide strain relief. This method of bonding has proved very successful throughout the testing program for temperatures up to $400^{\circ} \mathrm{C}$.

Thermocouple layouts for the small and large graphite rings are shown in Figs. 5.9 and 5.10. Five thermocouples, on a radius of $45^{\circ}$ to the load axis, were used to measure the temperature profile in the ring for all tests. In addition, certain tests were more heavily instrumented with thermocouples (i.e., along other radii and on top and bottom surfaces of the ring) in order to verify that the temperature profile was axially symmetric. For plotting purposes, the temperature profile along the radius was determined by calculating a least-squares fit to the logarithmic profile using the five temperature measurements along that radius.

The strain gages for these tests must be capable of withstanding high temperatures and must be very small because of the high strain gradients. Micro-Measurements type WK03 $350 \mathrm{r}$ gages with a gage length of $1.6 \mathrm{~mm}$ were used for all the high temperature applications. Bonding of the gages is a complicated process due to the temperature requirements and the differences between the gage backing material and the backing material used in the soldering tabs. The soldering tabs can only be subjected to about $200^{\circ} \mathrm{C}$, while the strain gages must be postcured at a temperature at least $50^{\circ} \mathrm{C}$ above the testing temperature. For the higher temperature test, this meant 


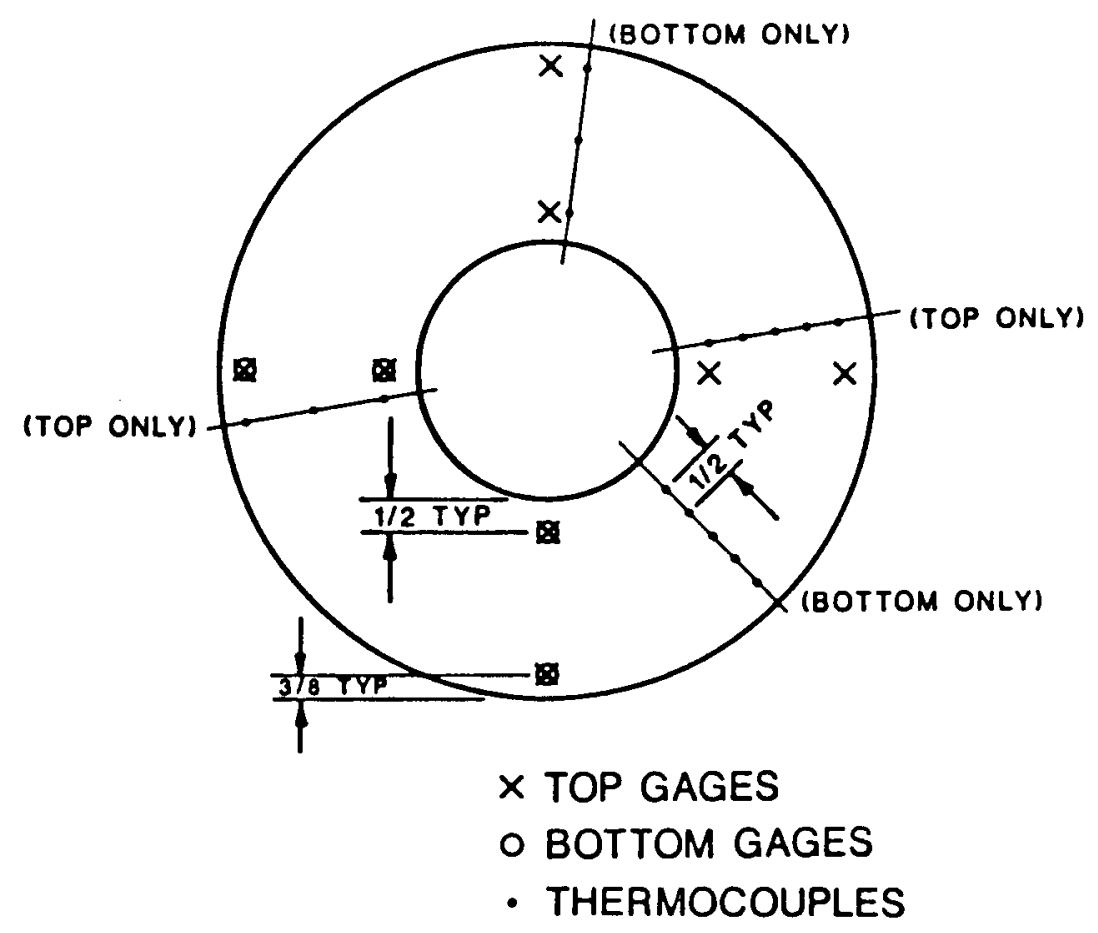

(ALL DIMENSIONS IN INCHES)

F1g. 5.9. Thermocouple and strain gage layout on the small graphite ring.

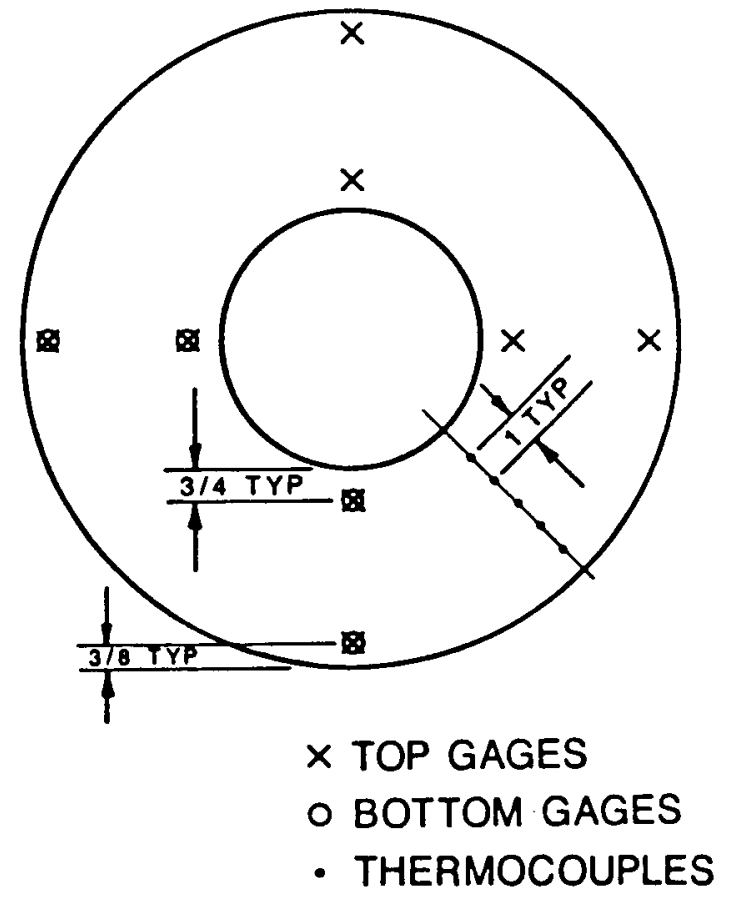

(ALL DIMENSIONS IN INCHES)

Fig. 5,10. Thermocouple and strain gage layout on the large graphite ring. 
postcuring temperatures of up to $375^{\circ} \mathrm{C}$, which is close to the maximum temperature capability of the adhesion.

Much time and effort were invested in developing an acceptable procedure for applying the strain gages to graphite. First, the graphite is cleaned with acetone and ethanol for degreasing and removal of loose graphite. The gages are then mounted using Micro-Measurements M610 epoxy. The gages are covered with silicone rubber, and aluminum plates are clamped to each side of the ring to apply pressure to the gages. The gages are cured at a temperature of $175^{\circ} \mathrm{C}$ for two hours. After a slow cooldown, the clamps and silicone rubber pads are removed and the gages are postcured at a temperature of $50^{\circ} \mathrm{C}$ above the test temperature $\left(250^{\circ} \mathrm{C}\right.$ for the low temperature test, $375^{\circ} \mathrm{C}$ for the high temperature test). Since only one side can be bonded at a time, the process is repeated for the second side. After the gages are postcured, the soldering tabs can be mounted. The soldering tabs are teflon-backed copper pads. If the tabs are heated above $200^{\circ} \mathrm{C}$, the copper pads come off during soldering. The tabs are mounted using the M610 epoxy. They are clamped and cured in the same manner as the strain gages, though no postcuring cycle is required. After curing, the strain gage leads and the bridge wires can be soldered onto the tabs. Because of the high-temperature requirements, high melting point solders must be used, and since the graphite conducts heat away quickly, high wattages must be supplied to the soldering iron. However, if the tip of the iron is to be hot initially, the tab will peel off. The most acceptable solution here was a high wattage soldering iron with a temperature controlled tip. After soldering, the bridge connection wires are taped down with fiberglass tape and bonded in the same manner as the thermocouple leads. This provides strain relief for the leads and prevents the soldering tabs from being pulled off during handling. After the strain gages and soldering tabs are in place and the leads mounted, the thermocouples can be mounted as described above.

Figures 5.9 and 5.10 show a typical strain gage location diagram for a fully instrumented test of the small and large graphite rings. The gages are located as close to the inner and outer diameters as possible and directly on the load axis and the axis perpendicular to the load axis because these are the highest accessible strain points. Some consideration was given to the posstblitty of placing strain gages on the inner and outer surfaces of the ring, but the penalty associated with distortion of the temperature gradient and influencing the graphite fracture behavior weighed against doing this. For the 
unheated tests of the large graphite rings, the strain gages were placed $1 / 8 \mathrm{in}$. from the inner surface of the ring.

There were two levels of instrumentation employed in the test program--the full instrumentation of thermocouples and strain gages as shown in Figs. 5.9 and 5.10 and a partial instrumentation of a ring that includes a reduced number of strain gages located only at the outside of the ring and that could be mounted with low temperature adhesive, which considerably reduced the time required to instrument the ring. The fully instrumented rings were used to develop baseline strain data, while the partially instrumented rings were used on repeat tests.

Data acquisition is performed with a Hewlett Packard 3097A data acquisition unit. Thermocouple inputs are handled on special type $K$ thermocouple input cards that automatically generate a zeroing signal. Strain gage inputs are gathered on standard analog to digital (A-D) cards. Each strain gage has its own three-lead-wire external bridge to minimize false signal due to lead wire resistance. Power is supplied through a B\&H power and balance unit. A control program was written which allows for software zeroing and calibration of the strain gages. Additional inputs are also gathered on the standard $A-D$ cards.

A special data acquisition program was written for these tests to obtain some special features not available in Hewlett Packard standard sof tware. The program allows up to 50 data inputs that can be split between thermocouples, strain gages, and special inputs. Special functions are provided for displaying segments of the data, plotting the temperature profiles, and storing the data at required intervals. The program cycles through all of the inputs every 30 seconds. Storage and plotting functions are interrupt driven so they do not disturb the normal collection of data. The two most recent sets of data are kept in the memory at all times. When a store function is requested, the most recent data is stored, but when a shutdown occurs due to fracture of the graphite, both the last and the next-to-the-last data sets are stored. This assures getting the most recent complete set of data.

\section{E. Test Procedure}

A series of tests was laid out to first establish a baseline room temperature load versus strain curve and then to determine the effect of thermal 
strains on the load-strain curve and on the fracture load. The basic procedure for testing the nonisothermal specimens was to first heat the specimen internally until the proper temperature difference across the specimen was attained; then the specimen was mechanically loaded in a series of small load steps until fracture occurred. At each load step, the load was allowed to come to equilibrium, and a set of strain, load, and temperature data was taken and stored in the data acquisition system.

To obtain a minimum of statistical information, at least two tests were run in the isothermal case and at each of the prescribed radial temperature drops. This allowed calculation of an approximate mean and standard deviation, although a significantly larger number of tests would be required to obtain an accurate mean and standard deviation. Since instrumentation of the test specimens and execution of the tests were very time consuming, it was not possible in the scope of this work to run the ten or so tests that would be required to determine these more accurate values.

As mentioned previously, the test specimens are thick-walled cylindrical rings. There are two sizes of rings, a smaller 8-in.-diameter ring and a larger 17-in.-diameter ring. This size variation was used to see if there is any influence of scale on the test results. The other distinguishing feature of the two different size graphite specimens is the orientation of the material axes (i.e., the grain) with respect to the plane of the test rings. The large rings have the grain of the material oriented with the longitudinal axis of the cylinder so that the material is isotropic in the plane of the ring and the location of the loading axis is not critical. For the small rings, however, the grain of the material is located along a diameter of the ring so that the rings can be loaded either along the with-grain direction or along the across-grain direction.

\section{F. Free Thermal Expansion of $\mathrm{H} 440$ Graphite and the Correction Curve}

As described above, during a test sequence the strain gage readings and corresponding temperatures were recorded at the desired loads. These strain gage readings were then reduced to stress-induced-strain by correcting the reading with the apparent strain for the gage type used when mounted on an unrestrained graphite sample at the same orientation (i.e., with or across grain) and temperature. 
The compensation curve (apparent strain vs temperature) was determined with a free expansion test having the gages bonded to a graphite coupon with the same technique used in mounting the gages to the graphite rings to be loaded. Two gages along each of the three orthogonal material axes of each coupon were used. The free expansion test was conducted by slowly heating this coupon to a selected temperature, allowing a state of uniform temperature to be reached (indicated by all readings becoming stable), recording the strain gage readings and temperature, and then repeating the process for a series of temperatures up to $225^{\circ} \mathrm{C}$. The raw data and the resulting correction curves for the two material axes of the 4440 graphite are shown in Figs. 5.11 and 5.12.

The coefficient of thermal expansion for the $H 440$ graphite used in the test program was found by subtracting from the above correction curve the strain from the gage itself caused by its elevated temperature. That strain versus temperature curve was taken from the manufacturer's data sheets. The results are shown in Fig. 5.13. The slope of the best linear fit to the data points gives the thermal expansion coefficient for the temperature range of interest. These values are
With-grain axis:
$4.0 \times 10^{-6},{ }^{\circ} \mathrm{C}$, and
Across-grain axis:
$5.0 \times 10^{-6},{ }^{\circ} \mathrm{C}$.

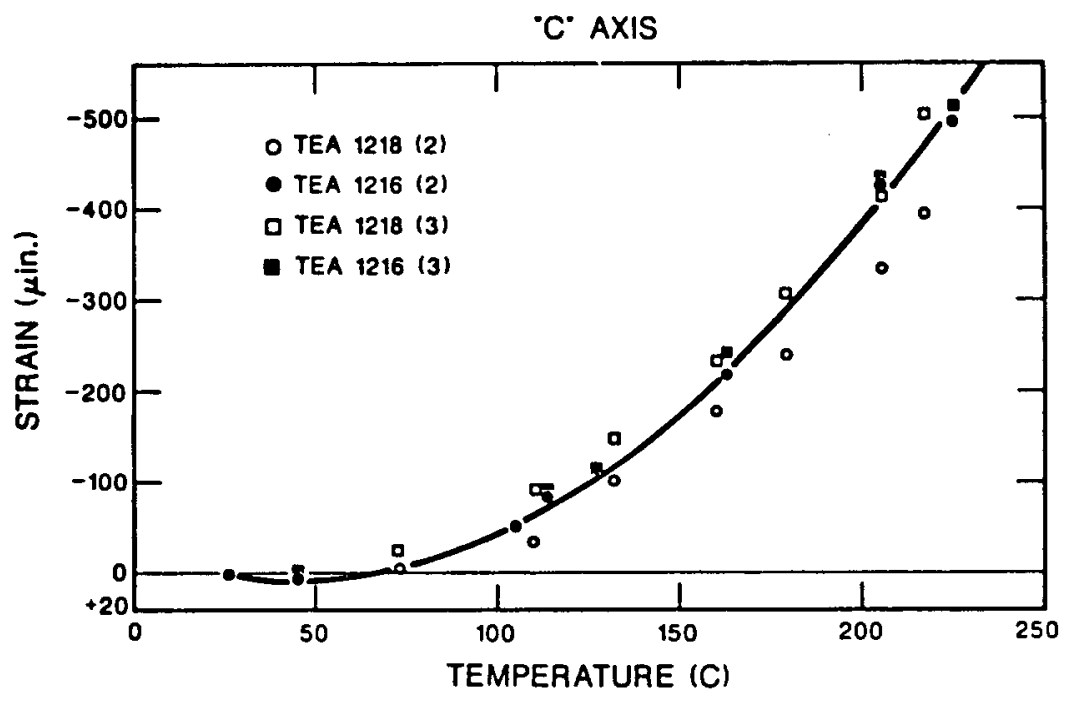

Fig. 5.11. Apparent strain versus temperature curve for the with-grain axis of 1440 graphite. 


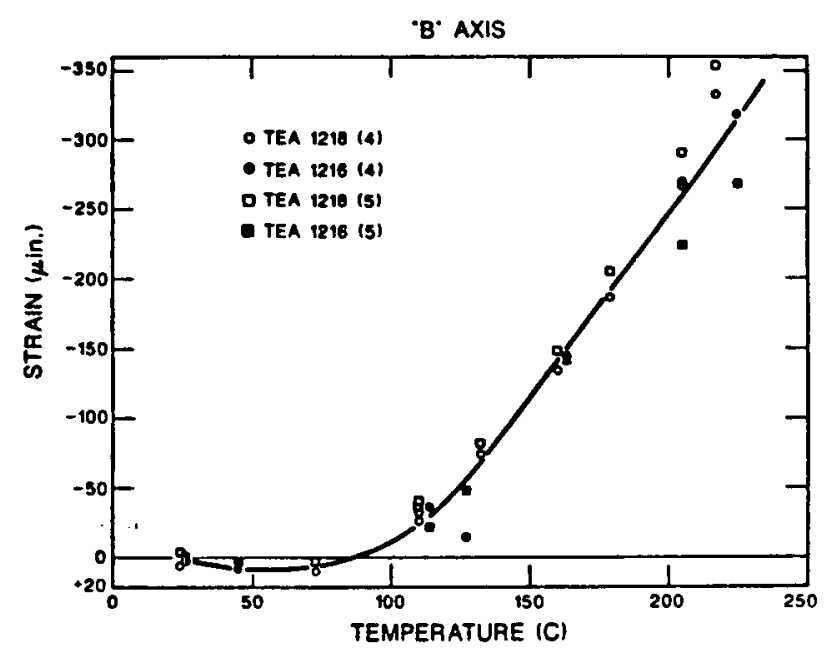

Fig. 5.12. Apparent strain versus temperature curve for the across-grain axis of $H 440$ graphite.
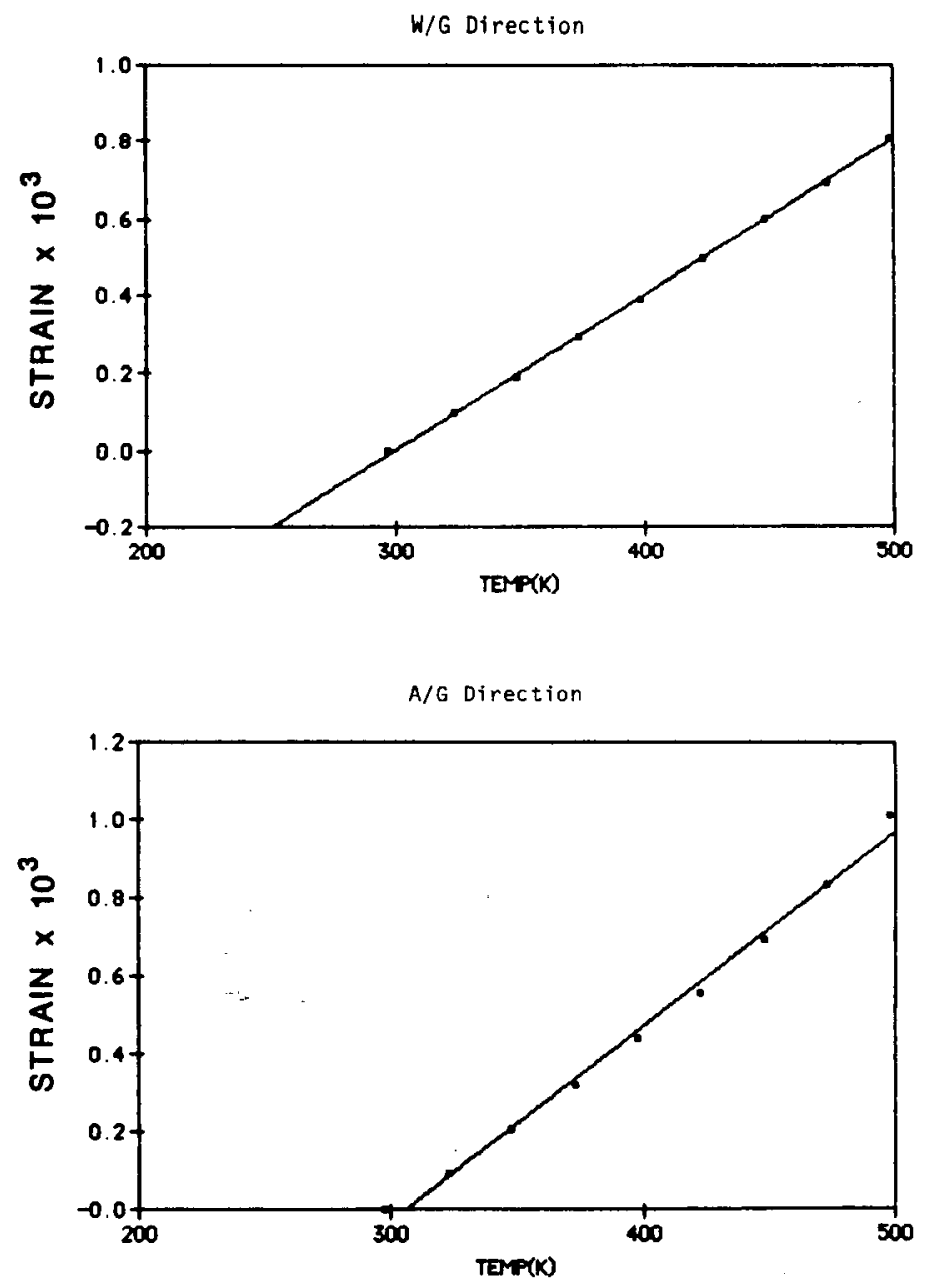

Fig. 5.13. Thermal expansion of $H 440$ graphite (strain versus temperature) in the with-and across-grain directions. 
VI. EXPERIMENTAL RESULTS AND COMPARISONS WITH THEORY

Sixteen successful tests of $H 440$ graphite rings subjected to combinations of direct loads and thermal loads were carried out using the liquid-metalcoupled heater described in section V.B. The tests varied in the size of the graphite ring, the orientation of the load axis with respect to the material axes of the ring, the temperature drop across the ring, and the degree of instrumentation on the test. All graphite specimens except for one were loaded to fallure, and, in almost all cases, a duplicate test was conducted in order to get an estimate of the variation caused by material property differences, test procedural differences, and other non-quantifiable effects. A listing of the tests, in chronological order, and the salient features of each test are given in Table 6.1 .

TABLE 6.1

SUMMARY DATA FOR GRAPHITE RING TESTS

\begin{tabular}{|c|c|c|c|c|c|c|}
\hline $\begin{array}{l}\text { Test } \\
\text { No. }\end{array}$ & $\begin{array}{l}\text { Ring } \\
\text { Diam in. }\end{array}$ & $\begin{array}{c}\text { Ultimate } \\
\text { Load in lbs } \\
\end{array}$ & $\begin{array}{l}\text { Nominal } \\
\Delta T \text { in }{ }^{\circ} \mathrm{C}\end{array}$ & $\begin{array}{l}\text { Measured } \\
\Delta \mathrm{T} \text { in }{ }^{\circ} \mathrm{C} \\
\end{array}$ & $\begin{array}{l}\text { Loading } \\
\text { Axis } \\
\end{array}$ & $\begin{array}{c}\text { Date } \\
\text { of Test }\end{array}$ \\
\hline 1 & 8 & 9264 & 0 & 0 & $b^{\star}$ & \\
\hline 2 & 8 & 5980 & 0 & 0 & c & \\
\hline 3 & 8 & 9140 & 0 & 0 & b & \\
\hline 4 & 8 & 9240 & 110 & 110 & b & \\
\hline 5 & 8 & 8864 & 110 & 115 & b & $2 / 10 / 85$ \\
\hline 6 & 8 & $\begin{array}{ll}9461\end{array}$ & 175 & 184 & b & $2 / 25 / 85$ \\
\hline 7 & 8 & 9869 & 225 & 224 & b & $4 / 18 / 85$ \\
\hline 8 & 8 & $11 \quad 114$ & 225 & 240 & b & $5 / 14 / 85$ \\
\hline $9 * *$ & 8 & 9120 & 0 & 0 & b & $6 / 13 / 85$ \\
\hline 10 & 8 & 11425 & 225 & 220 & b & $6 / 6 / 85$ \\
\hline 11 & 8 & 8573 & 0 & 0 & b & $6 / 12 / 85$ \\
\hline 12 & 8 & 9610 & 175 & 172 & b & $6 / 18 / 85$ \\
\hline 13 & 17 & 17363 & 0 & 0 & b & $7 / 8 / 85$ \\
\hline 14 & 17 & 19245 & 225 & 235 & b & $9 / 4 / 85$ \\
\hline 15 & 17 & 19385 & 225 & 199 & b & $10 / 1 / 85$ \\
\hline 16 & 17 & 15255 & 0 & 0 & b & $10 / 8 / 85$ \\
\hline
\end{tabular}

* b axis is perpendicular to the with-grain material axis; a and $c$ axes are parallel to the with-grain material axis.

* Test 9 used the graphite ring from Test 8 , which was undamaged during a heat test to 11114 lbs applied load. 

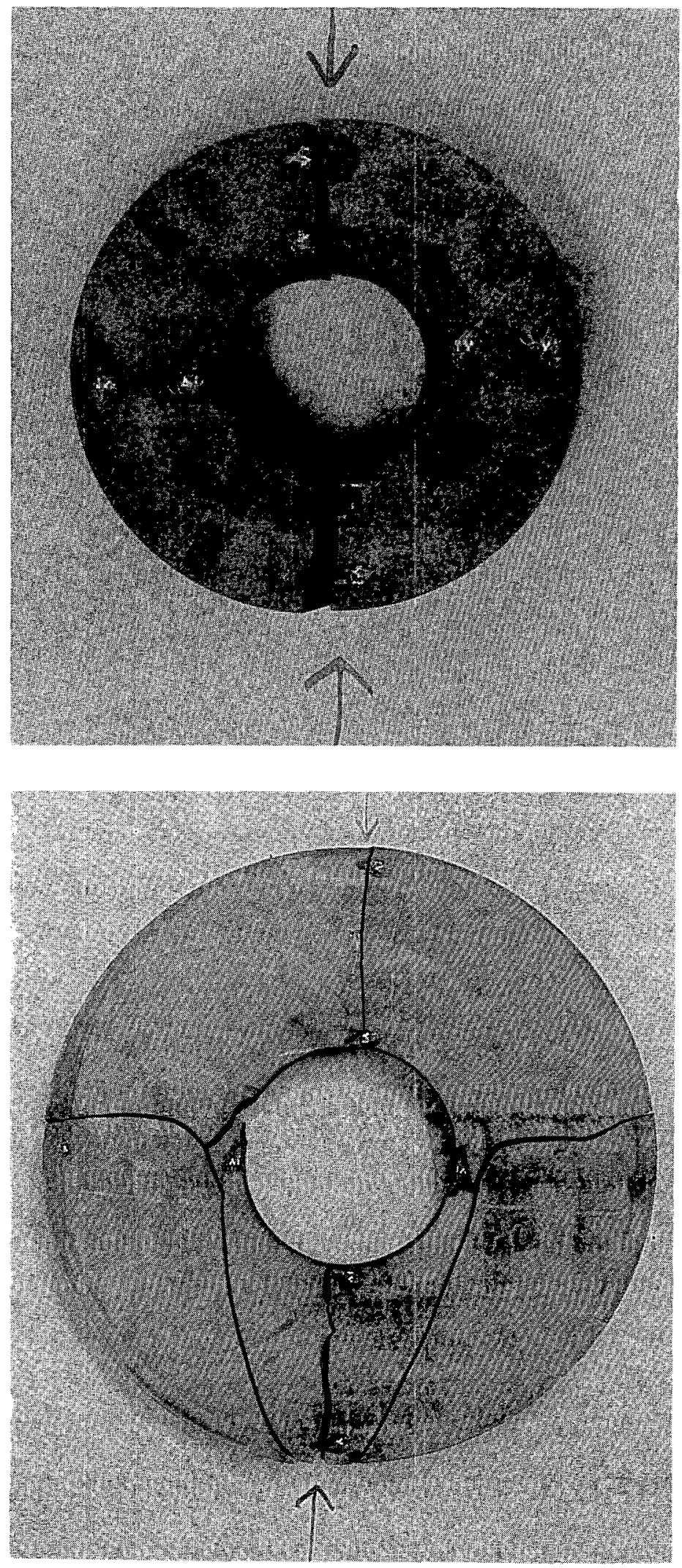

Fig. 6.1. Typical fracture patterns for graphite rings loaded in the across-grain direction at room temperature. 


\section{A. Results from Unheated Tests (Mechanical Load Only)}

Four tests of unheated small ring specimens and two tests of the large graphite rings were conducted at room temperature. Three of the small rings were loaded in the across-grain direction, which puts the maximum tensile stress in the with-grain or strong direction. At the fracture load, these rings broke in both the with and across-grain directions (i.e., along and perpendicular to the load axis) because the tensile stresses on the inner surface under the load and at the outer surface at $90^{\circ}$ from the load are more nearly equal to the fracture stress in the circumferential directions at the two locations. Figure 6.1 shows typical fracture patterns for these specimens. One of the tests, Test No. 2, was loaded along the with-grain direction, which put the maximum tensile stress in the ring along the weaker material direction (at the inner surface along the load axis). Thus, the fracture load was significantly lower, and the fracture occurred only along the with-grain axis.

Two large rings were tested at room temperature. The rings were both loaded along an across-grain axis, and because of the fact that the with-grain directions are aligned the same as in the case of the smaller rings (see Fig. 3.1), the fracture characteristics of the large rings are simflar to those of the small rings loaded along the across-grain axis. of course, because the rings are larger, the fracture loads were much higher than for the smaller diameter rings.

Figures 6.2-6.5 illustrate the circumferential strains developed near the inner and outer surfaces of the large graphite ring at points on the load axis and at $90^{\circ}$ from the load axis as calculated by the ABAQUS code. The calculation used the orthotropic, elastic-plastic model and the finite element mesh described in Section. IV.B of this report; the calculation was continued to ultimate load defined as the load where the tensile circumferential strain at the inner ring surface on the load axis achieved the fracture strain in the with-grain direction, $3.7 \times 10^{-3}$. Also plotted on these figures are the strain values measured from Test 13 (see Table 6.1) at gage locations nearest the calculational points. Since there are several measurements of strains for each calculational point (e.g., on both top and bottom surfaces of the ring and reflected points about the load axis), there are many experimental measurements for each calculated strain. As can be seen from the four figures, there is a good correlation between the experimentally measured strains and 
TEST NO.13

- GaGe I

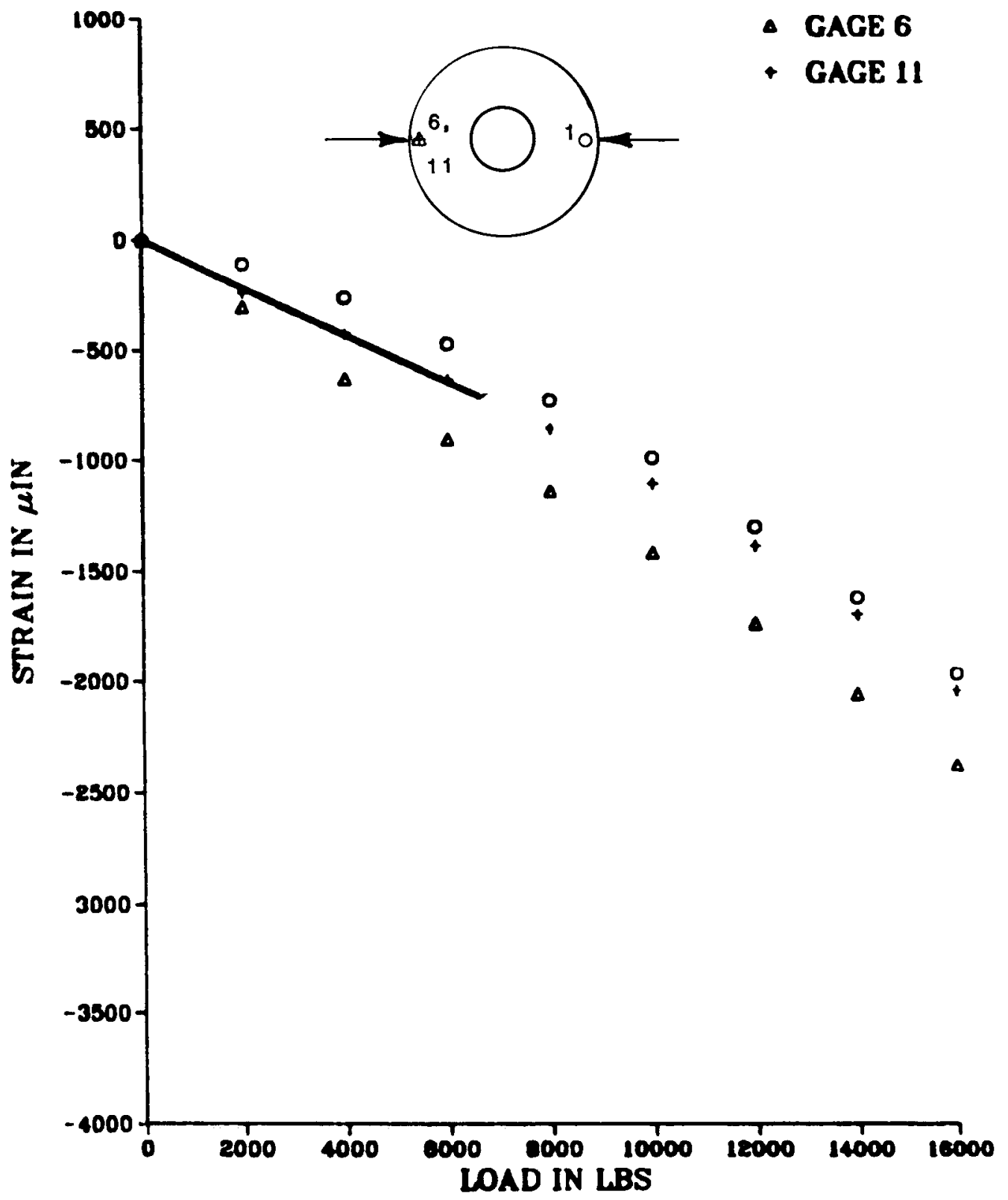

Fig. 6.2. Circumferential strain under the applied load versus load for Test 13 showing experimental values and values calculated by the ABAQUS code using the orthotropic elastic-plastic model and the mesh of Fig. 4.6. 
TEST N0.13

- GAGE 2

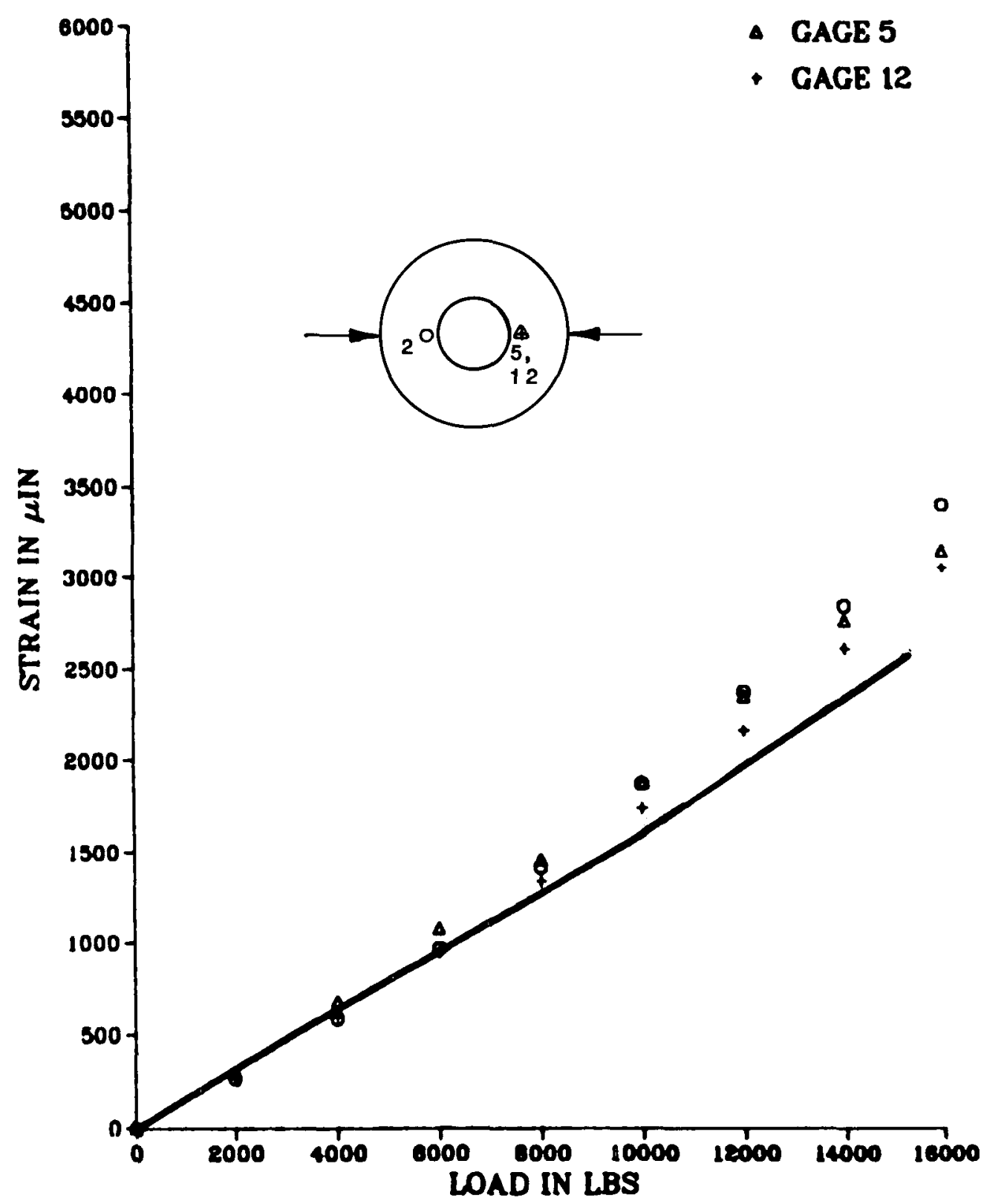

Fig, 6.3. Circumferential strain on the load axis near $r=a$ versus load for Test 13 showing experimental values and values calculated by the ABAQUS code using the orthotropic elastic-plastic model and the mesh of Fig. 4.6. 


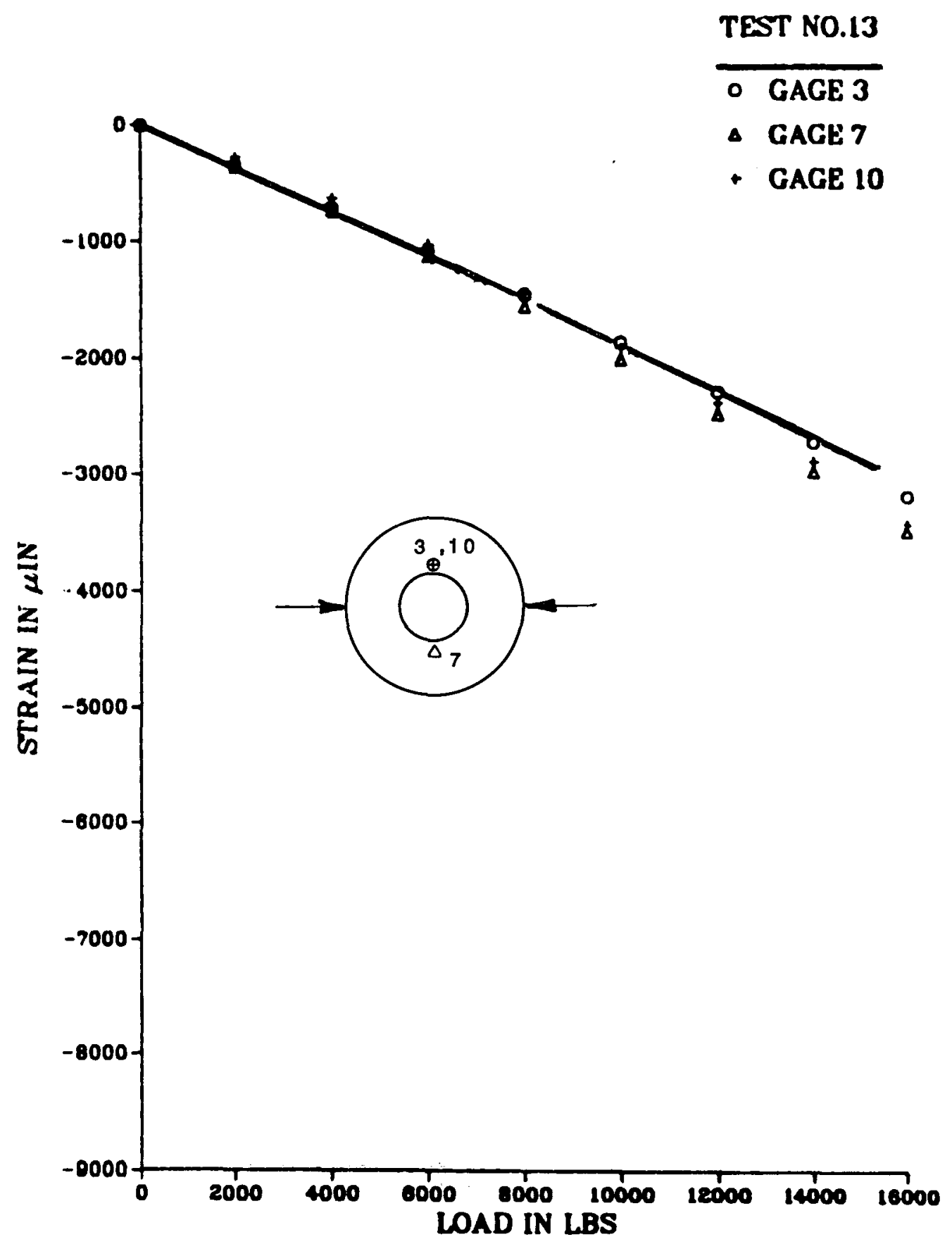

Fig. 6.4. Circumferentlal strain at $90^{\circ}$ from the load axis near $r=a$ versus load for Test 13 showing experimental values and values calculated by the ABAQUS code using the orthotropic elastic-plastic model and the mesh of Fig. 4,6. 
TEST N0.13

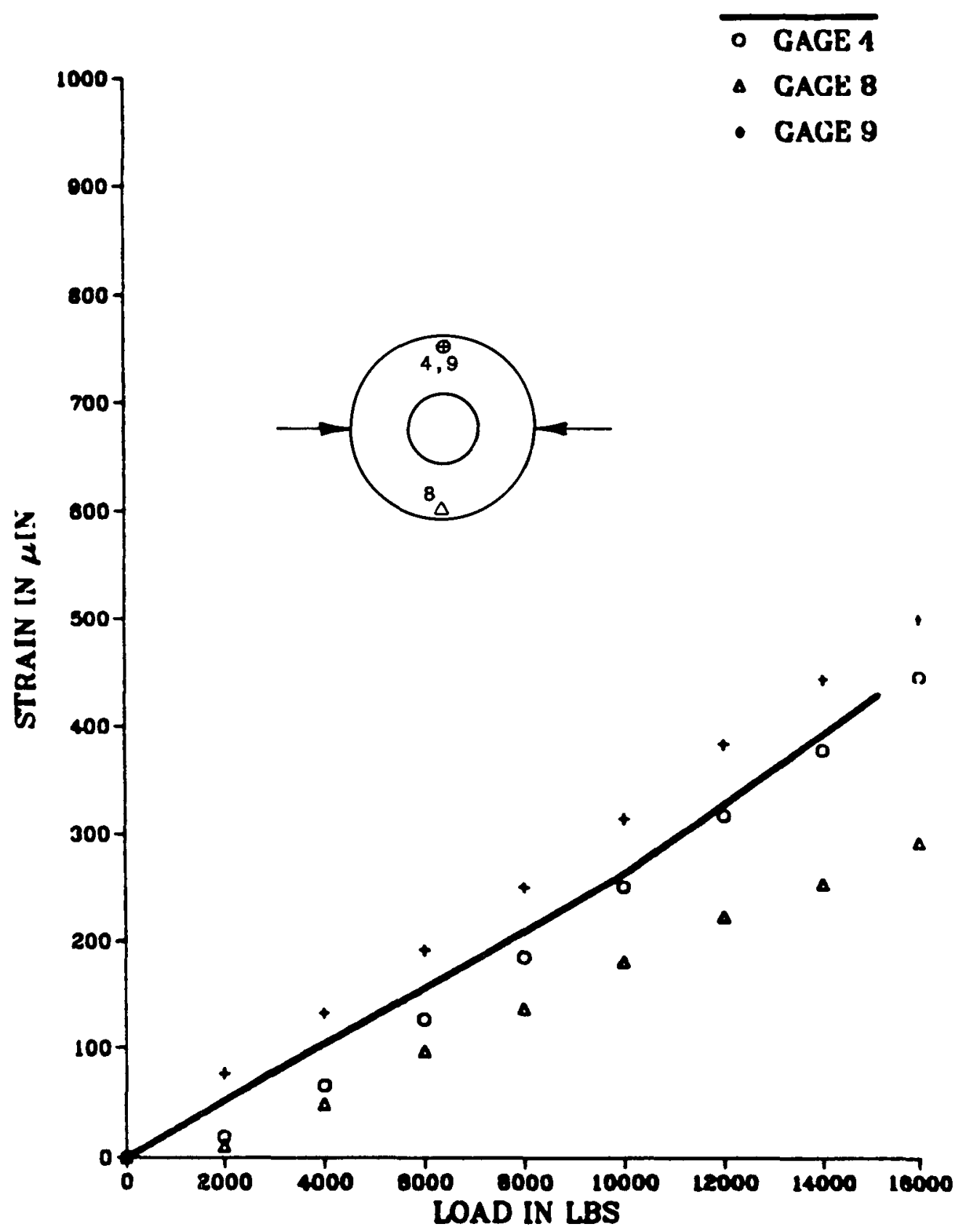

Fig. 6.5. Circumferential strain at $90^{\circ}$ from the load axis near $r=b$ versus load for Test 13 showing experimental values and values calculated by the ABAQUS code using the orthotropic elastic-plastic model and the mesh of Fig. 4.6 . 
those calculated by the ABAQUS code--even though the fracture loads themselves were significantly different for the two room temperature tests of the large graphite ring.

Table 6.2 below illustrates the statistics of the fracture loads for the room temperature tests of 1440 graphite rings. The $x-2 \sigma$ and $x+2 \sigma$ represent $95 \%$ confidence intervals on the fracture loads.

TABLE 6.2

STATISTICAL DATA ON ROOM TEMPERATURE TESTS

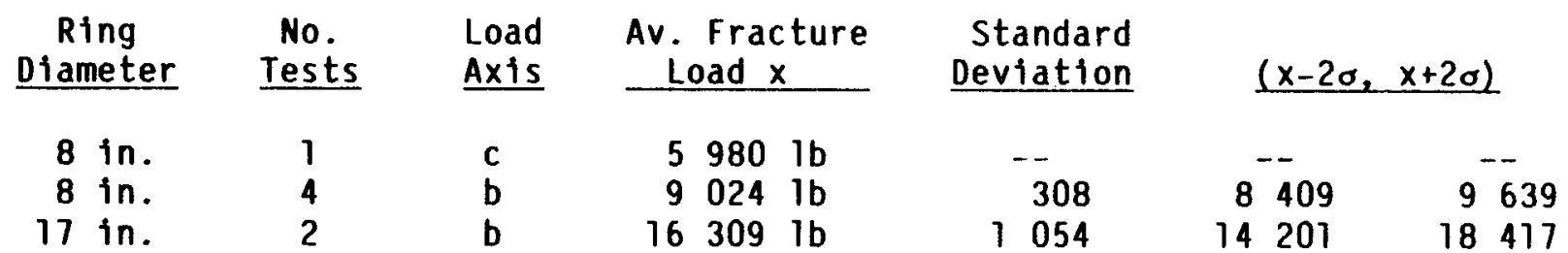

The ratio of the average fracture load of the large graphite rings to that of the smaller rings is 1.81 . Based on the analytical elasticity solutions developed in Section IV.B and the values of $\beta$ (the loading angle), the ring diameters, and the ring thicknesses, we calculated a ratio of the fracture loads of 1.95. Thus there appears to be a small size effect in the ultimate strength behavior of the unheated $H 440$ graphite rings although the scatter in the ultimate load values precludes us from making a confident statement of the observed size effect.

Finally, the prediction of the probability of failure curve for the small unheated graphite rings (see Fig. 4.8) using the technique of Section IV.D and the Weibull parameters from the small sample tensile strength data of Section III.B appears to be an acceptable procedure if the unit volume strength is adjusted slightiy.

\section{B. Results from Heated Tests with Mechanical Load}

Seven tests of heated small graphite rings and two tests of the large graphite rings were carried out with temperature drops over the ring as 
specifled in Table 6.7. The small graphite rings fractured in the same pattern as was observed for the unheated small rings loaded in the across-grain direction. The large rings also fractured in the pattern observed when the large rings were tested at room temperature.

Symmetry of the imposed temperature field was measured by thermocouples located at several angular positions at the same radius (see Fig. 5.9). Figure 6.6 illustrates measured temperatures at various radial positions at the different angular positions for Test No. 8 of Table 6.1. (This was a graphite ring that was heavily instrumented with thermocouples as shown in Fig. 5.9). As can be seen from Fig. 6.5, the maximum temperature difference on the top or bottom surface of the ring at a given radial position is less than $5^{\circ} \mathrm{C}-$ although there is about a $10^{\circ}$ drop through the thickness of the ring. Over

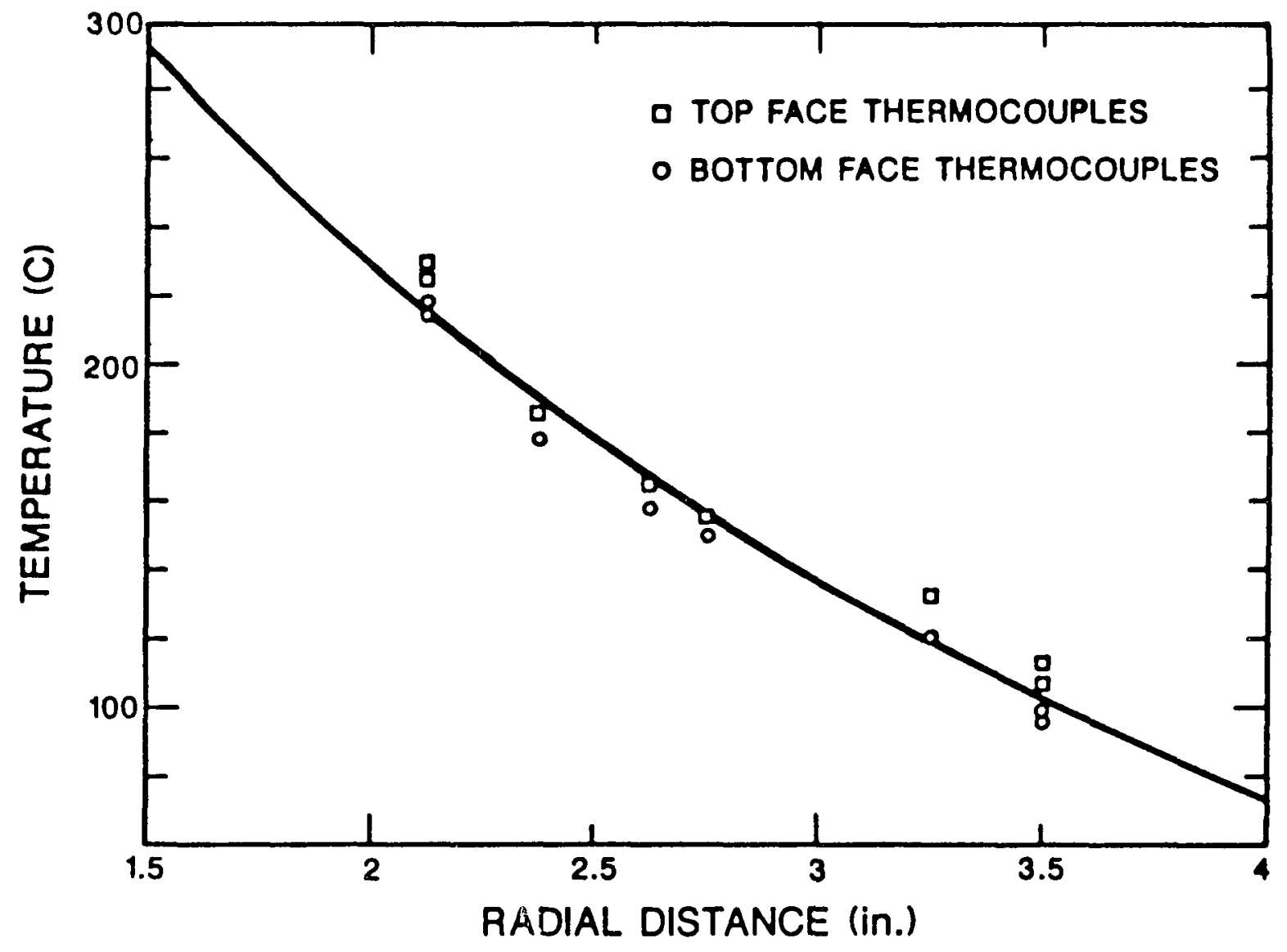

Fig. 6.6. Temperatures measured at various radial positions and angles on the graphite ring as well as the $\log r$ fit to the data. 
the life of the test, usually about six hours, the temperature at a given position on the graphite ring varied less than five degrees out of $225^{\circ} \mathrm{C}$. Notice that the measured points lie close to the analytical curve for a heated ring shown as the solid curve in fig. 6.6.

Measurements of the circumferential strain developed by the mechanical loads in the presence of the thermal gradient were in many cases unsatisfactory. Whether it was caused by inadequate bonding of the strain gages to the graphite or whether it was caused by inaccurate compensation for the free thermal expansion of the graphite, the strain caused by the imposed stress often exhibited erratic behavior as a function of load.

Figures $6.7,6.8$, and 6.9 illustrate the circumferential strains measured near the inner surface at $0^{\circ}$ and $90^{\circ}$ from the load axis and near the outer surface at $90^{\circ}$ from the load axis as a function of the applied load for Test No. 14 of Table 6.1. This test produced the best set of strain records. Also shown in the three figures are the strains calculated by the ABAQUS code for the large graphite ring model with the orthotropic, elastic-plastic material law and subjected to a flux on the inner surface of the ring that produced the requisite temperature drop through the ring. Because of the presence of the heater, the inner strain gages had to be located about $3 / 4$ in. from the inner surface of the ring, which precluded obtaining good estimates of the fracture strain (or its decomposition into thermal and mechanical components) at the inner surface on the load axis. Thus, from strain measurements alone we have only been able to verify that the analytical predictions based on an elasticplastic model and additivity of the thermal and mechanical stress components appear to be correct.

Since the measurement of strain in the heated tests was not adequate to indicate how thermal and mechanical stresses combined to produce fracture in large graphite structural components, we proceeded to analyze how the fracture load was affected by the imposed temperatue drop through the ring and to see if it varied with temperature drop as was assumed in Section IV.B. Table 6.3 below illustrates the statistics of the fracture loads for the heated and unheated tests of the small H440 graphite rings. 


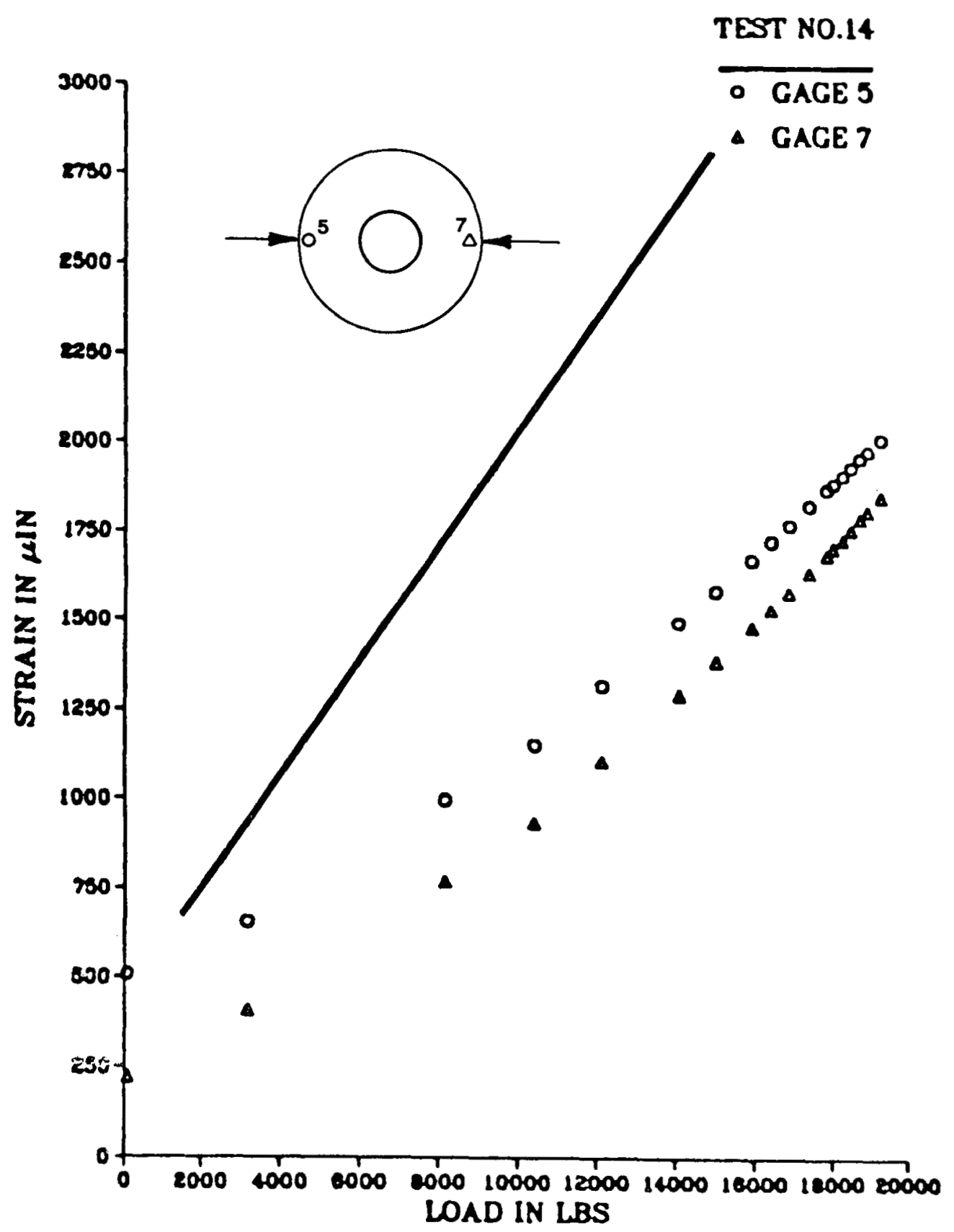

F19. 6.7. Circumferential strain on the load axis near $r=a$ versus load for Test 14 showing experimental values and values calculated by the ABAQUS code using the orthotropic elastic-plastic model and the mesh of Fig. 4.6. 


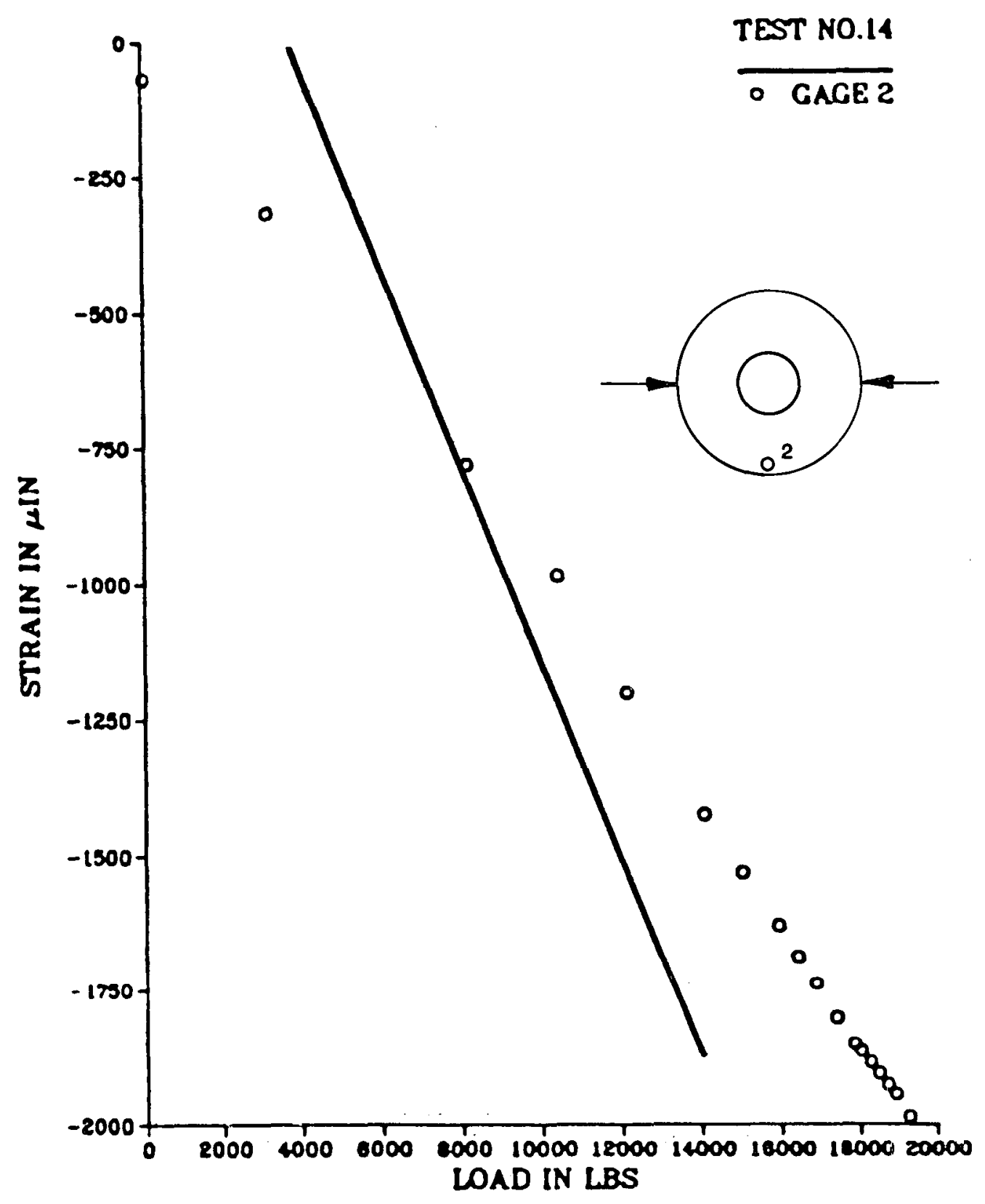

Fig. 6.8. Circumferential strain at $90^{\circ}$ from the load axis near $r=$ a versus load for Test 14 showing experimental values and values calculated by the ABAQUS code using the orthotropic elastic-plastic model and the mesh of Fig. 4.6. 
TEST NO.14

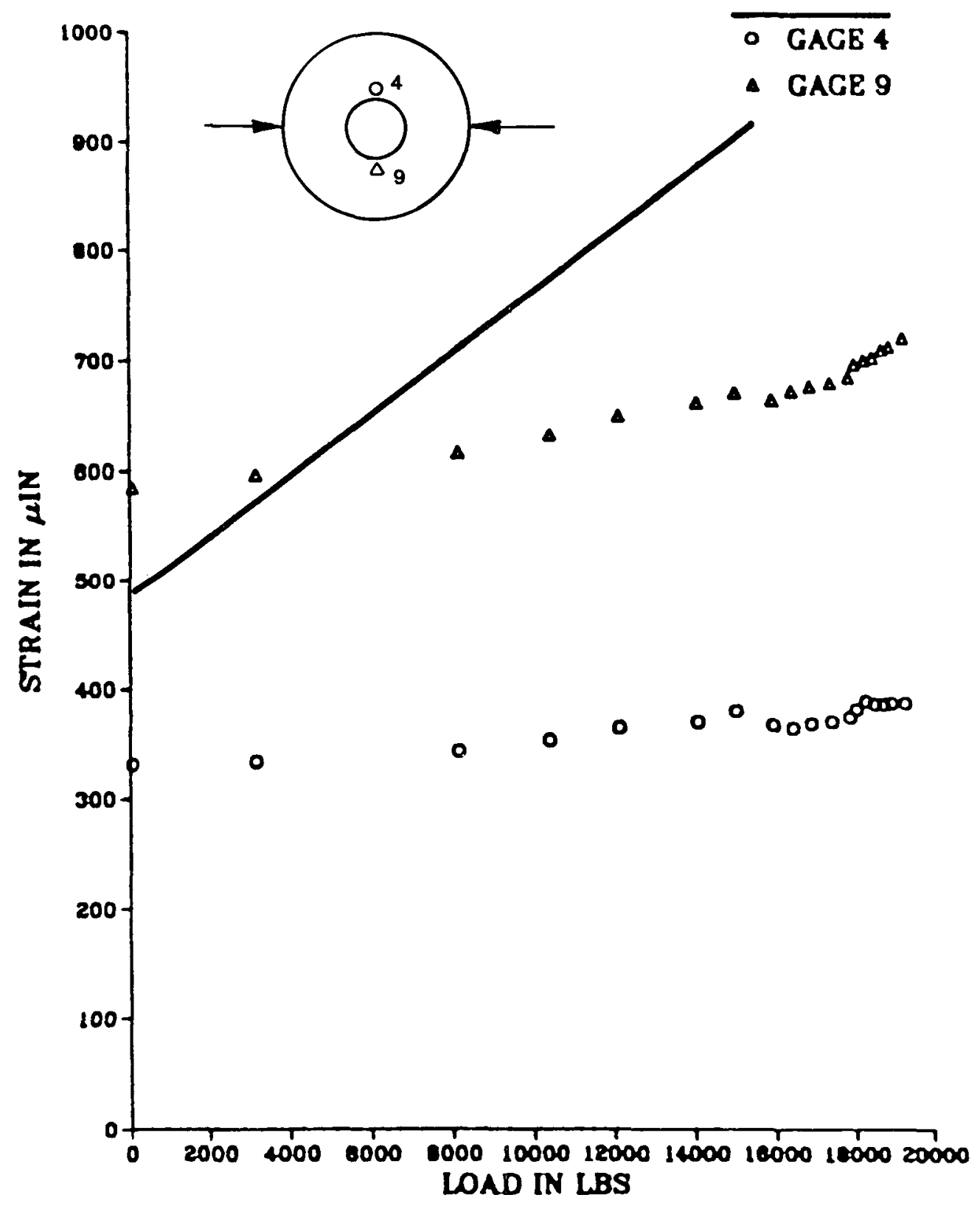

Fig. 6.9. Circumferential strain at $90^{\circ}$ from the load axis near $r=b$ versus load for Test 14 showing experimental values and values calculated by the ABAQUS code using the orthotropic elastic-plastic model and the mesh of Fig. 4.6. 
TABIEE 6.3

STATISTICAL DATA ON SMALL GRAPHITE RING TESTS

\begin{tabular}{|c|c|c|c|c|c|}
\hline $\begin{array}{c}\text { Ring } \\
\text { Diameter }\end{array}$ & $\begin{array}{l}\text { No. } \\
\text { Tests }\end{array}$ & $\begin{array}{l}\text { Load } \\
\text { Axis } \\
\end{array}$ & $\begin{array}{r}\text { Nominal } \\
\Delta \mathrm{T} \text { in } \mathrm{O}^{\mathrm{C}} \\
\end{array}$ & $\begin{array}{l}\text { Av. Fracture } \\
\text { Load } \mathrm{P}_{f} \\
\end{array}$ & $\begin{array}{r}\text { Standard } \\
\text { Deviation }\end{array}$ \\
\hline $\begin{array}{l}8 \text { in. } \\
8 \text { in. } \\
8 \text { in. } \\
8 \text { in. }\end{array}$ & $\begin{array}{l}4 \\
2 \\
2 \\
3\end{array}$ & $\begin{array}{l}b \\
b \\
b \\
b\end{array}$ & $\begin{array}{c}0 \\
110 \\
175 \\
225\end{array}$ & $\begin{array}{rrr}9 & 024 & 1 b \\
9 & 050 & 1 b \\
9 & 540 & 1 b \\
10 & 800 & 1 b\end{array}$ & $\begin{array}{l}308 \\
265 \\
105 \\
823\end{array}$ \\
\hline
\end{tabular}

In Fig. 6.10 we 11 lustrate the average fracture load $P_{f}$ plotted versus the temperature drop $\Delta T$ across the small graphite ring. To the four points we have $f i t$, by least squares, a straight line as shown. The slope of that line is $d P_{f} / d(\Delta T)$ and is $7.01 b /{ }^{\circ} \mathrm{C}$. Referring to Fig. 4.5, we see that for small $\Delta T s$, the slope of the initial segment of the fracture surface is $1 / \alpha E d p_{f} / d(\Delta T)$ and is equal to 0.42 . Now using

$$
p_{f}=\frac{p_{f}}{2 \beta b h} \text {, }
$$

where $h$ is the ring thickness ( 2 in.), $b$ the outer radius ( 4 in.), and $\beta$ the half angle over which the pressure is applied $\left(13.5^{\circ}\right)$, and using $\alpha=4.0 \times$ $10^{-6},{ }^{\circ} \mathrm{C}$ and $\mathrm{E}=1.2 \times 10^{6} \mathrm{psi}$, we obtain the result that $\mathrm{dP}_{\mathrm{f}} / \mathrm{d}(\Delta \mathrm{T})=7.61 \mathrm{~b} /{ }^{\circ} \mathrm{C}$, in excellent agreement with the experimentally derived value.

We conclude that for fracture analysis of $H 440$ graphite structural components subjected to combined loadings that the thermal and mechanical stresses be treated as generically the same and be added together (algebraically) with no reduction factors and compared with the ultimate tensile stress of the graphite. 


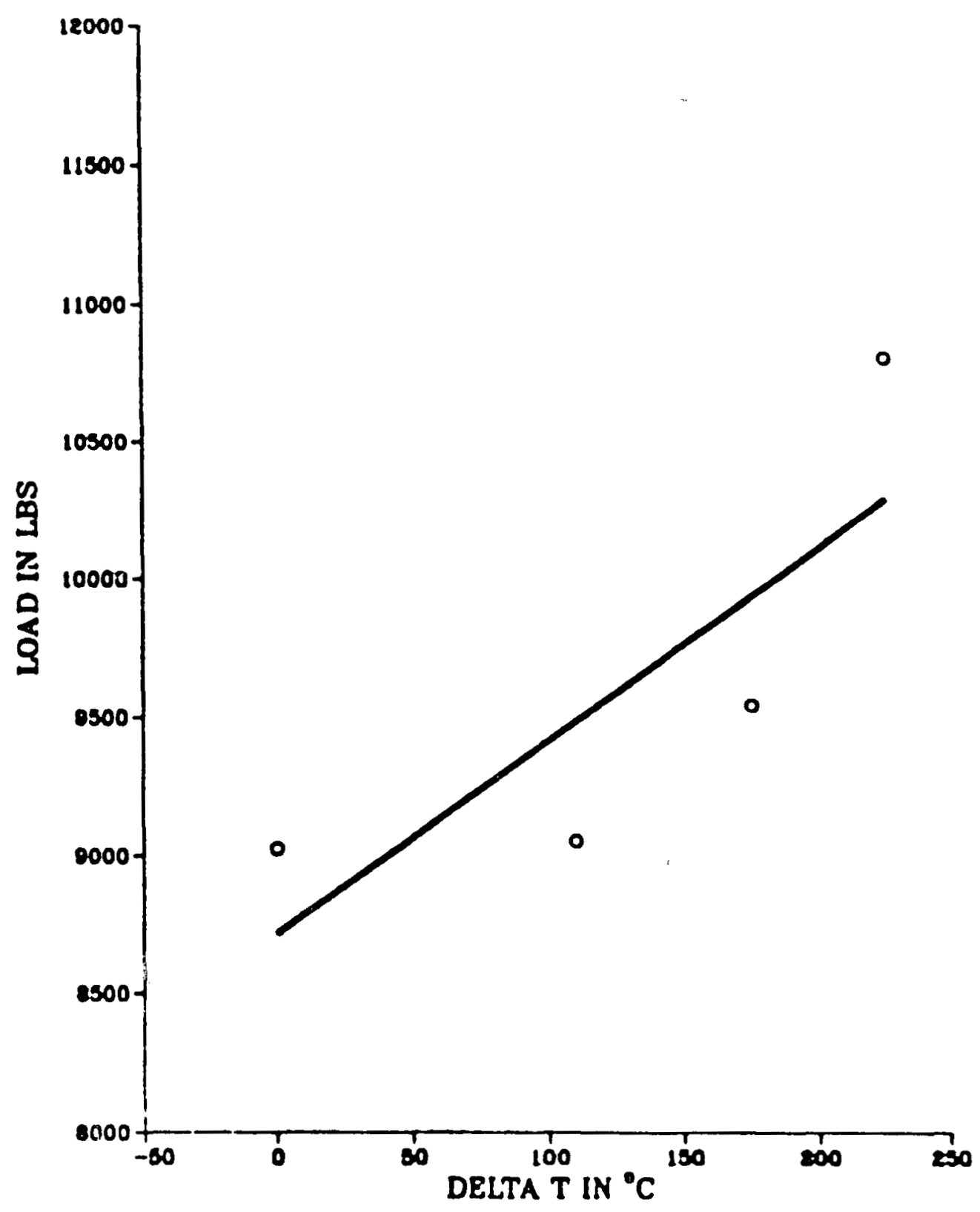

Fig. 6.10, Average fracture load $P_{f}$ versus temperature drop $\Delta T$ and least-squares fit to the experimental data. 


\section{REFERENCES}

1. J. D. Buch, J. G. Crose, and E. Y. Robinson, "Fallure Criteria in Graphite Program," Air Force Materials Laboratory, Wright-Patterson Air Force Base, final report AFML-TR-77-16 (March 1977).

2. T. A. Butler and C. A. Anderson, "Three-Dimensional Thermoelastic Analysis of a Fort St. Vrain Core Support Block," Los Alamos National Laboratory report NUREG/CR-2319 (September 1981).

3. G. B. Engle, "Properties of Unirradiated HTGR Core Support and Permanent Side Reflector Graphites: PGX, HLM, 2020 and H440N," General Atomic report GA-A14328 (May 1977).

4. R. J. Price, "Statistical Study of the Strength of Near-Isotropic Graphite," General Atomic report GA-A13955 (May 1976).

5. "Design Requirements for Graphite Core Supports," ASME Boiler and Pressure Vessel Code, Section III, Division 2, Subsection CE proposed (March 1982).

6. V. Svalbonas, T. Stilwell, and Z. Zudans, "Evaluation of the Structural Integrity of High Temperature Gas-Cooled Reactor Core and Support Elements," Franklin Institute Research report (prepared for the U.S. Nuclear Regulatory Commission) F-C4230 (April 1976).

7. F. Ho and E. Chin, "Test Evaluation Report of the Thermal Stress Test for Core Support Graphite," General Atomic report 904445A (August 1980).

8. M. A. Sherman, "Mechanical Property Evaluations of H440 Fine-Grained Graphite," Southern Research Institute report SoRI-EAS-84-146 (February 1984).

9. S. P. Timoshenko, Theory of Elasticity, 2nd ed., (McGraw-Hi11, New York, 1951), pp. 412-414.

10. J. C. Jaeger and E. R. Hoskins, "Stress and Failure in Rings of Rock Loaded in Diametral Tension or Compression," Brit. J. App 1. Phys., 17, 685-692 (1966).

11. J. C. Jaeger and N. G. W. Cook, Fundamentals of Rock Mechanics, (Science Paperbacks, Chapman and Hall, Ltd., London, 1971).

12. ABAQUS User's Manual, Version 4, Hibbitt, Carlson, and Sorenson, July 1982.

13. A. E. Green and W. Zerna, Theoretical Elasticity, (0xford, 1954) pp. 159-160.

14. K. J. Bathe, "ADINA: A Finite Element Program for Automatic Dynamic Incremental Analysis," Massachusetts Institute of Technology report 82448-1

(December 1978).

15. P. Stanley, H. Fessler, and D. V. Sivill, "An Engineer's Approach to the Prediction of Failure Probability of Brittle Components," Proc. Brit.

Ceramic Soc. 22, 453-487 (1973). 
16. J. Margetson, "Failure Probability Evaluation of an Anisotropic Brittle Structure Derived from a Thermal Stress Solution," Proc. of Int. Conf. on Thermal Stresses in Materials and Structures in Severe Thermal Environments, (Plenum Press, New York, 1980) pp. 503-519. 


\section{DISTRIBUTION}

Nuclear Regulatory Commission, R8, Laurel, Maryland

Copies

Technical Information Center, Oak Ridge, Tennessee

Los Alamos National Laboratory, Los Alamos, New Mexico 


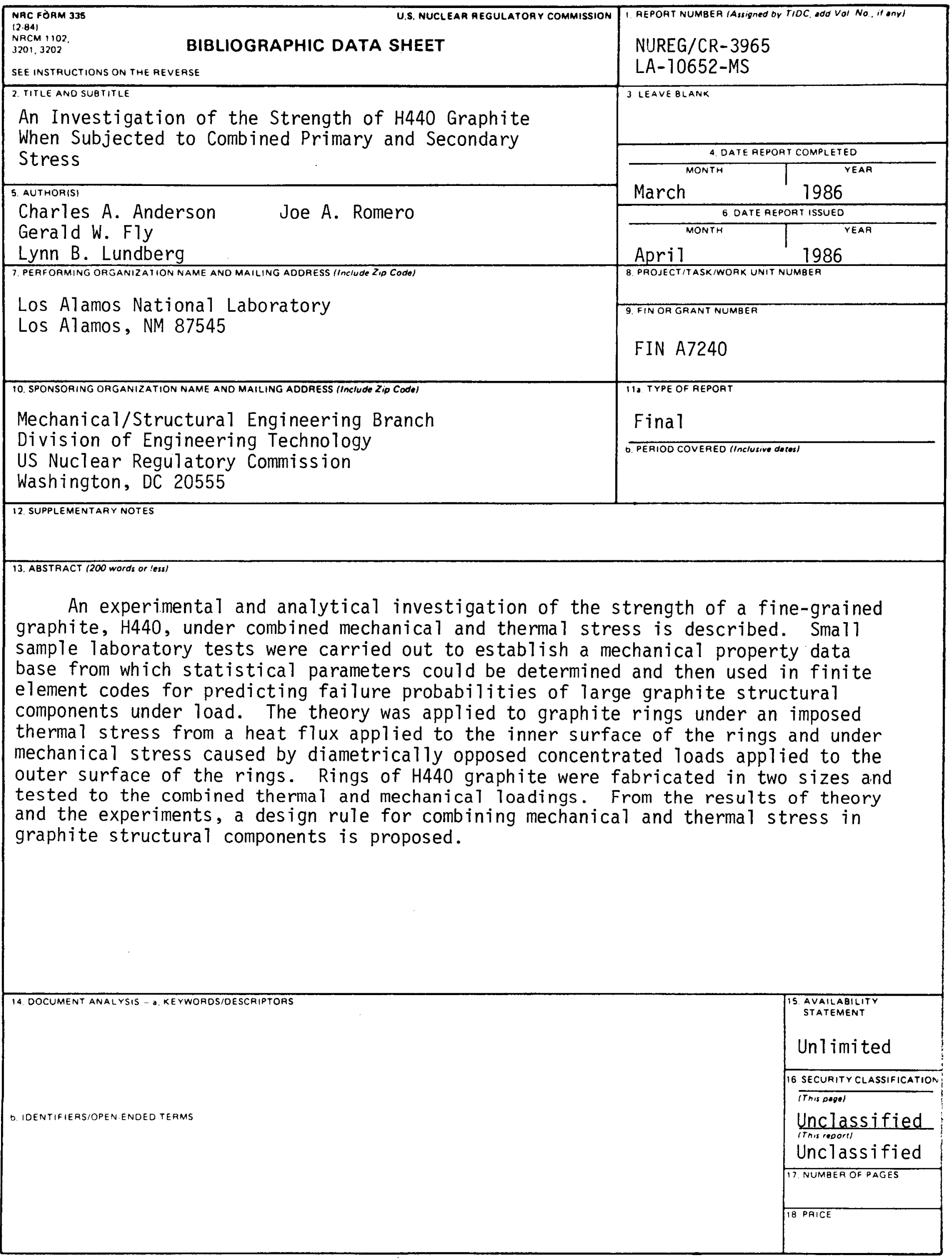

